\title{
ESTIMATION OF REQUIRED RESTRAINT FORCES IN Z-PURLIN SUPPORTED, SLOPED ROOFS UNDER GRAVITY LOADS
}

\author{
by \\ Michael C. Neubert \\ Thesis submitted to the Faculty of the \\ Virginia Polytechnic Institute and State University \\ in partial fulfillment of the requirements for the degree of \\ MASTER OF SCIENCE \\ in \\ Civil and Environmental Engineering
}

Approved:

T. M. Murray, Chairman

W. S. Easterling

T. E. Cousins

August 1999

Blacksburg, VA

Key words: cold-formed steel, metal roof, restraint, Z-purlin 


\title{
ESTIMATION OF REQUIRED RESTRAINT FORCES IN Z-PURLIN SUPPORTED, SLOPED ROOFS UNDER GRAVITY LOADS
}

\author{
by \\ Michael C. Neubert \\ Committee Chairman: Thomas M. Murray \\ Civil and Environmental Engineering
}

\begin{abstract}
(ABSTRACT)
The current specification provisions for the prediction of lateral restraint forces in Z-purlin supported roof systems under gravity loads are in Section D3.1 of the 1996 AISI Cold-Formed Specification. The design equations contained in these provisions are empirical and based on statistical analysis. They were developed using elastic stiffness models of flat roofs and were verified by experimental testing. The provisions need refinement, because the treatment of roof slope and system effects is incorrect. Also, the current design provisions are based upon an assumed panel stiffness value, ignoring the significant difference in required restraint force that occurs when panel stiffness is varied.

Therefore, a new restraint force design procedure, having a stronger reliance on engineering principles, is proposed. This new treatment of the static forces in Z-purlin roofs led to a more accurate method of addressing roof slope. Elastic stiffness models, with varying roof slope, panel stiffness, and cross-sectional properties, were used to develop the proposed procedure. The basis of the procedure is to determine the lateral restraint force required for a single purlin system and then extend this result to systems with multiple restrained purlin lines. Roof slope is incorporated into the calculation of the single purlin restraint force, which includes eccentric gravity loads and forces induced by Z-purlin asymmetry. The procedure includes a system effect factor to account for the observed nonlinear increase in restraint force with the number of restrained purlins. An adjustment factor varies the predicted restraint force depending on the shear stiffness of the roof panel. The proposed procedure applies to five bracing configurations: support, third-point, midspan, quarter point, and third-point plus support restraints.
\end{abstract}




\section{ACKNOWLEDGEMENTS}

I first wish to extend my gratitude to Dr. Thomas Murray, principal advisor to this research, for his invaluable direction and assistance. Thank you for urging me to pursue this research and enriching my graduate studies. I also have sincere appreciation for Dr. W. Samuel Easterling and Dr. Thomas Cousins, who aided me greatly as members of the research committee.

I acknowledge the Metal Building Manufacturer's Association and the American Iron and Steel Institute for their financial support of this work. It is truly an honor to have been selected as an MBMA Graduate Fellowship Award Winner. The interest and support of these two organizations made this research possible.

Many friends and family deserve recognition for the support that they have given me in the course of my graduate work. I thank my parents Marilyn and Robert Neubert for their emotional support and their interest in my studies. Many friends assisted me with my research and studies; these friends include Juan Archilla, Mark Boorse, Amy Dalrymple, Anthony Farmer, Rob Krumpen, Rich Meyerson, John Ryan, Rob Schottler, Jolyn Senne, and Anthony Temeles. They made graduate school more enjoyable by providing a supportive environment for me to learn and grow. 


\section{TABLE OF CONTENTS}

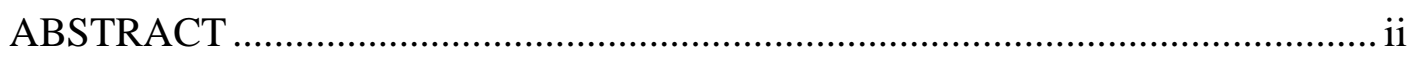

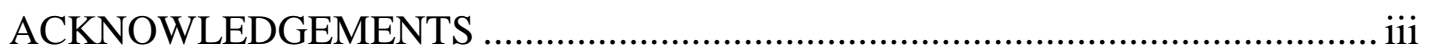

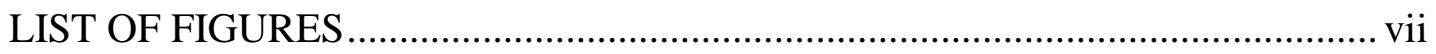

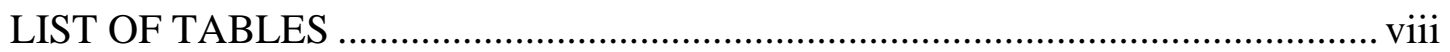

\section{CHAPTER}

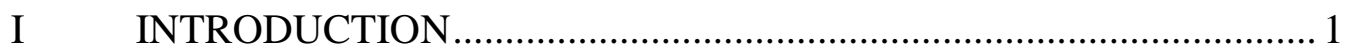

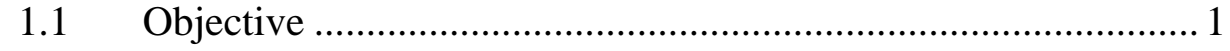

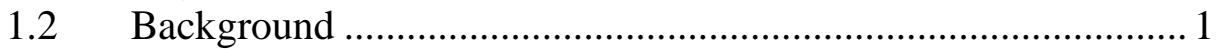

1.3 Literature Review .............................................................. 3

1.4 Current Design Practice............................................................. 10

$1.5 \quad$ Scope of Work ........................................................................ 12

II MATHEMATICAL MODELING ..................................................... 14

2.1 Introduction to Modeling......................................................... 14

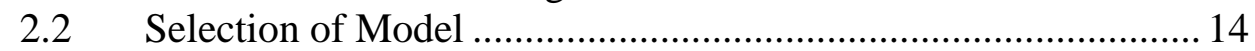

2.3 Stiffness Model Development ..................................................... 15

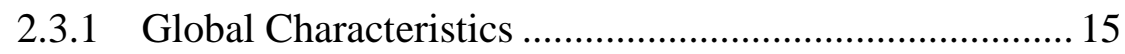

2.3.2 Axes Orientation ....................................................... 16

2.3.3 Modeling of Purlins....................................................... 17

2.3.4 Modeling of Roof Panel ................................................. 20

2.3.5 Modeling of Braces ......................................................... 23

2.3.6 Joints and Boundary Conditions …………….................. 23

2.3.7 Model Loading ……………........................................ 25

2.3.8 Summary of Model........................................................ 27

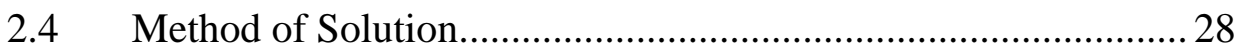

2.5 Validation of Model to Experimental Results..............................2 29

III THEORETICAL FORMULATION OF DESIGN EQUATION ..............32

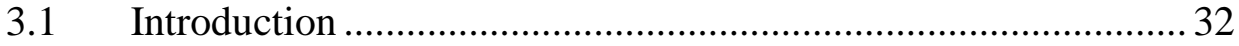

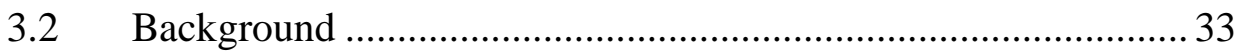

3.3 Equation Development ............................................................. 37

3.3.1 Form of Equation ........................................................... 37

3.3.2 Single Purlin Restraint Force …………............................. 38

3.3.3 System Effect Factor, $\alpha$.................................................... 39

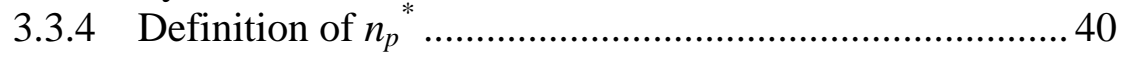

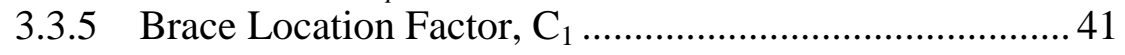




\section{TABLE OF CONTENTS, CONTINUED}

3.3.6 Panel Stiffness Modifier, $\gamma$........................................... 42

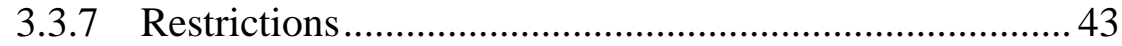

3.3.8 Summary of Equation........................................... 44

IV COMPUTER TESTS AND EQUATION DEVELOPMENT.................46

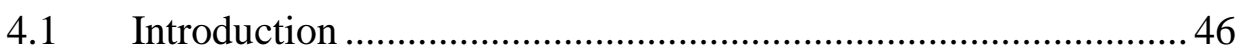

4.2 System Behavior Analysis................................................. 46

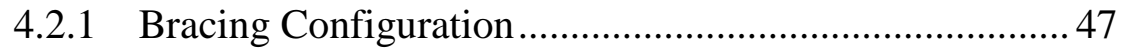

4.2.2 Number of Spans ....................................................... 47

4.2.3 Number of Restrained Purlin Lines................................. 48

4.2.4 Purlin Span Length..................................................... 48

4.2.5 Purlin Depth, Thickness, and Flange Width .................. 49

4.2.6 Purlin Moments of Inertia ..............................................51

4.2.7 Roof Slope ........................................................ 51

4.2.8 Roof Panel Stiffness ................................................ 53

4.3 Development of Computer Test Matrix ..................................53

4.4 Solution of Computer Test Matrix …....................................... 58

4.5 Statistical Analyses.......................................................... 58

4.5.1 Regression Characteristics ........................................58

4.5.2 Determination of Coefficients $C_{1}, C_{2}, C_{3} \ldots \ldots \ldots \ldots \ldots \ldots \ldots . \ldots 1$

4.6 Verification of Panel Stiffness and Roof Slope Interaction ........ 65

V APPLICATION OF DESIGN PROCEDURE .................................. 70

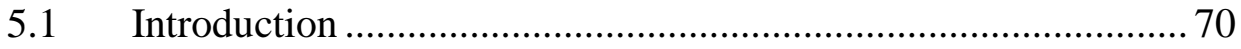

5.2 Design Examples........................................................... 72

VI SUMMARY, CONCLUSIONS, AND RECOMMENDATIONS ......... 79

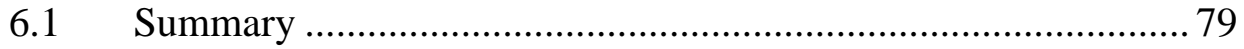

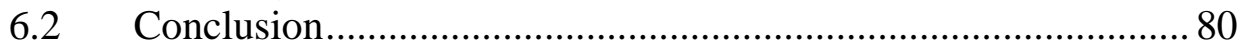

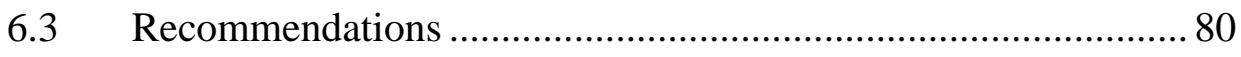

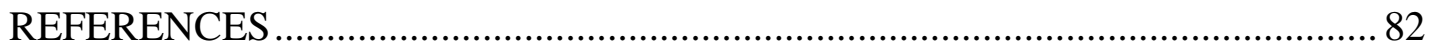

APPENDIX A: Stiffness Model Example ...................................................... 84

APPENDIX B: Model Loads and Section Properties ........................................... 87

APPENDIX C: Restraint Force Data from Stiffness Model ................................ 91 


\section{TABLE OF CONTENTS, CONTINUED}

APPENDIX D: Regression Analysis Sample Reports ...................................... 102

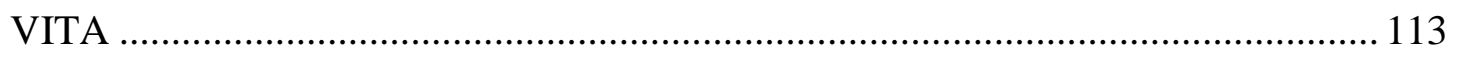




\section{LIST OF FIGURES}

Figure

Page

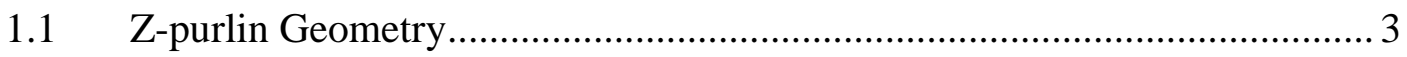

$1.2 \quad$ Elhouar and Murray's Stiffness Model ................................................ 5

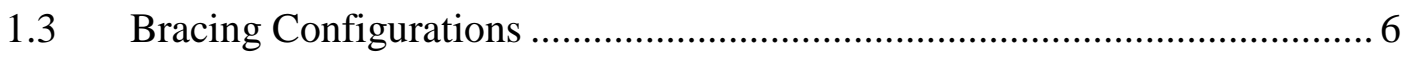

1.4 Restraint force vs. Panel Stiffness ........................................................ 9

1.5 Percent Restraint force vs. Roof Slope.................................................. 10

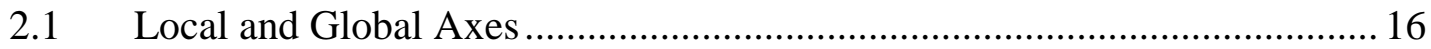

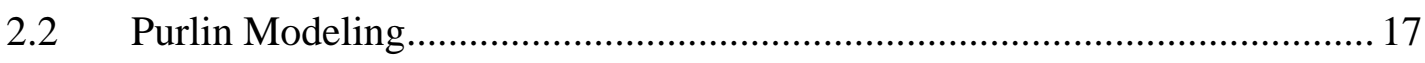

2.3 Effect of $I_{z z}$ in Type C Elements on Purlin Bending …............................. 20

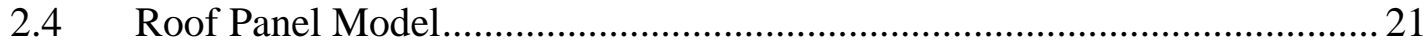

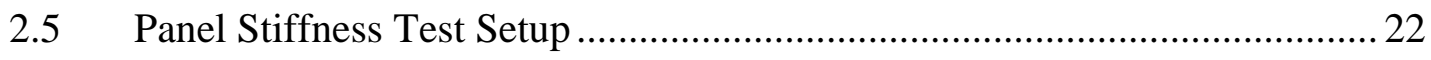

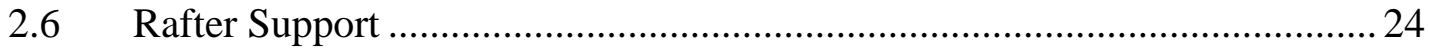

2.7 Lateral Brace Boundary Conditions ..................................................... 24

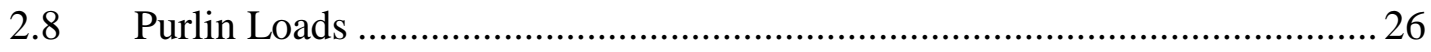

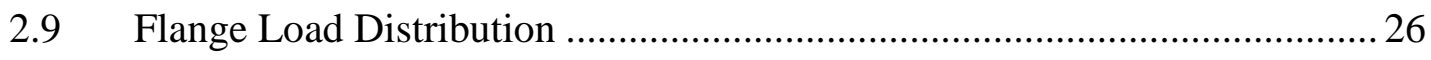

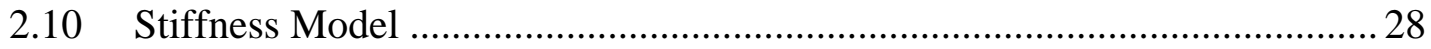

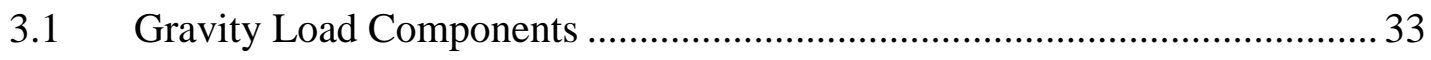

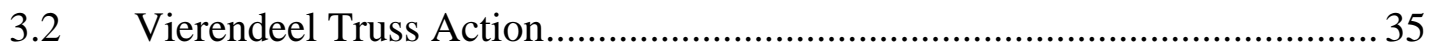

3.3 Restraint force vs. Number of Purlins (Typical) ..................................... 35

$3.4 \quad$ Restraint force vs. Roof Slope (Typical) ............................................ 35

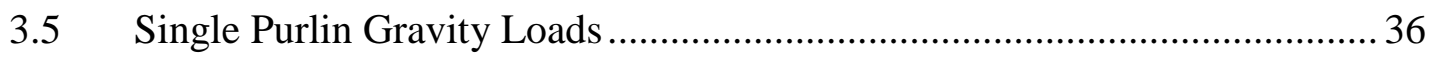

3.6 Restraint force vs. Panel Stiffness (Model)................................................. 38

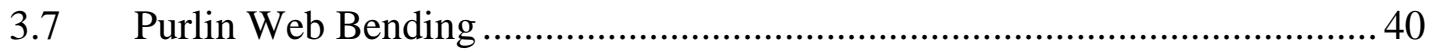

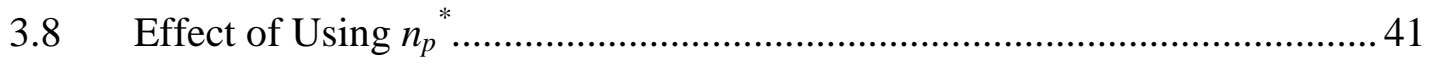

3.9 Restraint force vs. Panel Stiffness (Proposed) ......................................... 43

3.10 Comparison of Restraint force vs. Roof Slope ............................................. 44

3.11 Comparison of Restraint force vs. Number of Purlins .............................. 45 


\section{LIST OF FIGURES, CONTINUED}

3.12 Summary of Design Equations.................................................................. 45

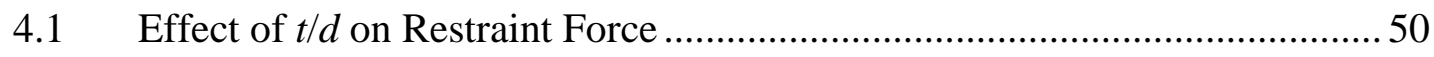

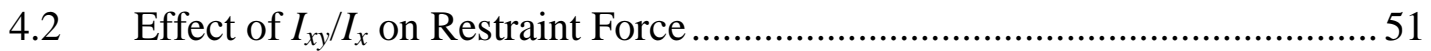

$5.1 \quad$ Summary of Proposed Design Procedure ........................................................ 71

5.2 Restraint Forces for Example 1 …......................................................... 74

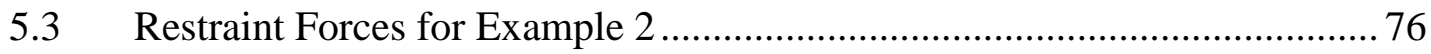

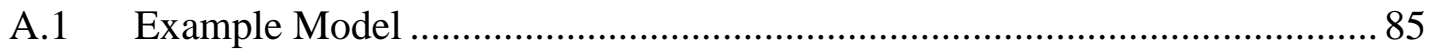




\section{LIST OF TABLES}

Table

Page

2.1 Comparison of Section Property Designations ......................................... 18

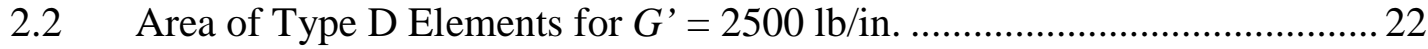

2.3 Summary of Section Properties............................................................. 28

2.4 Experimental Test Parameters................................................................ 29

2.5 Comparison of Brace Force Ratio Results. ............................................ 30

2.6 Statistics for Model Evaluation ............................................................. 31

4.1 Effect of Span Length on Restraint Force ................................................ 49

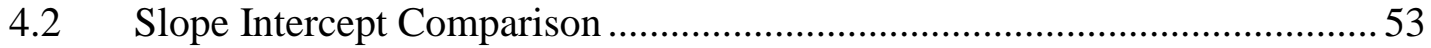

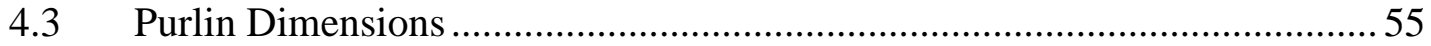

4.4 Purlin Section Properties ........................................................................ 55

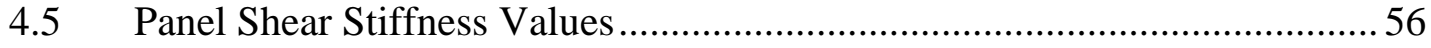

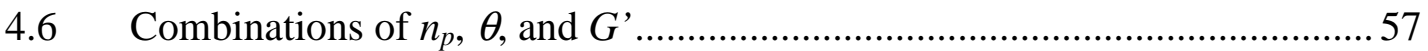

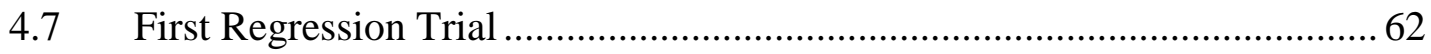

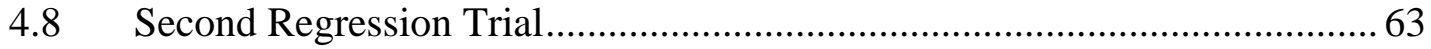

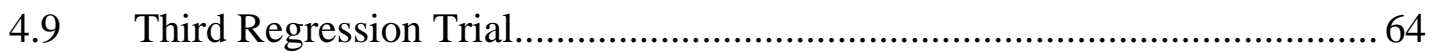

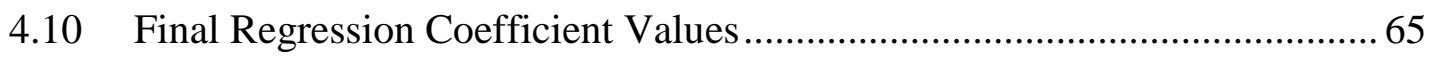

4.11 Test Series for Roof Slope and Panel Stiffness Interaction......................... 66

4.12 Results of Roof Slope and Panel Stiffness Interaction Tests .......................66

4.13 Comparison of Verification Tests to Design Equation ................................ 68

$5.1 \quad$ Design Equation Coefficient Values ..................................................... 70

A.1 Section Properties for Example Model …................................................ 86

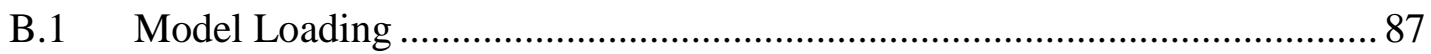

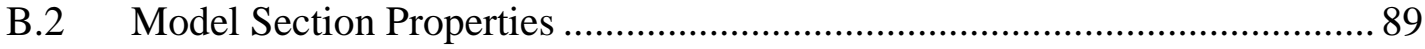

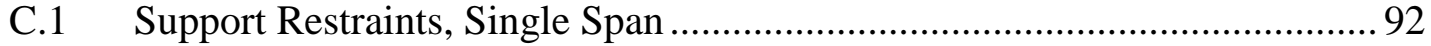

C.2 Support Restraints, Multiple Span, Exterior .......................................... 93

C.3 Support Restraints, Multiple Span, Interior.......................................... 93 


\section{LIST OF TABLES, CONTINUED}

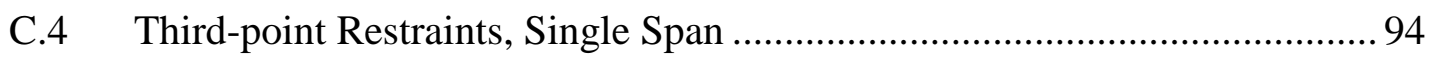

C.5 Third-point Restraints, Multiple Span, Exterior............................................... 94

C.6 Third-point Restraints, Multiple Span, Interior ………………………….... 95

C.7 Midspan Restraint, Single Span .............................................................. 95

C.8 Midspan Restraints, Multiple Span, Exterior ................................................... 96

C.9 Midspan Restraints, Multiple Span, Interior ……………………………...... 96

C.10 Quarter-point Restraints, Single Span, Exterior............................................ 97

C.11 Quarter-point Restraints, Single Span, Interior …………………………..... 97

C.12 Quarter-point Restraints, Multiple Span, Exterior 1/4 Span ............................ 98

C.13 Quarter-point Restraints, Multiple Span, Interior $1 / 4$ Span ……..................... 98

C.14 Quarter-point Restraints, Multiple Span, $1 / 2$ Span ………………………..... 99

C.15 Third-point plus Support Restraints, Single Span, Exterior.............................99

C.16 Third-point plus Support Restraints, Single Span, Interior ............................ 100

C.17 Third-point plus Support Restraints, Multiple Span, Exterior Support.......... 100

C.18 Third-point plus Support Restraints, Multiple Span, Interior Support.......... 101

C.19 Third-point plus Support Restraints, Multiple Span, Third-point.................. 101 


\section{CHAPTER I}

\section{INTRODUCTION}

\subsection{OBJECTIVE}

This research is an analytical study to formulate design equations for the estimation of required lateral restraint forces in Z-purlin supported, sloped roofs under gravity loads. The current design equations for these restraints, contained in Section D3.2.1 of the American Iron and Steel Institute's Specification for the Design of Coldformed Steel Members (1996), have several deficiencies. These provisions have an incorrect treatment of roof slope and depend too heavily upon statistical regression. The current specification also does not consider roof panel stiffness, which can have a significant effect on the required restraint force. Furthermore, there is a range of roof slopes for which no lateral restraint is necessary, but Section D3.2.1 does not address this issue.

Thus, the goal of this research is to develop new and more suitable design equations to replace Section D3.2.1 of the Specification. The proposed equations must be less empirical and have a stronger reliance on engineering principles. The other deficiencies must be remedied by using a more accurate treatment of sloped roofs, including an adjustment for roof panel stiffness, and setting a minimum restraint force value for which lateral restraint is necessary.

\subsection{BACKGROUND}

Metal building systems are commonly used for the construction of low-rise, industrial buildings. The roof system in these buildings is often composed of corrugated metal roof panels connected to cold-formed purlins (either $\mathrm{C}$ or Z-sections). Two fastening systems are currently used to attach the roof panels to the purlins. In a throughfastened roof system, the panels are attached directly to the purlins with self-drilling or 
self-tapping fasteners, typically spaced every $12 \mathrm{in}$. along each purlin, that penetrate through the panels. A standing seam roof system has vertical side laps for joining panels, and the panels are attached to the purlins by means of concealed clips, typically spaced every 18-24 in. along each purlin. These clips do not penetrate the panels, making the roof more watertight than a through-fastened system.

Cold-formed Z-purlins come in sizes ranging from 3 to $12 \mathrm{in.}$ in depth, 1.75 to 3.25 in. in flange width, and 0.036 to 0.135 in. in thickness (see Figure 1.1). These purlins are fabricated from steel sheets, which are then subjected to a cold bending process, either press braking or roll-forming, to obtain a Z-shaped cross-section. Coldforming increases strength due to the strain hardening and strain aging that occurs during the process. The outer edges of the flanges are usually lipped for stiffening, to increase their local buckling strength. The primary advantage of Z-purlins is that the cross-section allows them to be nested for shipping and lapped to provide continuity. Also, Z-purlins are often used in metal roofs because they are lightweight, easily fabricated and erected, and tend to be very economical.

Due to the asymmetric cross-section of a Z-purlin, it will twist and deflect laterally when loaded obliquely to its principal axes, as is the case for gravity loading on a flat roof. The presence of a roof panel usually prevents the purlins from moving relative to each other, but the entire system will tend to move laterally. This lateral movement and twisting is detrimental to flexural strength, and necessitates a restraint system, typically provided by a number of discrete eave braces along each purlin span. The most common bracing schemes are support (or torsional) restraints, third-point restraints, and midpoint restraint, each having braces attached to the purlin web, just below the top flange. The geometry of a Z-purlin, and the composite action between panel and purlin, have made the prediction of the required bracing forces very difficult. 


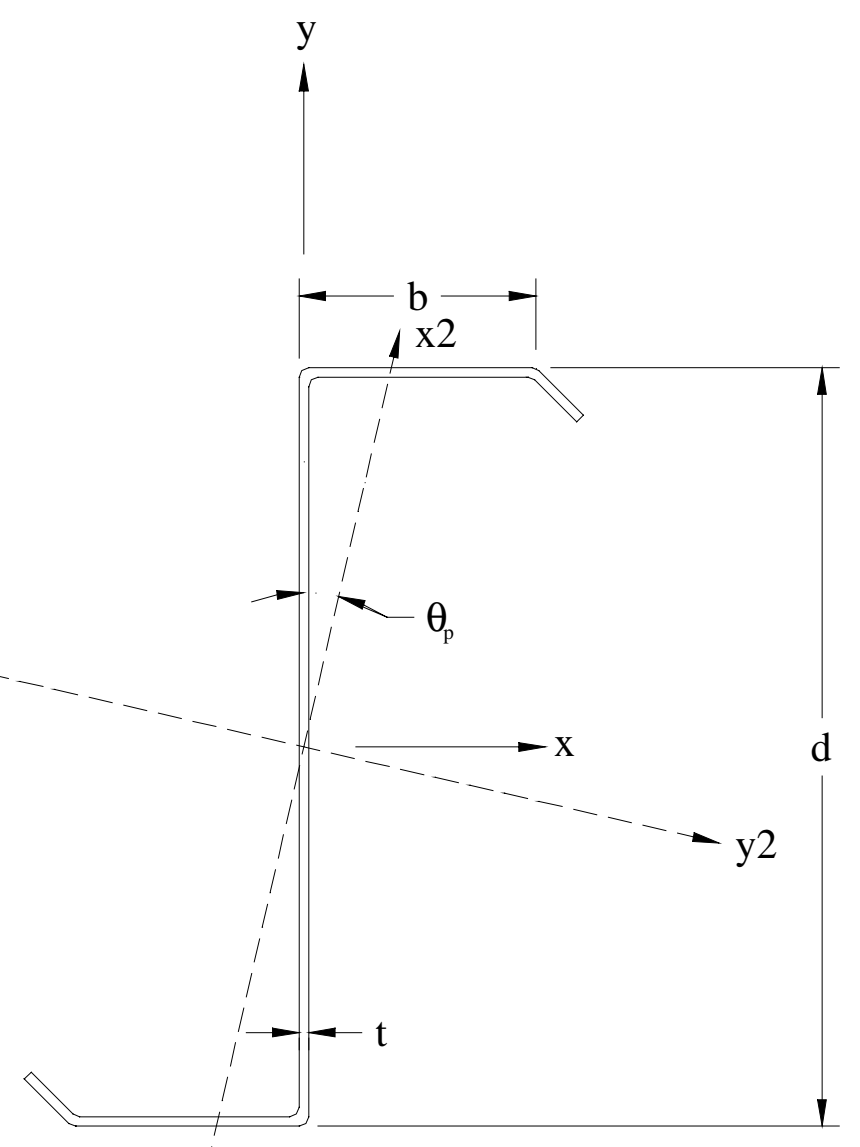

Figure 1.1 Z-purlin Geometry

\subsection{LITERATURE REVIEW}

Theoretical Studies. Zetlin and Winter (1955) studied single span, simply supported, Z-purlins, with various loadings applied in the plane of the web. They assumed lateral bracing was present at both flanges at all locations of applied loads. Through basic principles of mechanics, the following equation for total restraint force was developed:

$$
P_{L}=\left(I_{x y} / I_{x}\right) W
$$

where $P_{L}$ is the restraint force, $I_{x y}$ is the product moment of inertia, $I_{x}$ is the moment of inertia with respect to an axis perpendicular to the purlin web, and $W$ is the applied load. This equation shows a linear variation of restraint force with the applied loading, and the ratio of restraint force to applied load depends solely on the cross-sectional properties of 
the purlin. Note that torque effects on restraint force, caused by eccentric loading of the top flange, are not accounted for in this expression.

Another limitation of Equation 1.1 is that it considers only a single purlin by itself. In actual roof systems, the shear and torsional stiffness of roof panels gives partial restraint to the purlins. Needham (1981) developed a mathematical model to incorporate these panel forces. Assumptions made in the model were: 1) simply supported purlins, 2) no lateral bracing, 3) the panel acts as an infinitely rigid diaphragm, and 4) the panel cannot move laterally with respect to the purlins. In practice, a gravity loaded purlin has a distributed load acting on its top flange. Needham approximated this loading with a point load acting at $b / 6$ away from the web, where $b$ is the flange width (refer to Figure 1.1). The net torque acting on the cross-section was set equal to the sum of torques induced by the applied loading and by panel restraint. The primary force in the panel was taken to be $\left(I_{x y} / I_{x}\right) W$, based on the work of Zetlin and Winter. To satisfy equilibrium, a secondary force in the purlin, $W_{p s}$, was given to the panel. This force acts at a distance of $d / 2$ from the shear center of the purlin, leading to $W_{p s}=T /(d / 2)$, where $d$ is the depth of the purlin. Based on these expressions and assumptions, Needham derived an equation for total bracing force, and extended it to account for sloped roofs:

$$
P_{L}=W\left[\left(\frac{I_{x y}}{I_{x}}\right)(\cos \theta-1)-\sin \theta+\frac{b}{3 d}\right]
$$

where $\theta$ is the roof angle with respect to horizontal. Needham found Equation 1.2 to be in good agreement with laboratory test results, depending on the value of eccentricity $(e=$ $b / 6$ was not always accurate).

Ghazanfari and Murray (1983) developed a method to predict restraint forces in simply supported Z-purlins attached to conventional roof panels. Various bracing schemes were examined, all under uniform gravity loading. Assumptions in their model include: 1) no panel rotational restraint, 2) no lateral movement of the purlins relative to the panel, 3) the eccentricity of the vertical load is $b / 3,4) \mathrm{W}_{\mathrm{h}}$ (lateral panel force) is uniformly distributed and acts at the top flange in a horizontal plane, 5) and all braces are infinitely rigid and connected to immovable supports. In their model, Ghazanfari and 
Murray accounted for the effects of panel deformation on restraint forces. Panel deformation cannot be determined unless the lateral force acting on the panel is known. However, this lateral force is depends on the torque loading, which is in turn dependent on the panel deformation. Thus, an iterative computer program was developed to calculate these second order effects. The effect of several parameters on restraint force was studied, and panel stiffness, span, load eccentricity, and principal axes location were found to be the most critical.

The above research had not examined the effects of multiple spans and multiple restrained purlin lines. Elhouar and Murray (1985) remedied this deficiency in developing a design procedure for bracing requirements in through fastened, corrugated steel panel, roof systems. A computer stiffness model (see Figure 1.3) was built and adjusted to match full-scale (Curtis and Murray, 1983) and quarter-scale (Seshappa and Murray, 1985) experimental results. The model was made using STRUDL (Structural Design Language) and represented Z-purlins with space frame line elements and roof panels with plane trusses. Braces were connected to the top line elements of purlins, and the eccentricity of the applied loading was assumed to be $b / 3$. Other assumptions were that purlins could not move relative to the roof panel, and that braces and purlins were attached to rigid supports that prevent all translations. Three bracing configurations (see Figure 1.3) were examined: end restraints, third-point restraints, and midpoint restraint.

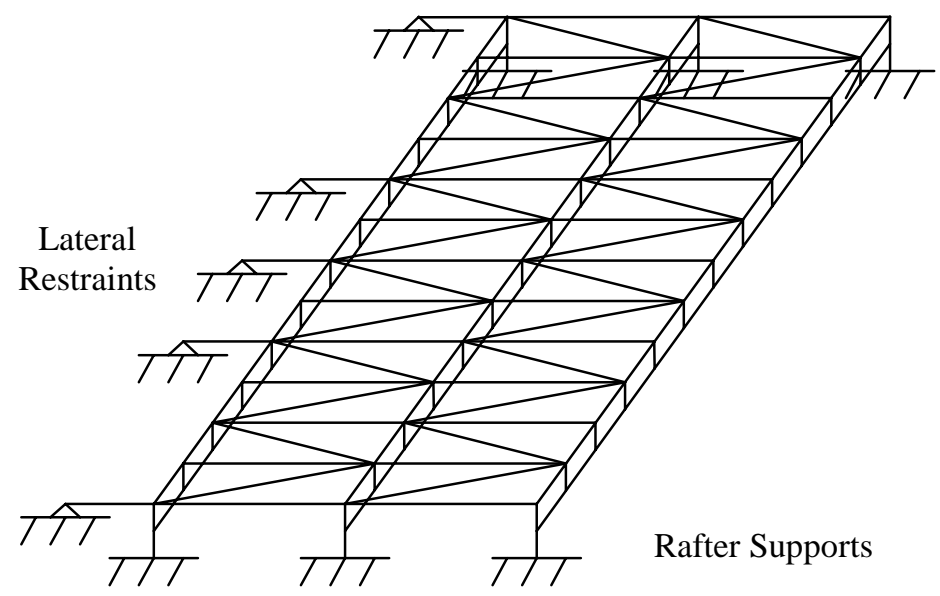

Figure 1.2 Elhouar and Murray's Stiffness Model 


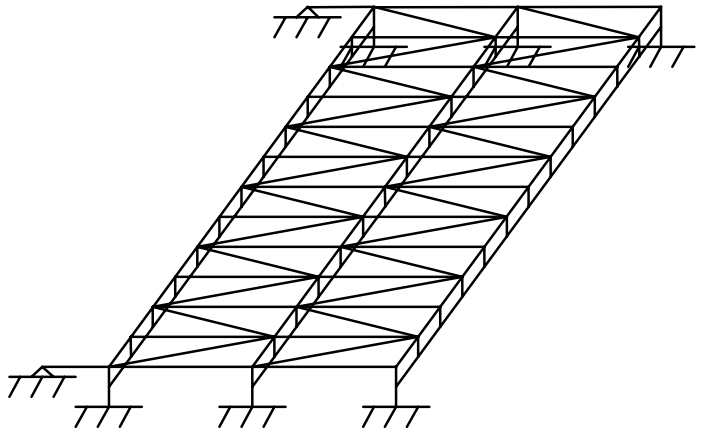

(a) Support Restraints

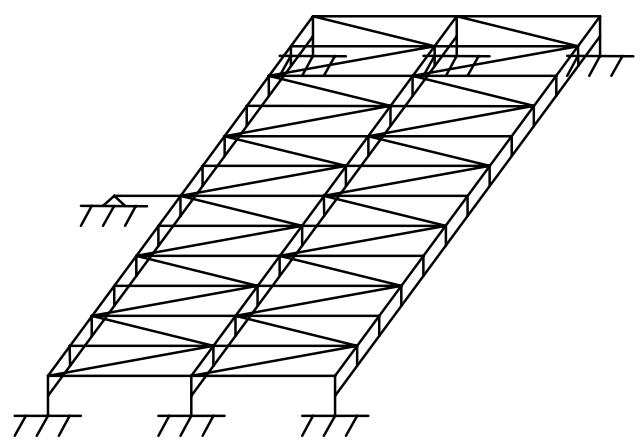

(c) Midpoint Restraint

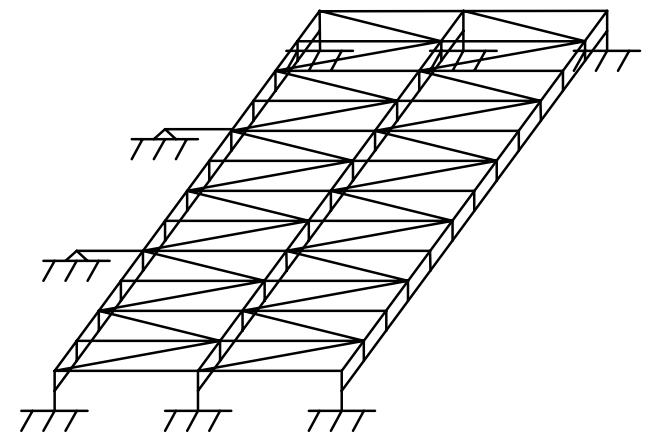

(b) Third-point Restraints

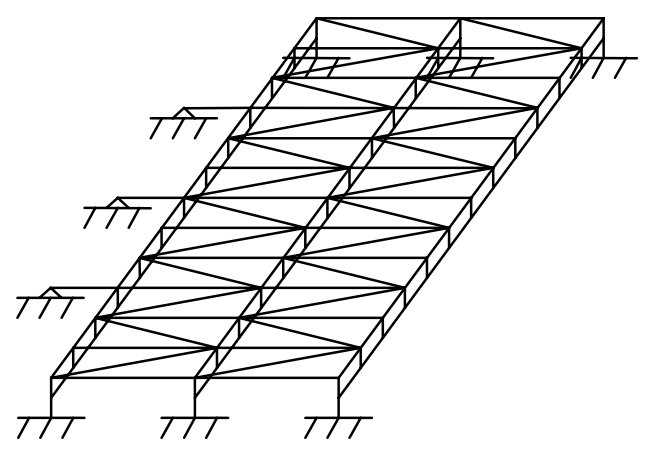

(d) Quarter-point Restraints

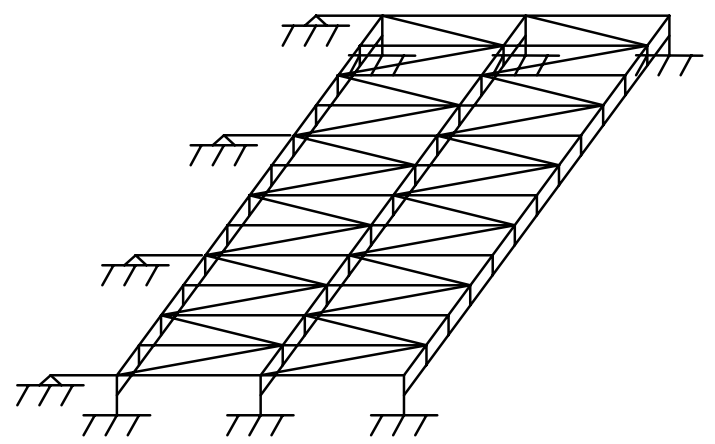

(e) Third-point Plus Support Restraints

Figure 1.3 Bracing Configurations 
Based upon data taken from the stiffness model, a parametric study was performed to determine how restraint force is affected by cross-sectional properties, number of restrained purlin lines, span length, number of spans, and the bracing configuration. Roof slope was not included in the parametric study, but based on quarterscale tests by Seshappa and Murray (1985), Elhouar and Murray (1985) corrected for slope through the following relationship:

$$
P_{L}=P_{L_{O}}-W \tan \theta
$$

where $P_{L_{O}}$ is the restraint force on a flat roof. Roof panel stiffness was also not examined, because a stiffness of $2500 \mathrm{lb} / \mathrm{in}$. was assumed for all cases. It was believed that the increase in required restraint force was negligible for roof panels stiffer than 2500 lb/in, based on experimental results by Ghazanfari and Murray (1983). A regression analysis was then performed on the data to derive prediction equations for the various span and bracing conditions considered. As an example, Elhouar and Murray's equation for the force in each brace of a single span system with end restraints is:

$$
P_{L}=0.5\left(\frac{0.220 \cdot b^{1.500}}{n_{p}^{0.716} d^{0.901} t^{0.600}}-\tan \theta\right) W
$$

where $n_{p}$ is the number of restrained purlin lines and $t$ is the purlin thickness. Previous experimental results indicated a "system effect" whereby increasing the number of restrained purlin lines in a system decreases the ratio of lateral force to vertical applied force. The primary cause of this system effect is believed to be the torsional resistance of the purlins. Elhouar and Murray's equations take this system effect into account with the regression terms.

Several more recent studies on the modeling of Z-purlin behavior have been conducted. Fenske and Yener (1990) treated Z-purlin roof systems as stiffened plates, with section properties based upon composite action between the roof panel and the purlins. Generalized beam theory was applied to Z-purlin design by Heinz (1994). Lucas et al (1997) developed a non-linear, elasto-plastic finite element model for Z-purlin roof systems. 
In 1998, Danza and Murray extended the work done by Elhouar to include two new bracing configurations (refer to Figure 1.3): quarter-point restraints and third-point plus support restraints. A series of computer tests was run using elastic stiffness models, similar to those used by Elhouar, but with minor modifications. The parameters varied included purlin cross-section, number of restrained purlin lines, number of spans, and span length. The study did not include sloped roofs, and assumed a panel stiffness value of $2500 \mathrm{lb} / \mathrm{in}$. A regression analysis was then performed on the stiffness model results, to obtain a set of empirical design equations. The form of the equations was modified slightly from the one used by Elhouar and Murray, and includes span length in the regression. For example, the following is Danza and Murray's design equation for single span systems with quarter-point restraint:

$$
P_{L}=C\left[\left(\frac{t}{L}\right)^{0.16}-\frac{0.407 t^{0.75} d^{0.50} n^{0.39}}{b^{1.25}}\right] W
$$

where $C=0.25$ for braces near supports, $C=0.50$ for brace at midspan, and $W$ is the total applied gravity load (lb).

Experimental Studies. Needham (1981) conducted a small number of full-scale tests on flat roofs to confirm his analysis. The test apparatus had two $9.5 \mathrm{in}$. deep purlins spaced $5 \mathrm{ft}$ apart, each fastened to roof panels. The bracing configuration was end restraints, and simulated gravity loading was applied. Lateral loads were measured with load cells and found to be between $9.1 \%$ and $9.7 \%$ of the total applied load.

Ghazanfari and Murray (1982) also did full-scale tests to confirm their analytical results. They performed nine tests on flat, single span, two purlin line systems with four different bracing schemes. Deck stiffness was varied, and results showed a negligible increase in restraint force for two purlin systems, when the deck stiffness was increased above $1500 \mathrm{lb} / \mathrm{in}$. (see Figure 1.4). The predicted restraint forces were in agreement with experimental results, though slightly conservative at loads below the purlin failure load. For systems with intermediate braces, second order effects were negligible. Restraint force was found to vary from $14 \%$ to $29 \%$ of the total applied load, depending on the span and bracing scheme. 


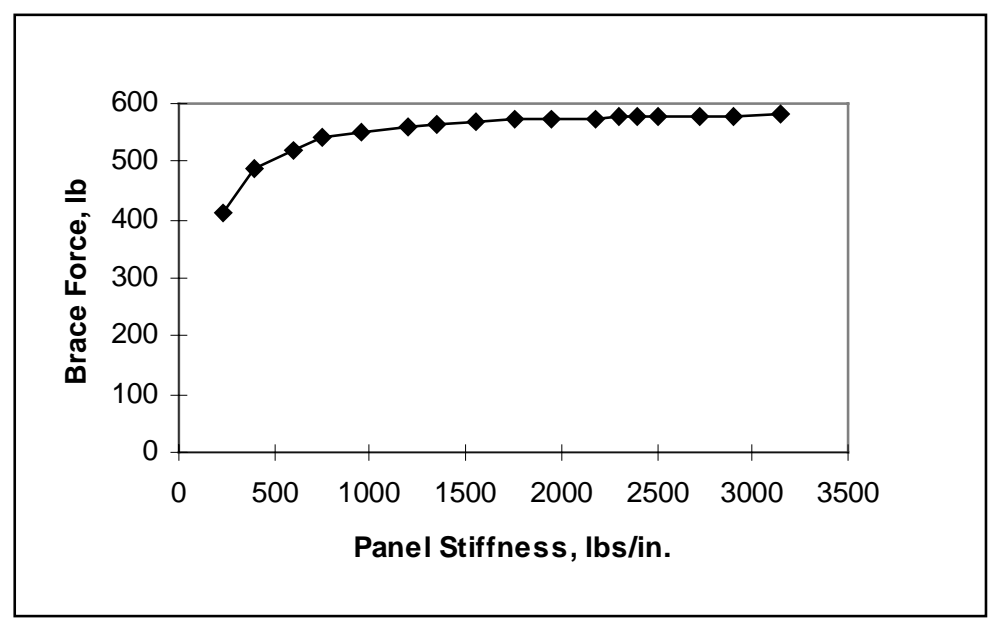

\section{Figure 1.4 Restraint force vs. Panel Stiffness (Ghazanfari and Murray, 1983)}

Twenty full-scale tests were conducted by Curtis and Murray (1983) on flat, single-span systems with two, six and seven restrained purlin lines. All tests measured the end restraint restraint forces, which were induced by gravity loading. Their results identified the existence of the system effect in Z-purlin supported roof systems. They determined that increasing the number of restrained purlin lines decreased the lateral restraint force by $5 \%$ to $10 \%$ of the applied load.

Seshappa and Murray (1985) used quarter-scale model Z-purlins to study throughfastened roof systems under gravity loading. Basic similitude concepts were followed whenever possible, and some identical full-scale tests were done for verification. Roof panels and fasteners did not fully satisfy similitude laws, but it was determined that this difference was negligible. A total of 28 tests were performed to measure lateral restraint forces for multiple span, multiple purlin line systems with end restraints, third point restraints, and midpoint restraint. One series of tests was conducted on systems with roof slopes varying from 0:12 to 1.5:12. The results of this test series are shown in Figure 1.5. It was concluded that the bracing force for sloped roofs could be predicted by subtracting off the lateral component of the applied load from the flat roof prediction (Equation 1.3). The interaction of system effects along with roof slope was not considered. 


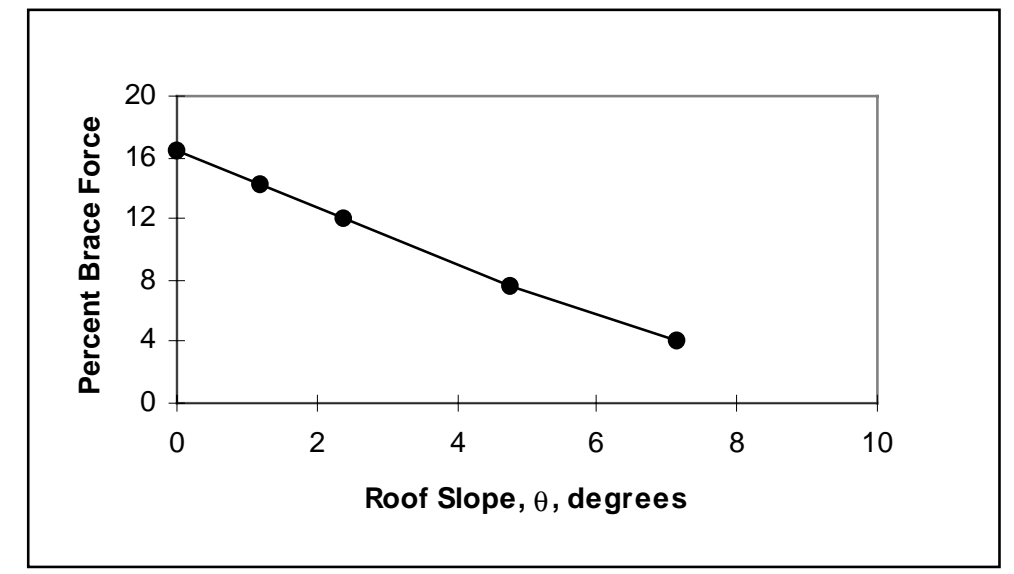

\section{Figure 1.5 Percent Restraint force vs. Roof Slope} (Seshappa and Murray, 1985)

Rivard and Murray (1986) performed six single span and six three-span continuous tests for lateral restraint forces in standing seam roof systems with Z-purlins. One single span test was done on a through-fastened system for comparison. The bracing schemes considered were again end restraints, third-point restraints, and midpoint restraint. Two piece clips were used for both pan type and rib type roof panels. The results indicated that the equations developed by Elhouar and Murray (1985) were applicable to standing seam roofs as well as through-fastened roofs.

\subsection{CURRENT DESIGN PRACTICE}

In the United States, the specification used for the design of lateral bracing for Zpurlin supported roof systems is generally the Specification for the Design of ColdFormed Steel Structural Members (1996). This specification defines the force that lateral restraints must be designed to resist, for single and multiple purlin line systems of any roof slope. Three bracing configurations are addressed: end restraints, third-point restraints, and midpoint restraint. The specification applies to both through-fastened and standing seam roof systems, but only to systems with all purlins facing in the direction of upward roof slope. The design equations are based on the prediction equations developed 
by Elhouar and Murray (1985) through regression analysis, with slight modifications. These equations, as they appear in the specification, are as follows:

(1) Single-span System with Restraints at the Supports:

$P_{L}=0.5\left[\frac{0.220 b^{1.50}}{n_{p}{ }^{0.72} d^{0.90} t^{0.60}} \cos \theta-\sin \theta\right] W$

(2) Single-span System with Third-point Restraints:

$P_{L}=0.5\left[\frac{0.474 b^{1.22}}{n_{p}{ }^{0.57} d^{0.89} t^{0.33}} \cos \theta-\sin \theta\right] W$

(3) Single-span System with Midspan Restraint:

$P_{L}=0.5\left[\frac{0.224 b^{1.32}}{n_{p}{ }^{0.65} d^{0.83} t^{0.50}} \cos \theta-\sin \theta\right] W$

(4) Multiple-span System with Restraints at the Supports:

$P_{L}=C_{t r}\left[\frac{0.053 b^{1.88} L^{0.13}}{n_{p}{ }^{0.95} d^{1.07} t^{0.94}} \cos \theta-\sin \theta\right] W$

with $\quad \mathrm{C}_{\mathrm{tr}}=0.63$ for braces at end supports of multiple-span systems

$\mathrm{C}_{\mathrm{tr}}=0.87$ for braces at the first interior supports

$\mathrm{C}_{\mathrm{tr}}=0.81$ for all other braces

(5) Multiple-span System with Third-point Restraints:

$P_{L}=C_{t h}\left[\frac{0.181 b^{1.15} L^{0.25}}{n_{p}^{0.54} d^{1.11} t^{0.29}} \cos \theta-\sin \theta\right] W$

with $\quad C_{\mathrm{th}}=0.57$ for outer braces in exterior spans

$\mathrm{C}_{\mathrm{th}}=0.48$ for all other braces

(6) Multiple-span System with Midspan Restraints:

$P_{L}=C_{m s}\left[\frac{0.116 b^{1.32} L^{0.18}}{n_{p}{ }^{0.70} d t^{0.50}} \cos \theta-\sin \theta\right] W$

with $\quad \mathrm{C}_{\mathrm{ms}}=1.05$ for braces in exterior spans

$\mathrm{C}_{\mathrm{ms}}=0.90$ for all other braces 
where $b=$ Flange width

$\mathrm{d}=$ Depth of section

$\mathrm{t}=$ thickness

$\mathrm{L}=$ span length

$\theta=$ Angle between the vertical and the plane of the web of the Z-section, degrees

$\mathrm{n}_{\mathrm{p}}=$ Number of parallel restrained purlin lines

$\mathrm{W}=$ Total load supported by the restrained purlin lines between adjacent supports

In these equations, positive restraint force indicates that restraint is needed to keep the purlin flanges from moving in the direction of upward roof slope. Systems having less than four restrained purlin lines have a required bracing force equal to 1.1 times the force given by $E q$. D3.2.1-1 through $E q$. D3.2.1-6, calculated using $\mathrm{n}_{\mathrm{p}}=4$. Systems having more than twenty restrained purlin lines have a required bracing force determined by Eq. D3.2.1-1 through Eq. D3.2.1-6, calculated using $\mathrm{n}_{\mathrm{p}}=20$.

Compared to Elhouar's Equation 1.4, the only significant difference is the addition of a $\cos \theta$ factor to the regression term, and the replacement of the $\tan \theta$ term with a $\sin \theta$ term. Note that for small angles, $\cos \theta \rightarrow 1$ and $\sin \theta \rightarrow \tan \theta$, which makes the two equations equivalent for this approximation. For examples showing this design procedure, refer to A Guide for Designing with Standing Seam Roof Panels (Fisher and LaBoube, 1997).

\subsection{SCOPE OF RESEARCH}

The intent of this research is to develop restraint force design equations for five lateral bracing configurations for both single and multiple span roof systems, with multiple Z-restrained purlin lines: support restraints, third-point restraints, midspan restraint, quarter-point restraints, and third-point plus support restraints. A space frame stiffness model was developed to test the restraint force behavior of many different roof 
system conditions. Parameters varied in the study include: purlin cross-section, span length, roof panel stiffness, roof slope, and number of restrained purlin lines.

Theoretical design equations were developed based on a new treatment of Zpurlin statics, with coefficients varying for each bracing condition. These coefficients were determined by a regression analysis of the stiffness model results. The result of this work is a set of proposed specification provisions, intended to replace the current provisions in Section D3.2.1 of the Specification for the Design of Cold-Formed Steel Structural Members (1996). 


\section{CHAPTER II}

\section{MATHEMATICAL MODELING}

\section{$2.1 \quad$ INTRODUCTION TO MODELING}

The purpose of this chapter is to develop a mathematical model of a Z-purlin supported roof system, consisting of parallel purlin lines, a roof panel, rafter supports, and lateral braces. Mathematical modeling, by definition, is a means of approximating an actual physical system with a numerical representation. To develop and verify design equations for the estimation of restraint force in Z-purlin roof systems, a large amount of data is necessary. This data must have the required restraint forces for conditions representing the full range of parameters used in Z-purlin supported roofs. A numerical model is necessary for this research, because the number of experimental tests needed to collect this data would be impractical, and the existing data from previous tests is insufficient. Also, experimental research on sloped, full-scale Z-purlin roof systems is difficult due to the possibility of test apparatus collapse.

\subsection{SELECTION OF MODEL}

After identifying the need for modeling, the next step is to choose the most appropriate model. The model has to be an accurate representation of the physical system, so it should be as detailed and representative as possible. The basic principles of structural modeling must be followed: equilibrium of forces and physical compatibility, along with the use of proper material properties. The most accurate model would be a three-dimensional solid that includes second order effects. However, the model must be analyzed thousands of times to collect the necessary data, so execution time must be minimized. This makes highly sophisticated computer models, where each analysis run takes several hours, impractical for this research. Furthermore, this study is only 
concerned with the axial forces in the lateral restraints, and not stresses or deflections throughout the system, so complex modeling would not be advantageous.

In their research, Elhouar and Murray (1985) used a space frame stiffness model to generate restraint force data for their design equations. Their model, hereafter referred to as the Elhouar and Murray model, is appropriate because solid effects and second order effects are negligible on the restraint forces of Z-purlin supported roof systems. The Elhouar and Murray model showed excellent agreement with experimental results, and was later used by Danza and Murray (1998) to develop additional restraint force equations. In both the Elhouar and Murray model and the Danza and Murray model, purlins and the roof panel were represented by space trusses, which were attached to form

the main roof system, and then braced laterally by restraint members. Uniform gravity loads were approximated by discretizing the total gravity force into point and line loads. The resulting model retains the key aspects of the physical system and has a manageable execution time. The model also allows for roof parameters to be easily modified, which further reduces the time required for data collection. Therefore, an elastic stiffness model, based on the Elhouar and Murray model, was chosen for this investigation and is hereafter called the current model.

\subsection{STIFFNESS MODEL DEVELOPMENT}

\subsubsection{Global Characteristics}

The first step towards creating a stiffness model is to establish the global parameters. All of the models used for this project were created in United States Customary (USD) units (kip, in., ft) as is most commonly used in industry in this country. Analysis specifications were set such that shear deformations, torsional warping effects, and second order effects were neglected. Warping and second order effects were not considered, because this study examines only axial forces. The material used for all elements of the model was linear elastic steel. The fundamental material properties are: $\mathrm{E}=29,000 \mathrm{ksi}, \mathrm{G}=11,154 \mathrm{ksi}$, and $\mathrm{v}=0.3$; thus defining the Young's modulus, shear 
modulus, and Poisson's ratio, respectively. The material was assumed to be below yield stress, and therefore elastic, at all times.

\subsubsection{Axes Orientation}

To define directions and locations in space, local and global axes must be defined for the model. For the current model, the global Y-axis is established normal to the plane of the roof panel, the global Z-axis points down the length of the parallel purlin lines, and the global $\mathrm{X}$-axis is in line with the lateral restraint members. The local axes for each element in the model are defined so that the local $\mathrm{x}$-axis is oriented down the length of the element, and is normal to the plane containing the local y-and z-axes (see Figure 2.1).

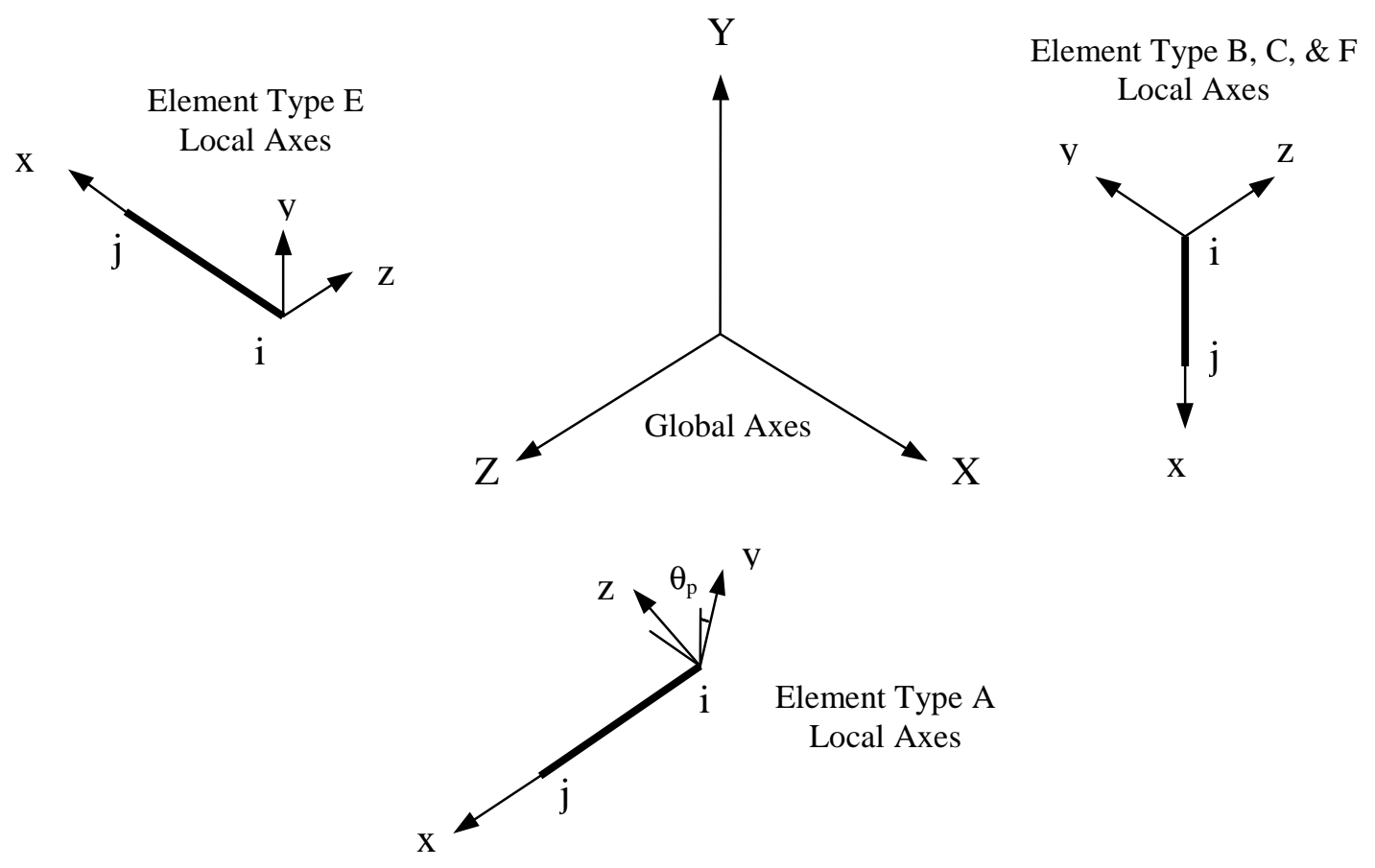

Figure 2.1 Local and Global Axes 


\subsubsection{Modeling of Purlins}

Similar to the Elhouar and Murray model, the current model represents a Z-purlin as a space truss. The truss consists of four different elements, and is divided into twelve sections of equal length (see Figure 2.2). Twelve divisions were chosen so that support, third-point, quarter-point, and midspan lateral restraints could frame into the available joints.

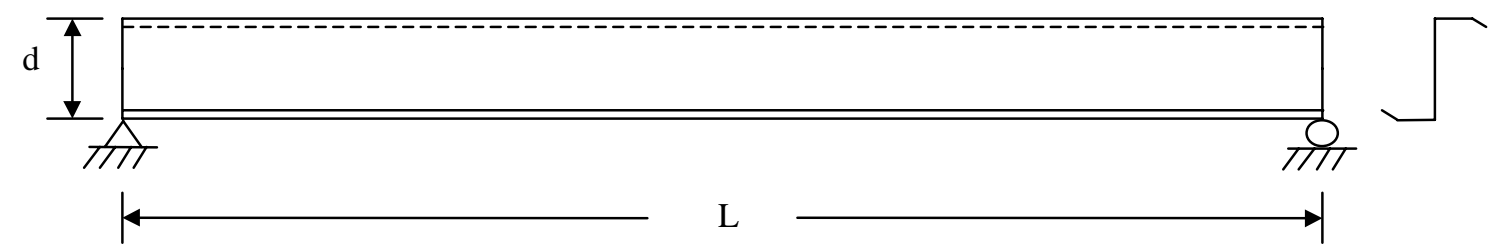

(a) Actual Purlin

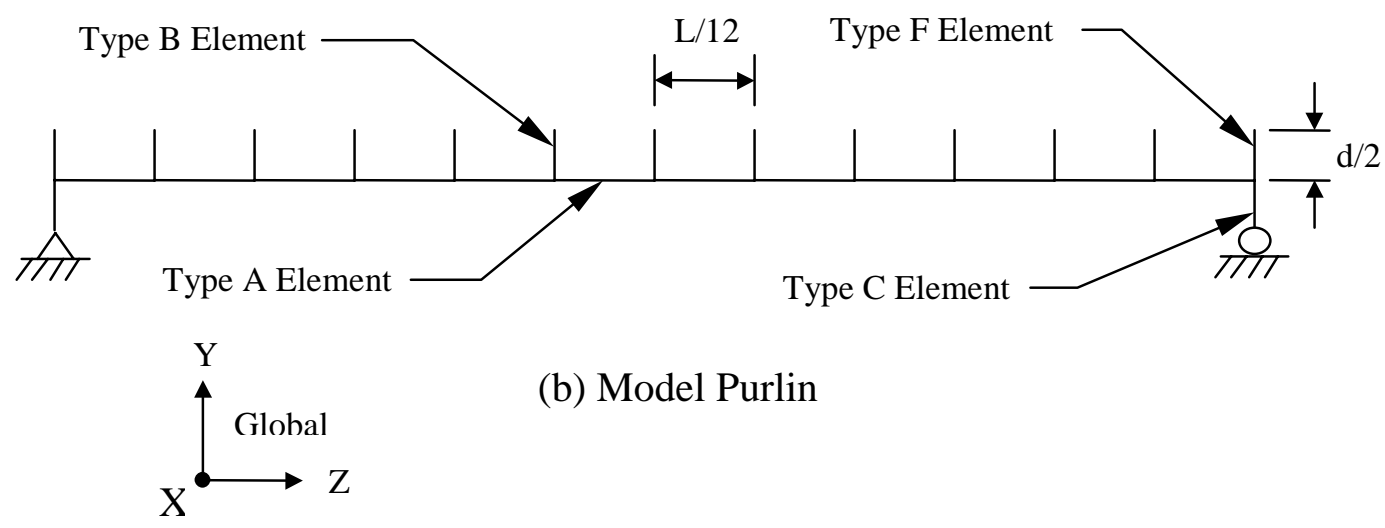

Figure 2.2 Purlin Modeling

The main purlin elements, oriented along the length of the purlin in the global $\mathrm{Z}$ direction, are type A elements. These elements are given different cross-sectional properties depending on the dimensions of the purlin that is being modeled. The section properties given in Table I-3 of the Cold-Formed Steel Design Manual (1996), for standard Z-sections with lips were used, with some adjustments. The nomenclature differs between the Cold-Formed Steel Design Manual and the current model for some properties (see Table 2.1). Notice that this comparison table pertains only to type A 
elements. For this discussion, section properties given in the design manual are referred to as purlin properties, and section properties for the current model are called model properties. Model section properties directly correspond to purlin section properties, except for $J$, the torsion constant. Due to the space truss nature of the purlin model, this model property was set at $J=10 \mathrm{in}^{4}$ for all cases, to prevent the type A elements from rotating with respect to their adjoining elements. This was done because purlin bending is modeled by the type B and $\mathrm{F}$ elements. Had element A been given the $J$ values from the Cold-Formed Steel Design Manual, which range from $J=0.000120$ in $^{4}$ to $J=0.0159$ in $^{4}$ for standard sections, extreme deformation would occur within the truss. This behavior would not be representative of actual purlins. Finally, to define the orientation of the principal axes of the purlin cross-section in the model, the local $\mathrm{x}$-axis was rotated by the principal angle (refer to Figure 2.1).

\section{Table 2.1 Nomenclature for Section Property Designations (Type A Elements)}

\begin{tabular}{|c|c|}
\hline $\begin{array}{c}\text { Cold-Formed Steel } \\
\text { Design Manual }\end{array}$ & Current Model \\
\hline Area $\left(\mathrm{in}^{2}\right)$ & Area $\left(\mathrm{in}^{2}\right)$ \\
\hline $\mathrm{I}_{\mathrm{x} 2}\left(\mathrm{in}^{4}\right)$ & $\mathrm{I}_{\mathrm{yy}}\left(\mathrm{in}^{4}\right)$ \\
\hline $\mathrm{I}_{\mathrm{y} 2}\left(\mathrm{in}^{4}\right)$ & $\mathrm{I}_{\mathrm{zz}}\left(\mathrm{in}^{4}\right)$ \\
\hline $\mathrm{J}\left(\mathrm{in}^{4}\right)$ & $\mathrm{J}\left(\mathrm{in}^{4}\right)$ \\
\hline$\theta(\mathrm{deg})$ & $\mathrm{x}-$ Axis Rotate $(\mathrm{deg})$ \\
\hline
\end{tabular}

Perpendicular to the type A elements are the type B and F elements, located at the ends of all twelve sections. The purpose of these elements is to model purlin web bending and connect the main purlin elements (type A) to the roof panel elements (type D). The type B and F elements have a length of half the purlin depth. Type F elements are located on the outside of each purlin line, while type B elements are located on the interior. For type B elements, the model properties are consistent with that of a $L / 12$ section of purlin:

$$
A=\frac{L t}{12}
$$




$$
I_{z z}=\frac{L t^{3}}{144}
$$

where $J=I_{x 2}$ of the purlin, $I_{y y}=J$ of the purlin, $L$ is the purlin span length (in.), and $t$ is the purlin thickness (in.). Since type F elements are on the outside of each purlin line, they have model section properties corresponding to a $L / 24$ length of purlin. These properties are exactly the same as for type B elements, except that:

$$
I_{z z}=\frac{L t^{3}}{288}
$$

For these elements, the only difference between the current model and the Elhouar and Murray model is the inclusion of type F elements. Previously, type B elements were used throughout every purlin span. Danza and Murray (1998) introduced the modification of including type F elements.

The last purlin element is type $\mathrm{C}$, which connects the purlin to the rafter supports. The model section properties for this member correspond to a $L / 2$ length of purlin:

$$
A=\frac{L t}{2}
$$

and as before, $J=I_{x 2}$ of the purlin and $I_{y y}=J$ of the purlin. However, for the current model, the last model section property is set such that $I_{z z}=1$ for all cases, instead of the value for a $L / 2$ length of purlin:

$$
I_{z z}=\frac{L t^{3}}{24}
$$

Elhouar and Murray (1985) originally used Equation 2.5-a to define $I_{z z}$ for type C elements. However, they noticed that this method allows type $\mathrm{C}$ elements to undergo large amounts of bending, which tended to offset the bending effects of the type B elements. This effect is described in Figure 2.3; note that type $\mathrm{C}$ elements are below purlin mid-height while type B elements are above it. If the type $\mathrm{C}$ elements are allowed to bend significantly, as in Figure 2.3(b) and Figure 2.3(c), the type A, B, and F elements are allowed to translate laterally to the left with respect to the rafter supports. When this occurs, the net displacement of the roof panel (type D elements) is reduced, because it is attached to the top of the type B and F elements. This reduced roof panel displacement 
causes a reduction in the axial force in the restraints and is not representative of Z-purlin supported roof systems. Realizing this, Elhouar and Murray (1985) arbitrarily increased the $\mathrm{z}$-axis moment of inertia as follows:

$$
I_{z z}=\frac{L t^{3}}{2}
$$

This significantly reduced the amount of bending by type $\mathrm{C}$ elements, and was deemed acceptable for their analysis. This modification, though, did not eliminate all bending in type $\mathrm{C}$ elements as required. Setting $I_{z z}$ equal to an arbitrarily high value, like $I_{z z}=1 \mathrm{in}^{4}$, virtually eliminates all of this bending. This achieves the goal of modeling the purlin such that all bending takes place in the type B elements.

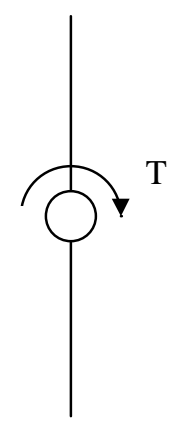

(a) Undeformed Purlin

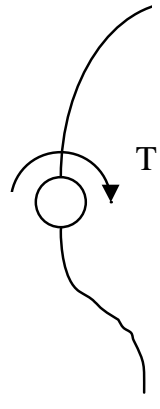

(b) Equation 2.5-a

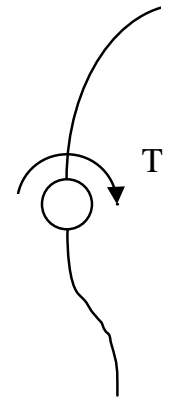

(c) Equation 2.5-b

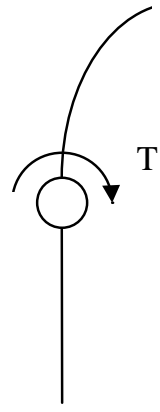

(d) $\mathrm{I}_{\mathrm{zz}}=1 \mathrm{in}^{4}$

\section{Figure 2.3 Effect of $I_{z z}$ in Type C Elements on Purlin Bending} (Danza and Murray, 1998)

\subsubsection{Modeling of Roof Panel}

The two prominent methods of purlin deck fastening are standing seam and through-fastened connections. In the current model, panel bending stiffness is neglected and only shear stiffness is considered. The roof panel is modeled as a space truss, consisting of $5 \mathrm{ft}$ wide sections between each purlin line, each with a series of diagonal members (see Figure 2.4). All of the elements in the roof panel have the same model section properties and are denoted as type D elements. To simulate the lack of bending 
stiffness, all moments of inertia for type D elements are made as close to zero as possible: $I_{y y}=I_{z z}=J=0.001 \mathrm{in}^{4}$.

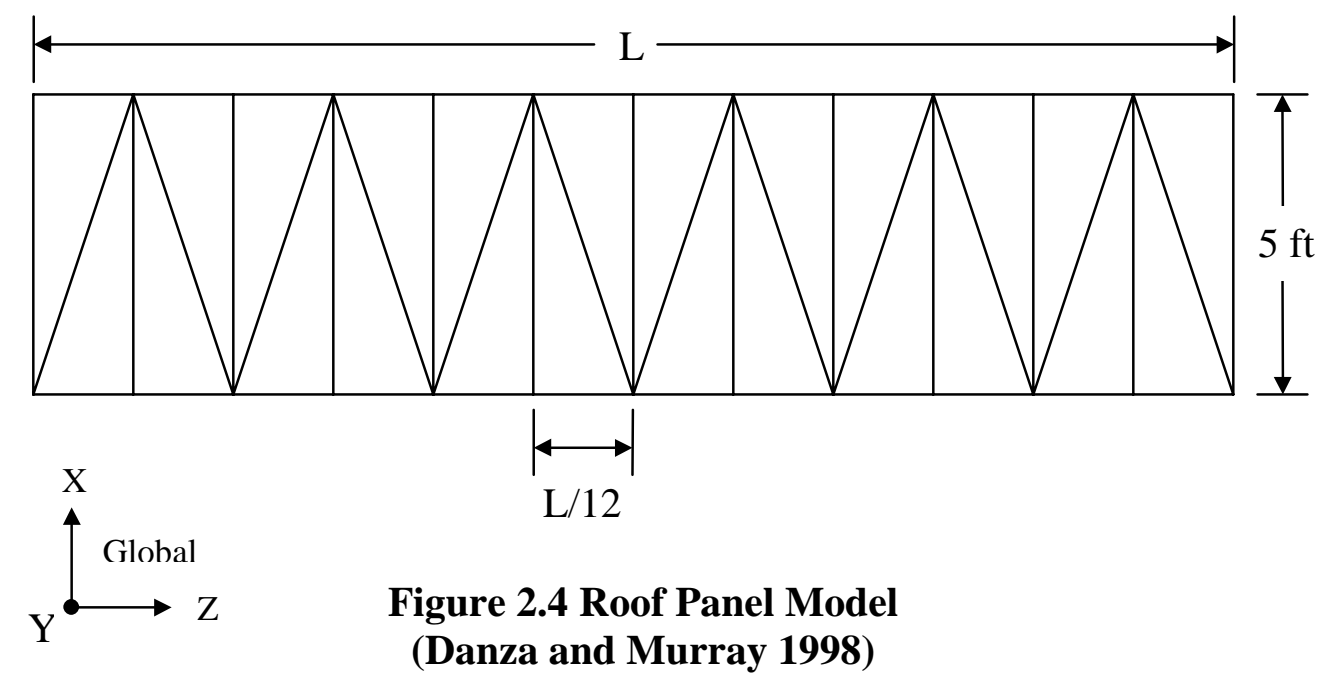

The Elhouar and Murray model, used to develop the AISI Provisions in Section D3.2.1, had an assumed roof panel shear stiffness of $2500 \mathrm{lb} / \mathrm{in}$. For this discussion, roof panel stiffness is defined as:

$$
G^{\prime}=\frac{P L}{4 a \Delta}
$$

where $P$ is a point load (lb) applied at midspan of a rectangular roof panel, $L$ is the panel's span length (ft), $a$ is the width of the panel (5 ft for all cases), and $\Delta$ is the deflection of the panel (in.) at the location of the point load. Figure 2.5 shows the test setup to calculate panel stiffness; note that the panel has two fully pinned supports and no rollers. Experimental tests done by Ghazanfari and Murray (1983) indicated that the increase in required restraint force for systems with roof panels stiffer than $1500 \mathrm{lb} / \mathrm{in}$. was negligible. An experimental study by Curtis and Murray (1983) determined that a panel stiffness of $2500 \mathrm{lb} / \mathrm{in}$. should be used for all mathematical models. However, these tests only considered systems with three or fewer restrained purlin lines. This research examines how restraint force is affected by roof panel shear stiffness, considering a wide range of parameters. 


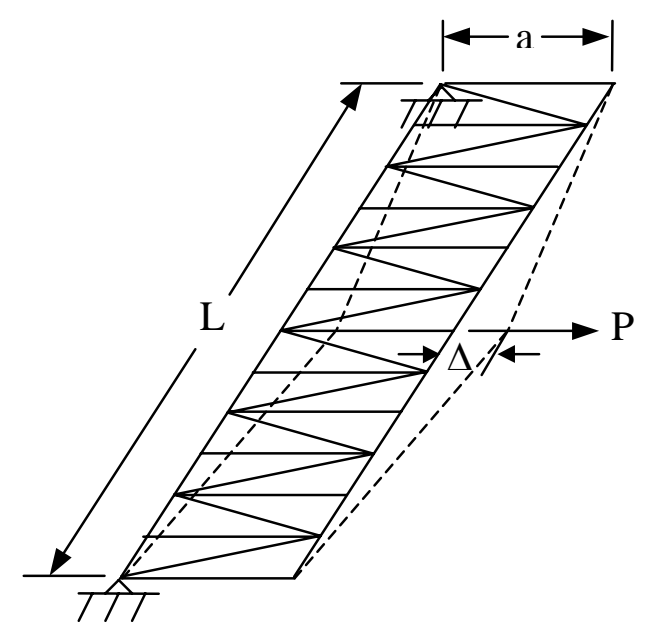

Figure 2.5 Panel Stiffness Test Setup

Despite the fact that shear stiffness is varied in this study, the value of $G^{\prime}=2500$ $\mathrm{lb} / \mathrm{in}$. provides an important base point for the design equations that are formulated in Chapter III. The model section property that defines the shear stiffness of the roof panel is the area of the type D elements. Using Equation 2.6 and the test setup of Figure 2.5, the area of the type D elements corresponding to a shear stiffness of $2500 \mathrm{lb} / \mathrm{in}$. can be obtained for any desired span length. The area values for the span lengths used in this research are presented in Table 2.2 below. Increasing the area of type $\mathrm{D}$ elements above the values given in Table 2.2 for each span length increases the panel shear stiffness above $2500 \mathrm{lb} / \mathrm{in}$. Similarly, decreasing the area of these elements decreases the panel stiffness below $2500 \mathrm{lb} / \mathrm{in}$.

Table 2.2 Area of Type D Elements for $G^{\prime}=2500 \mathrm{lb} / \mathrm{in}$.

\begin{tabular}{|c|c|}
\hline Area $\left(\mathbf{i n}^{2}\right)$ & Span length (ft) \\
\hline 0.0321 & 20 \\
\hline 0.0336 & 25 \\
\hline 0.0377 & 30 \\
\hline 0.0437 & 35 \\
\hline 0.0451 & 36 \\
\hline
\end{tabular}




\subsubsection{Modeling of Braces}

In the current model, lateral braces for the roof system are axial load only members, and are represented by line elements. To eliminate any bending in these members, referred to as type E elements, the eave connections are given fully pinned boundary conditions, and the restraint to purlin joints are given bending pin releases. Thus, type E elements cannot support any bending moment forces. For all cases, the area of these elements was arbitrarily set at $0.333 \mathrm{in}^{2}$, and the element length was set at $8 \mathrm{in}$. These values are intended to represent the typical lateral restraint used in practice and to match the values used in previous studies. Since no bending resistance is required, all moments of inertia for type D elements are made as small as possible: $I_{y y}=I_{z z}=J=0.001$ in $^{4}$.

\subsubsection{Joints and Boundary Conditions}

All element connections are modeled as rigid joints, except for the connection of lateral restraints to purlins, where bending pin releases were added, as previously described. This is of particular importance for the purlin to roof panel connection, where rigid joints are representing the deck fastening system. Based on the experimental findings by Rivard and Murray (1986), the restraint force equations formulated by Elhouar and Murray (1985) are applicable to both standing seam and through-fastened roof systems. Since these equations are based on a stiffness model with rigid joints, the current model developed here is appropriate for both standing seam and through-fastened roof systems.

The boundary conditions in the stiffness model are rafter supports and lateral restraint eave connections. The rafter supports (see Figure 2.6) are located at either end of every purlin span, at the base of all type $\mathrm{C}$ elements. As in the physical system, all translations are restrained at these boundaries. In the model, these supports are free to rotate about the global X- and Y-axes, but rotation is fixed about the global Z-axis. The $\mathrm{Z}$-axis rotation is fixed because the rafter support is assumed to prevent purlin web bending about this axis. In reality, this boundary is a rotational spring, offering significant resistance to purlin web bending, but allowing for some rotation. The spring 
constants needed to model the connection as a rotational spring are dependent on the type of purlins and rafters used, and are beyond the scope of this project. The effect of using fixed rotation restraint versus rotational springs is believed to be negligible.

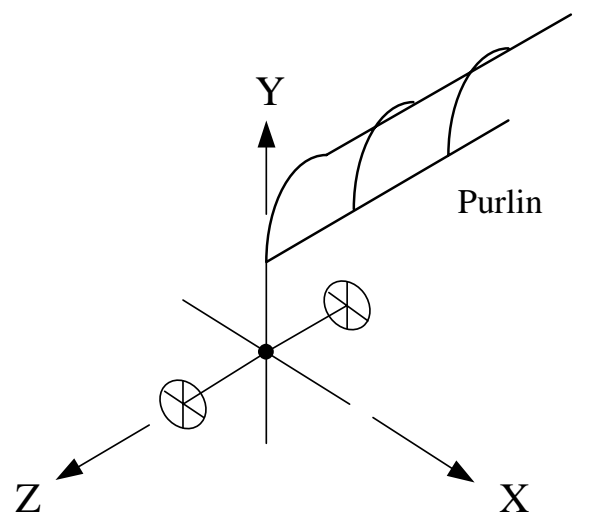

Figure 2.6 Rafter Support

The eave attachments (see Figure 2.7) for all of the lateral restraints are modeled as fully pinned connections, with all translations fixed and all rotations free. These boundaries are pinned connections so that all force in the restraint is taken up by axial load. Thus, it is conservative to ignore the bending resistance of these braces.

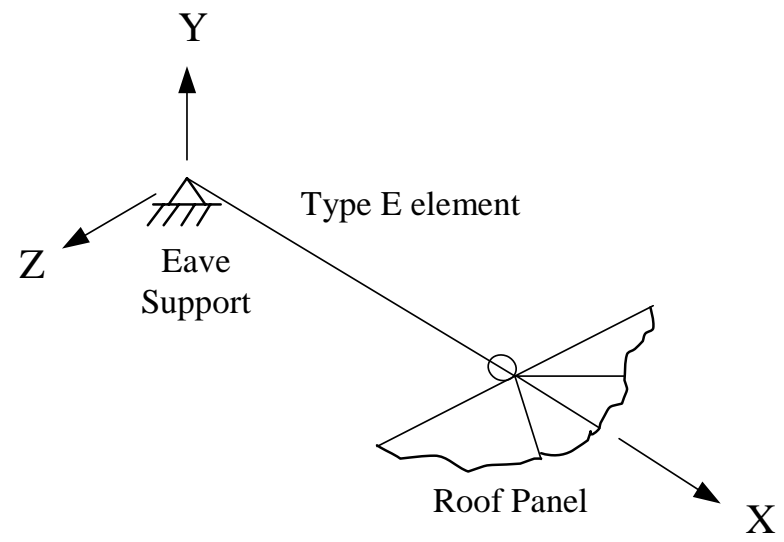

Figure 2.7 Lateral Brace Boundary Conditions 


\subsubsection{Model Loading}

This research deals exclusively with gravity loads and does not address uplift forces. Because load modeling has a critical effect on restraint force, the loading must resemble the physical system as closely as possible. Gravity loads are represented in the current model by sets of distributed line loads and point moments acting along each purlin line. Each purlin has two distributed line loads acting on the principle axes of every type A element. The total gravity load acting on the roof system, $W(\mathrm{lb})$, is distributed equally to all restrained purlin lines (including spandrels) such that the load carried by each is $w=100 \mathrm{plf}$, for all cases. The distributed load is first split into components parallel and perpendicular to the purlin web, which change depending on the slope angle of the roof:

$$
\begin{aligned}
& w_{w e b}=w \cos \theta \\
& w_{d s}=w \sin \theta
\end{aligned}
$$

The distributed load acting parallel to the web, $w_{\text {web }}$, was then split into components along each of the principle axes of the type A elements, where the load is applied (see Figure 2.8):

$$
\begin{gathered}
w_{y}=w_{\text {web }} \cos \theta_{p} \\
w_{z}=w_{\text {web }} \sin \theta_{p}
\end{gathered}
$$

The principle angle, $\theta_{p}$, is defined as the angle between the purlin web and the major principle axis (refer to Figure 1.1). The distributed load acting perpendicular to the web, also known as the downslope component, $w_{d s}$, is applied to the type $\mathrm{D}$ panel elements on top of each purlin line. The load was applied there to simulate the true point of application of the downslope load to the roof system; the purlin top flange. 


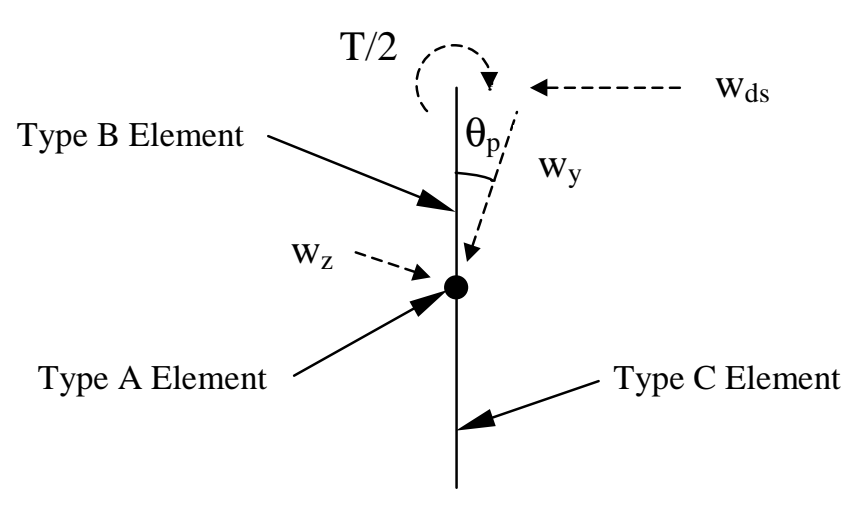

Figure 2.8 Purlin Loads

Due to roof slope and the asymmetry of the Z-purlin cross-section, purlins connected to sheathing receive an eccentric loading. The magnitude of this eccentricity, measured along the purlin top flange, determines the torque loading on each purlin line. In the physical system, the true load distribution on the purlin top flange is unknown, but for this model, a triangular load distribution was assumed (see Figure 2.9). This leads to an eccentricity of one third of the purlin flange width, as used in the studies by Elhouar and Murray (1985) and Danza and Murray (1998). A comparison of theoretical and experimental results by Ghazanfari and Murray (1983) confirmed the validity of this assumption.

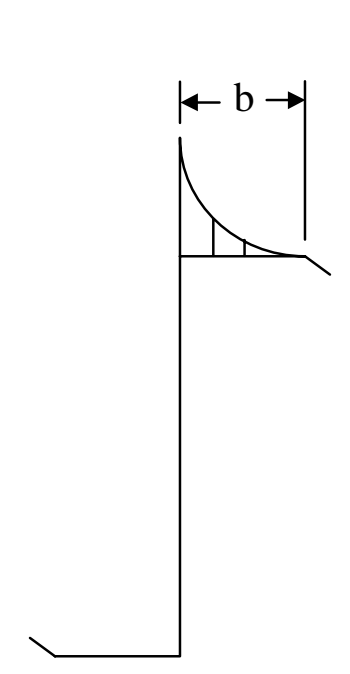

(a) True Load Distribution

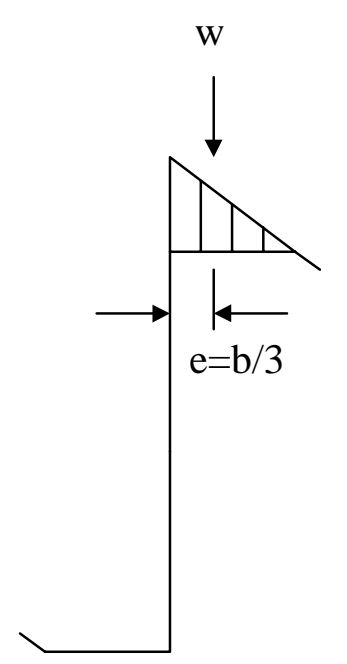

(b) Model Load Distribution

Figure 2.9 Flange Load Distribution 
From statics, the total torque acting on each purlin span is:

$$
T=\frac{b w_{w e b} L}{3}
$$

where $T$ is the total torque (ft-lb), $b$ is the flange width $(\mathrm{ft}), w_{\text {web }}$ is given by Equation 2.7 (plf), and $L$ is the span length (ft). A series of point moments is applied to the joints connecting the type $\mathrm{B}$ and $\mathrm{F}$ elements to the type $\mathrm{D}$ elements, along every purlin line. In both the Elhouar and Murray model and the Danza and Murray model, these moments were applied to the joints at both ends of the type A elements, corresponding to the purlin

centroid. However, applying moments at those locations causes most of the moment to be balanced by the rafter supports, due to the high stiffness of the type $\mathrm{C}$ elements. This is incorrect, because the lateral braces balance much of this moment in an actual roof system. Applying moments at the purlin to roof panel connection allows these moments to be properly transferred to the restraints. Since only half of the purlin depth is flexible in the current model, the point torque must be divided in half to obtain the correct effect on lateral restraint forces. Then, the total torque is distributed equally to every joint along each purlin span (T/24), except for the outside of each purlin line, where $T / 48$ is applied, due to a reduced tributary length.

\subsubsection{Summary of Model}

The current stiffness model consists of six different elements. Purlins are modeled as a space truss with type A, B, C, and F elements. A space truss of type D elements represents the roof panels, with strength in shear but not in bending. Lateral restraints are modeled with type E elements that are axial force only members. The combined system (see Figure 2.10) is a space frame, with pinned eave connections and rafter supports restricting Z-axis rotation. Model section properties for each element are given in Table 2.3. Gravity loads are approximated by a set of line loads and point moments along every purlin line. 
Table 2.3: Element Section Properties

\begin{tabular}{|c|c|c|c|c|}
\hline Member Type & Area $\left(\mathbf{i n}^{\mathbf{2}}\right)$ & $\mathbf{I}_{\mathbf{v y}}\left(\mathbf{i n}^{\mathbf{4}}\right)$ & $\mathbf{I}_{\mathbf{z z}}\left(\mathbf{i n}^{\mathbf{4}}\right)$ & $\mathbf{J}\left(\mathbf{i n}^{\mathbf{4}}\right)$ \\
\hline $\mathrm{A}$ & $A$ of purlin & $I_{x 2}$ of purlin & $I_{y 2}$ of purlin & 10 \\
\hline $\mathrm{B}$ & $(L t) / 12$ & $J$ of purlin & $\left(L t^{3}\right) / 144$ & $I_{x 2}$ of purlin \\
\hline $\mathrm{C}$ & $(L t) / 2$ & $J$ of purlin & 1 & $I_{x 2}$ of purlin \\
\hline $\mathrm{D}$ & $f\left(G^{\prime}, L\right)$ & 0.001 & 0.001 & 0.001 \\
\hline $\mathrm{E}$ & 0.333 & 0.001 & 0.001 & 0.001 \\
\hline $\mathrm{F}$ & $(L t) / 12$ & $\mathrm{~J}$ of purlin & $\left(L t^{3}\right) / 288$ & $\mathrm{I}_{\mathrm{x} 2}$ of purlin \\
\hline
\end{tabular}

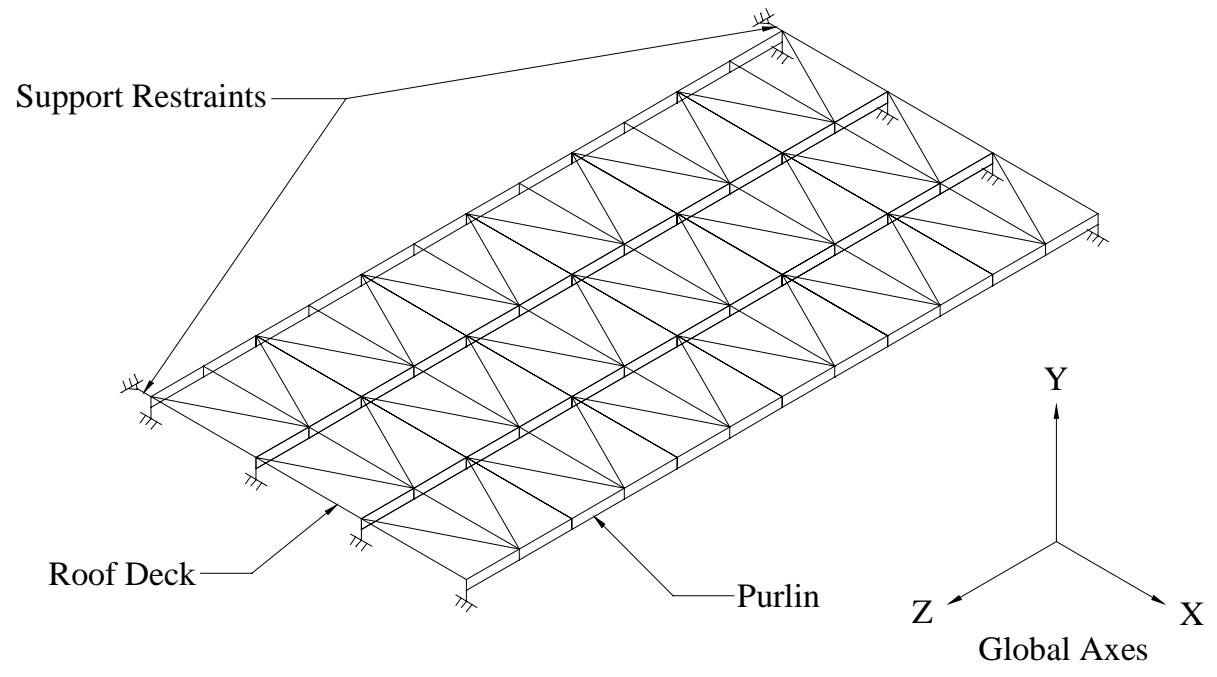

Figure 2.10 Stiffness Model

(Danza and Murray 1998)

\subsection{METHOD OF SOLUTION}

The stiffness models were assembled and analyzed using a commercial software program on a personal computer. The matrix method of stiffness analysis was used to solve each model case. Computational time for the models, using a $333 \mathrm{MHz}$ computer, was typically two seconds for single span models and four minutes for three span models. An examples showing model input parameters and results is found in Appendix A. 


\subsection{VALIDATION OF MODEL TO EXPERIMENTAL RESULTS}

To ensure the validity of the current modeling technique, results must be compared to those of laboratory tests. Comparison to real Z-purlin supported roof systems is essential to ensuring that the model is appropriate to predict lateral restraint forces. The stiffness models used by Elhouar and Murray (1985) and Danza and Murray (1998) were compared to full-scale tests by Curtis and Murray (1983) and quarter-scale tests by Seshappa and Murray (1985). For uniformity of comparison, the same set of tests used for comparison by Danza and Murray is presented here, with one additional test (3C/2-1). Table 2.4 gives the designations of the six tests used for comparison, along with a description of the parameters for each test.

Table 2.4 Experimental Test Parameters

\begin{tabular}{|c|c|c|c|c|c|c|c|}
\hline $\begin{array}{c}\text { Test } \\
\text { Name }\end{array}$ & $\begin{array}{c}\text { Bracing } \\
\text { Scheme }\end{array}$ & $\begin{array}{c}\text { Number } \\
\text { of Spans }\end{array}$ & $\begin{array}{c}\text { d } \\
\text { (in.) }\end{array}$ & $\begin{array}{c}\mathbf{t} \\
\text { (in.) }\end{array}$ & $\begin{array}{c}\text { b } \\
\text { (in.) }\end{array}$ & $\begin{array}{c}\text { Purlin } \\
\text { Lines }\end{array}$ & $\begin{array}{c}\text { L } \\
\text { (ft) }\end{array}$ \\
\hline $\mathrm{B} / 2-1-\mathrm{A}$ & Support & 1 & 8 & 0.088 & 2.40 & 2 & 22.25 \\
\hline $\mathrm{C} / 2-1$ & Support & 1 & 2 & 0.025 & 0.625 & 2 & 5 \\
\hline $\mathrm{C} / 6-1$ & Support & 1 & 2 & 0.025 & 0.625 & 6 & 5 \\
\hline $3 \mathrm{C} / 2-1$ & Support & 3 & 2 & 0.025 & 0.625 & 2 & 5 \\
\hline $\mathrm{C} / 2-15$ & Third-pt. & 1 & 2 & 0.025 & 0.625 & 2 & 5 \\
\hline $\mathrm{C} / 6-2$ & Third-pt. & 1 & 2 & 0.025 & 0.625 & 6 & 5 \\
\hline
\end{tabular}

All of the comparison tests are for zero slope (horizontal) roofs. The first test listed, B/2-1-A, is a full-scale test by Curtis and Murray (1983), while the remaining five tests are quarter-scale tests by Seshappa and Murray (1985). The panel shear stiffness was taken as $2500 \mathrm{lb} / \mathrm{in}$. for all of these tests, which were then modeled accordingly. The tests in Table 2.4 provide a good means of checking model behavior with respect to number of restrained purlin lines, number of spans, purlin cross-section, and span length.

To compare laboratory test and model results, the term brace force ratio, $\beta$, is introduced. Brace force ratio represents the percentage of the total applied gravity load, $W$, that is transferred to the lateral restraints: 


$$
\beta=\frac{\sum P_{L}}{W}
$$

where $\Sigma P_{L}$ is the summation of the restraint forces in every brace in the system. All of the tests in Table 2.4, except for test 3C/2-1, are single span support restraints or thirdpoint restraints, so there are only two braces per span. For these tests, the summation of brace forces is thus twice the brace force of each restraint; each restraint has an equal brace force due to symmetry. For comparison, the brace force ratio of the three span test $3 \mathrm{C} / 2-1$ is divided into $3 \mathrm{C} / 2-1(\mathrm{E})$ (where $\Sigma P_{L}$ is the sum of the restraint forces in the two symmetric exterior braces), and $3 \mathrm{C} / 2-1$ (I) (where $\Sigma P_{L}$ is the sum of the restraint forces in the two symmetric interior braces). Note this nomenclature in Table 2.5, which compares the brace force ratio results. Comparison of current model results to experimental results is very good (less than $10 \%$ difference) for the single span, support restraint tests (B/2-1A, C/2-1, C/6-1). Correlation was not as good for the third-point restraint tests $(\mathrm{C} / 2-15$, C/6-2) or the three span, support restraint test (3C/2-1), but results using the current model erred on the conservative side. Table 2.5 also shows brace force ratio results for the previous models by Elhouar and Murray (1985) and Danza and Murray (1998). These models have excellent agreement with the current model, as shown by the statistical measures in Table 2.6. The current model predicts restraint forces that differ from the previous models, due to the different modeling of the roof panel (refer to Section 2.3.4) and purlin torque loading (refer to Section 2.3.7).

Table 2.5 Comparison of Brace Force Ratio Results

\begin{tabular}{|c|c|c|c|c|}
\hline Test Name & $\begin{array}{c}\text { Experimental } \\
\text { Test }\end{array}$ & $\begin{array}{c}\text { Elhouar and } \\
\text { Murray Model } \\
(\mathbf{1 9 8 5})\end{array}$ & $\begin{array}{c}\text { Danza and } \\
\text { Murray Model } \\
(\mathbf{1 9 9 8})\end{array}$ & Current Model \\
\hline $\mathrm{B} / 2-1-\mathrm{A}$ & 0.22 & 0.21 & 0.21 & 0.23 \\
\hline $\mathrm{C} / 2-1$ & 0.26 & 0.23 & 0.29 & 0.24 \\
\hline $\mathrm{C} / 6-1$ & 0.19 & 0.17 & 0.18 & 0.20 \\
\hline $3 \mathrm{C} / 2-1(\mathrm{E})$ & 0.04 & 0.05 & - & 0.07 \\
\hline $3 \mathrm{C} / 2-1(\mathrm{I})$ & 0.11 & 0.10 & - & 0.15 \\
\hline $\mathrm{C} / 2-15$ & 0.14 & 0.22 & 0.27 & 0.21 \\
\hline $\mathrm{C} / 6-2$ & 0.13 & 0.17 & 0.22 & 0.20 \\
\hline
\end{tabular}


Table 2.6 Statistics for Model Evaluation

\begin{tabular}{|c|c|c|c|c|}
\hline Test Name & $\begin{array}{c}\text { Ratio of Exper. } \\
\text { Test to Current } \\
\text { Model }\end{array}$ & $\begin{array}{c}\text { Mean of All } \\
\text { Brace Force } \\
\text { Ratio Results }\end{array}$ & $\begin{array}{c}\text { Standard } \\
\text { Deviation }\end{array}$ & $\begin{array}{c}\text { Standard } \\
\text { Error }\end{array}$ \\
\hline $\mathrm{B} / 2-1-\mathrm{A}$ & 0.96 & 0.218 & 0.010 & 0.005 \\
\hline $\mathrm{C} / 2-1$ & 1.08 & 0.255 & 0.027 & 0.013 \\
\hline $\mathrm{C} / 6-1$ & 0.95 & 0.185 & 0.013 & 0.007 \\
\hline $3 \mathrm{C} / 2-1(\mathrm{E})$ & 0.57 & 0.053 & 0.015 & 0.009 \\
\hline $3 \mathrm{C} / 2-1(\mathrm{I})$ & 0.73 & 0.120 & 0.027 & 0.015 \\
\hline $\mathrm{C} / 2-15$ & 0.67 & 0.210 & 0.054 & 0.027 \\
\hline $\mathrm{C} / 6-2$ & 0.65 & 0.180 & 0.039 & 0.020 \\
\hline
\end{tabular}




\section{CHAPTER III}

\section{THEORETICAL FORMULATION OF DESIGN EQUATION}

\subsection{INTRODUCTION}

The stiffness model presented in Chapter II is now utilized to develop design equations for the prediction of lateral restraint forces in Z-purlin supported roofs under gravity loads. The objective is to form a completely new set of equations to predict these restraint forces, intended as an alternative to the current design equations in Section D3.2.1 of the 1996 AISI Cold-Formed Specification. These current specification provisions have some deficiencies, including a flawed treatment of roof slope and the system effect, which will be described later. For every Z-purlin supported roof system, there is a finite range of roof slopes for which no lateral restraint is required, but the specification does not address this aspect. The provisions have a strong reliance upon statistical regression, distancing them from engineering principles. Also, the provisions are based upon an assumed roof panel shear stiffness of 2500 lb/in., ignoring the change in restraint force that occurs when panel stiffness is changed from this assumed value.

New design equations are proposed to address these deficiencies. The proposed equations accurately predict restraint forces for all the bracing configurations addressed in the research by Elhouar and Murray (1985) and Danza and Murray (1998): support, third-point, midpoint, quarter-point, and third-point plus support restraints. Figure 1.3 shows each of these bracing configurations for single span systems. The new equations also account for all of the major parameters observed in Z-purlin supported roofs, including purlin cross-section, number of purlins, number of spans, roof slope, and panel shear stiffness. 


\subsection{BACKGROUND}

The AISI specification provisions of Section D3.2.1 are revisited here. The provisions were developed using elastic stiffness models of horizontal (flat) roofs (Elhouar and Murray, 1985) and verified by full-scale and model testing (Seshappa and Murray, 1985). For example, the predicted force in each brace for single span systems with anti-roll restraints only at the supports is:

$$
P_{L}=0.5(\beta W)
$$

where $W=$ the total applied vertical load (parallel to the web), and $\beta=\frac{0.220 b^{1.5}}{n_{p}^{0.72} d^{0.90} t^{0.60}}$. As before, $b$ is the flange width (in.), $n_{p}$ is the number of restrained purlin lines, $d$ is the section depth (in.), and $t$ is thickness (in.). The restraint force ratio, $\beta$, was developed from a regression analysis of stiffness model results. To account for roof slope, the latest balloted AISI provisions for single span systems with anti-roll restraints only at the supports is:

$$
P_{L}=0.5(\beta \cos \theta-\sin \theta) W
$$

where $\theta$ is roof slope measured from the horizontal. The terms $W \cos \theta$ and $W \sin \theta$ represent the gravity load components parallel and perpendicular to the purlin web as shown in Figure 3.1, respectively. The latter component is also referred to as the downslope component.

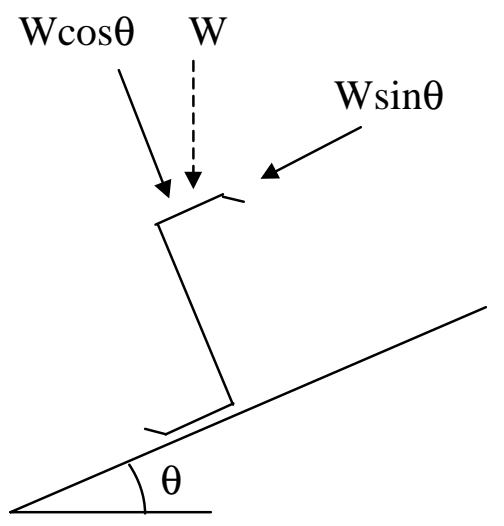

Figure 3.1 Gravity Load Components 
From basic principles (Zetlin and Winter, 1955), the required restraint force is:

$$
P_{L}=0.5\left(\frac{I_{x y}}{I_{x}}\right) W
$$

where $I_{x y}$ is the product moment of inertia $\left(\mathrm{in}^{4}\right)$ and $I_{x}$ is the moment of inertia with respect to the centroidal axis perpendicular to the web of the z-section (in ${ }^{4}$ ). The Elhouar and Murray (1985) study showed that the restraint force given by Equation 3.3 is conservative, that is $I_{x y} / I_{x}>\beta$, because of system effects. Equation 3.1 can be rewritten as:

$$
P_{L}=0.5 \alpha\left(\frac{I_{x y}}{I_{x}}\right) W
$$

where $\alpha=\frac{I_{x}}{I_{x y}} \beta=$ system effect factor. Thus, the system effect is identified as a function of the AISI Specification parameter $\beta$.

The system effect is the inherent restraint in the system because of purlin web flexural stiffness and a Vierendeel truss effect caused by interaction of the purlin web with the roof panel and the rafter flange (see Figure 3.2). This Vierendeel truss action explains the relative decrease in restraint force as the number of restrained purlin lines, $n_{p}$, increases as shown in Figure 3.3. Figure 3.4 is a plot of restraint force from Equation 3.2 versus the slope angle $\theta$. The value $\theta_{0}$ is the intercept where the restraint force is equal to zero. For roof slopes less than $\theta_{0}$, the AISI Specification provision, Equation 3.2, predicts a restraint force in tension. For slopes greater than $\theta_{0}$, Equation 3.2 predicts the restraint force to be in compression. 


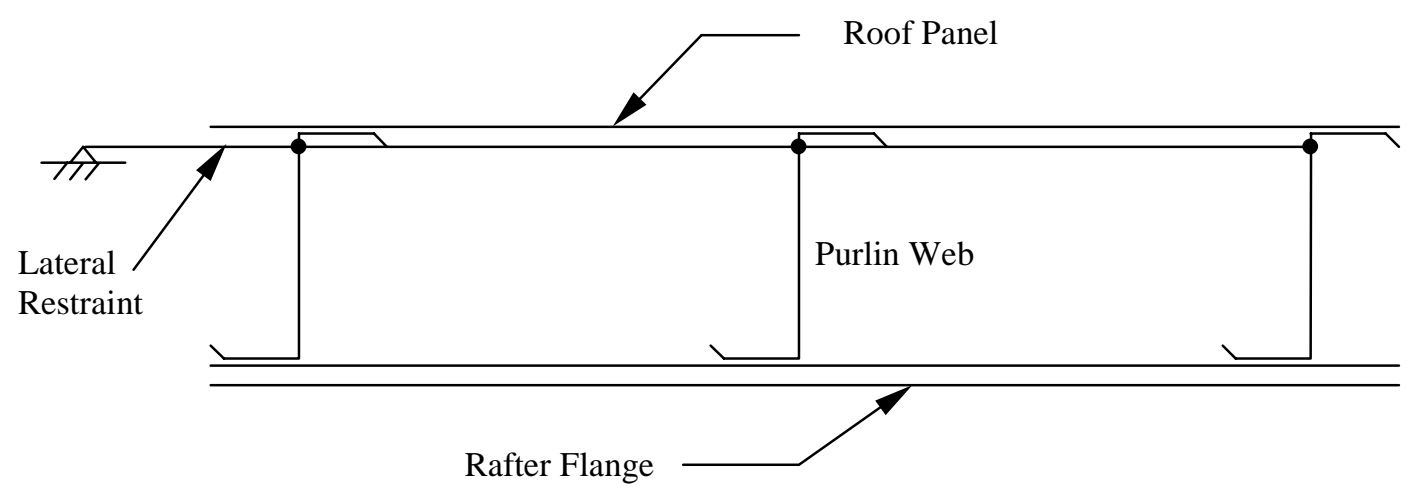

Figure 3.2 Vierendeel Truss Action

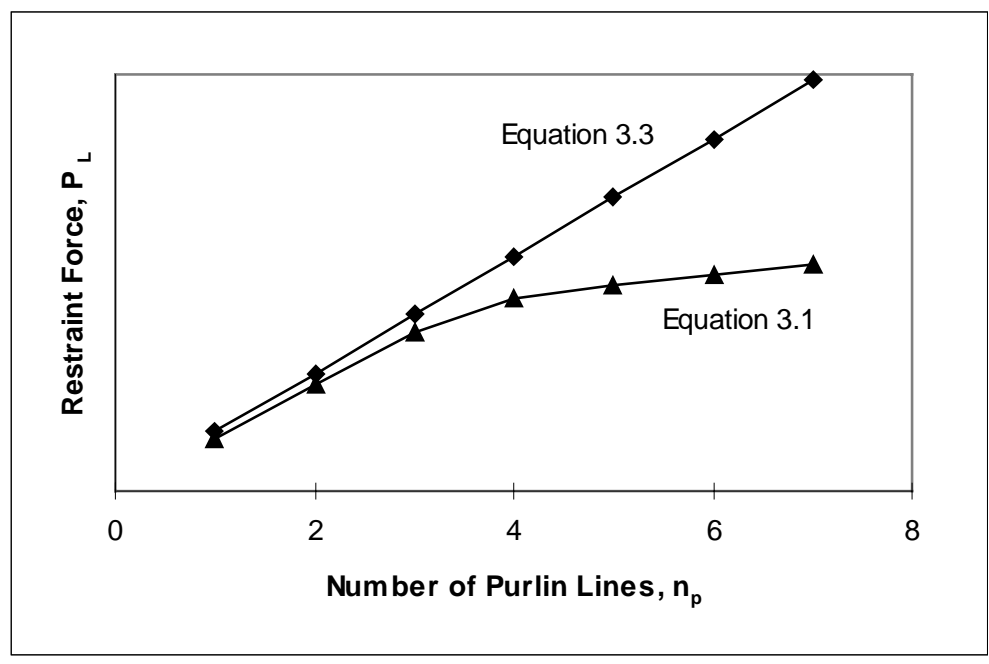

Figure 3.3 Restraint Force vs. Number of Purlins

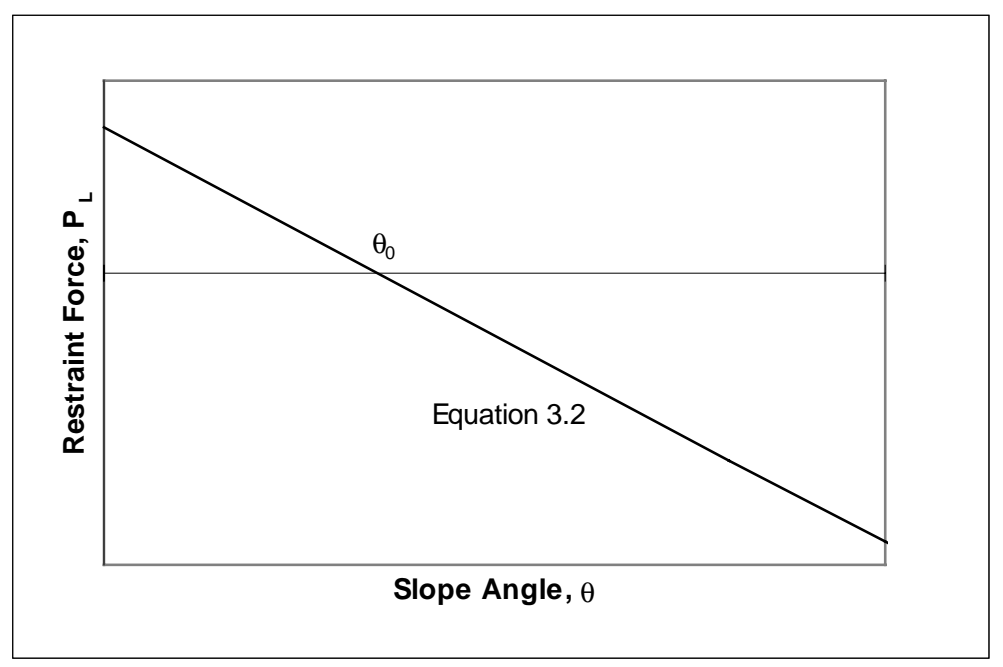

Figure 3.4 Restraint Force vs. Roof Slope (Typical) 
Equation 3.2 has a flawed treatment of both the system effect and roof slope, because two important effects are not taken into account. First, the internal system effect applies to both the fictitious force $W \cos \theta\left(I_{x y} / I_{x}\right)$ and the real force $W \sin \theta$. Second, the system effect reverses when the net restraint force, as shown in Figure 3.5, changes from tension to compression with increasing slope angle. As a result of these effects, the intercept value $\theta_{0}$ is in actuality dependent only on purlin cross-sectional properties, not $n_{p}$ or the bracing configuration. However, Equation 3.2 has $\theta_{0}$ dependent on $\beta$, which is a function of both $n_{p}$ and the bracing configuration:

$$
\theta_{0}=\tan ^{-1} \beta
$$

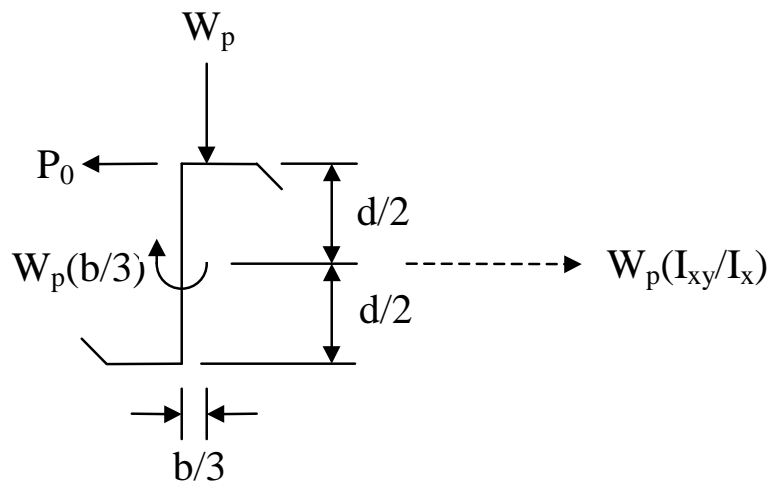

(a) Forces for a Single Purlin on a Flat Roof

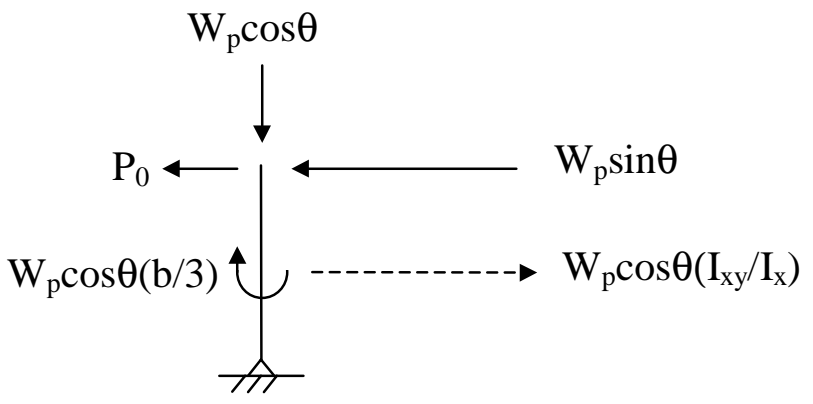

(b) Forces for a Single Purlin on a Sloped Roof

Figure 3.5 Single Purlin Gravity Loads 
As mentioned in Section 2.3.4, the Elhouar and Murray stiffness model used to develop the AISI Provisions had an assumed roof panel stiffness of $2500 \mathrm{lb} / \mathrm{in}$. Computer tests run by Elhouar and Murray (1985) indicated that the increase in required restraint force for systems with roof panels stiffer than $2500 \mathrm{lb} / \mathrm{in}$. was negligible. However, these tests only considered systems with three or fewer restrained purlin lines. After examining stiffness models of roof systems with up to eight restrained purlins, results showed that increasing panel stiffness above $2500 \mathrm{lb} / \mathrm{in}$. caused significant increases in the required restraint forces for systems with four or more purlin lines. Thus, the AISI Specification should be modified to address roof panels with varying shear stiffness values.

\subsection{EQUATION DEVELOPMENT}

\subsubsection{Form of Equation}

To develop a more accurate set of equations to predict the lateral restraint force in Z-purlin roof systems, the following form was assumed:

$$
P_{L}=P_{0} C_{1}\left(n_{p}^{*} \alpha+n_{p} \gamma\right)
$$

where $P_{0}$ is the restraint force on a single purlin system, $C_{1}$ is the brace location factor, $\alpha$ is the system effect factor, and $\gamma$ is the panel stiffness factor. The parameter $n_{p}$ is the number of parallel purlin lines located between restraint anchors. The parameter $n_{p}{ }^{*}$ is closely related to $n_{p}$ as will be described later. Equation 3.6 postulates that the predicted restraint force in any given system is equal to the force on a single purlin multiplied by the total number of purlins, a brace location factor, a reduction factor caused by system effects, and modified by a factor for roof panel stiffness. This equation was formulated by first considering a roof panel stiffness of $2500 \mathrm{lb} / \mathrm{in}$. to obtain a base point along the restraint force versus panel stiffness curve (see Figure 3.6). Notice that Figure 3.6 is shown with panel stiffness in a logarithmic scale. Thus, when $G^{\prime}=2500 \mathrm{lb} / \mathrm{in} ., \gamma=0$ and Equation 3.6 reduces to:

$$
P_{L}=P_{0} C_{1} n_{p}^{*} \alpha
$$




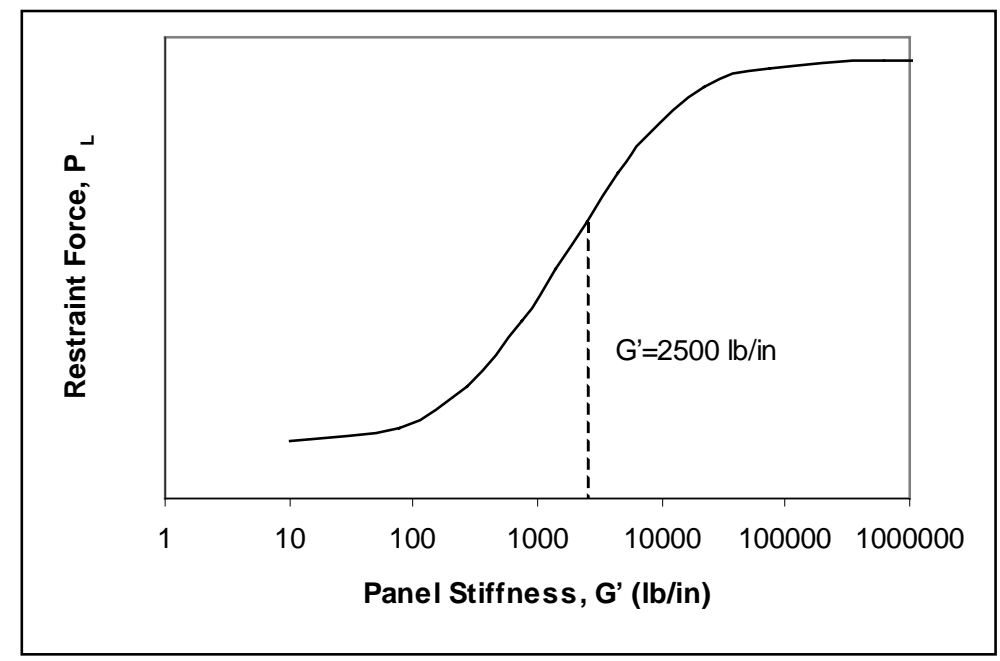

Figure 3.6 Restraint force vs. Panel Stiffness (Model)

\subsubsection{Single Purlin Restraint force}

To predict the base point restraint force, the diagrams in Figure 3.5 are now used to develop an expression for $P_{0}$, which considers the proper application of the system effect and its reversal. The key assumption to this model is that the purlin has a pinned support at the rafter connection. Figure 3.5(a) shows the Z-purlin with a gravity load $W_{p}$ and zero slope. $W_{p}$ is the total gravity load (force units) acting on each purlin span:

$$
W_{p}=w L
$$

where $w$ is the distributed gravity load on each purlin (force/length units) and $L$ is the span length (length units). The fictitious force $W_{p}\left(I_{x y} / I_{x}\right)$ is the overturning force from basic principles (Zetlin and Winter, 1955).

Figure 3.5(b) shows the set of real and fictitious forces associated with a single purlin on a roof with slope $\theta$. The set of forces account for the following effects: $W_{p} \sin \theta$ is the downslope component of the gravity loading, $W_{p} \cos \theta\left(I_{x y} / I_{x}\right)$ is the fictitious force as previously discussed, and $W_{p} \cos \theta(b / 3)$ is the torque induced by eccentric loading of the top flange. As with the stiffness model, this static analysis assumes the eccentricity of loading to be one third of the flange width. Here, however, the torque 
loading is applied at the centroid of the cross-section as per basic mechanics. Summation of moments about the pinned support results in:

$$
P_{0}=\left[\left(\frac{I_{x y}}{2 I_{x}}+\frac{b}{3 d}\right) \cos \theta-\sin \theta\right] W_{p}
$$

which is valid if $P_{0}$ is positive (tension) or negative (compression). Equation 3.9 can be solved for the intercept slope angle, where restraint force is zero:

$$
\theta_{0}=\tan ^{-1}\left(\frac{I_{x y}}{2 I_{x}}+\frac{b}{3 d}\right)
$$

Thus, the intercept is dependent only on purlin cross-sectional properties as required. For roof slopes less than $\theta_{0}, P_{0}$ is in tension, and for roof slopes greater than $\theta_{0}, P_{0}$ is in compression.

\subsubsection{System Effect Factor, $\alpha$}

When Elhouar and Murray (1985) used regression analysis to derive Equation 3.4, they assumed that the system effect factor, $\alpha$, was dependent on the following parameters: $I_{x y}, I_{x}, b, n_{p}, d$, and $t$. However, if the system effect is taken to be caused purely by purlin bending resistance, then only the parameters $n_{p}, d$, and $t$ should affect $\alpha$. Statistical analysis, based on stiffness model results, was used to develop a new equation for $\alpha$.

$$
\alpha=1-C_{2}\left(\frac{t}{d}\right)\left(n_{p}^{*}-1\right)
$$

where $C_{2}$ is a constant factor that depends on the bracing configuration. Note that $\alpha$ is a dimensionless factor and $\alpha=1$ when $n_{p}{ }^{*}=1$, as needed for consistency. Since $\alpha$ is a multiplicative factor in Equation 3.6, it accurately models the reversal of the system effect when $P_{0}$ changes from tension to compression.

For a rational basis to Equation 3.11, consider a purlin to be a cantilevered, rectangular beam with a point load acting at the free end (see Figure 3.7). The deflection of such a beam is proportional to the ratio $(d / t)^{3}$. Since $\alpha$ is a measure of bending resistance, it would naturally be assumed to vary with $(t / d)^{3}$. This does not consider the 
effects of panel restraint, though. Elastic stiffness model results indicate a complex relationship between $\alpha$ and $n_{p}$, which can be reasonably approximated by giving the slope of $\alpha$ a linear variation with $(t / d)$.

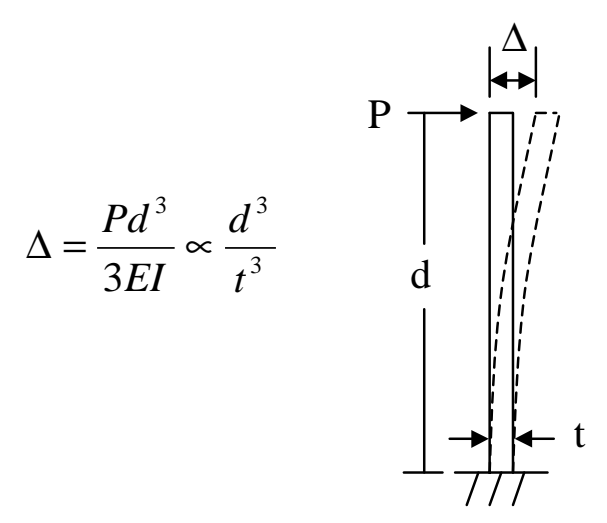

Figure 3.7 Purlin Web Bending

The coefficient $C_{2}$ in front of $(t / d)$ in Equation 3.11 was determined from a regression analysis, and is discussed further in Chapter IV. This coefficient differs for each bracing configuration because bending resistance changes depending on a brace's distance from rafter supports and other braces. The values determined for $C_{2}$ are presented later in Table 4.10 .

\subsubsection{Definition of $n_{p}{ }^{*}$}

At this point, the variable $n_{p}{ }^{*}$ must be explained. Observe that Equation 3.7 is quadratic with respect to $n_{p}$, because $\alpha$ is linear in $n_{p}$. Thus, for some value of $n_{p}$, denoted as $n_{p(\max )}, P_{L}$ will reach a maximum point and then decrease as $n_{p}$ is increased above $n_{p(\max )}$. From basic calculus, $n_{p(\max )}$ can be determined:

$$
n_{p(\max )}=0.5+\frac{d}{2 C_{2} t}
$$

For very thick purlins, $n_{p(\max )}$ can be significantly less than eight, the maximum number of restrained purlin lines for which the proposed equations were initially formulated. Obviously, the required bracing force can never decrease as the number of purlins is 
increased. This concern can be eliminated by using $n_{p}{ }^{*}$ instead of $n_{p}$ in Equation 3.7, where $n_{p}{ }^{*}$ is defined as the minimum of $n_{p(\max )}$ and $n_{p}$. This means that adding additional restrained purlin lines above $n_{p(\max )}$ will not affect the predicted restraint force; $P_{L}$ will remain constant (see Figure 3.8).

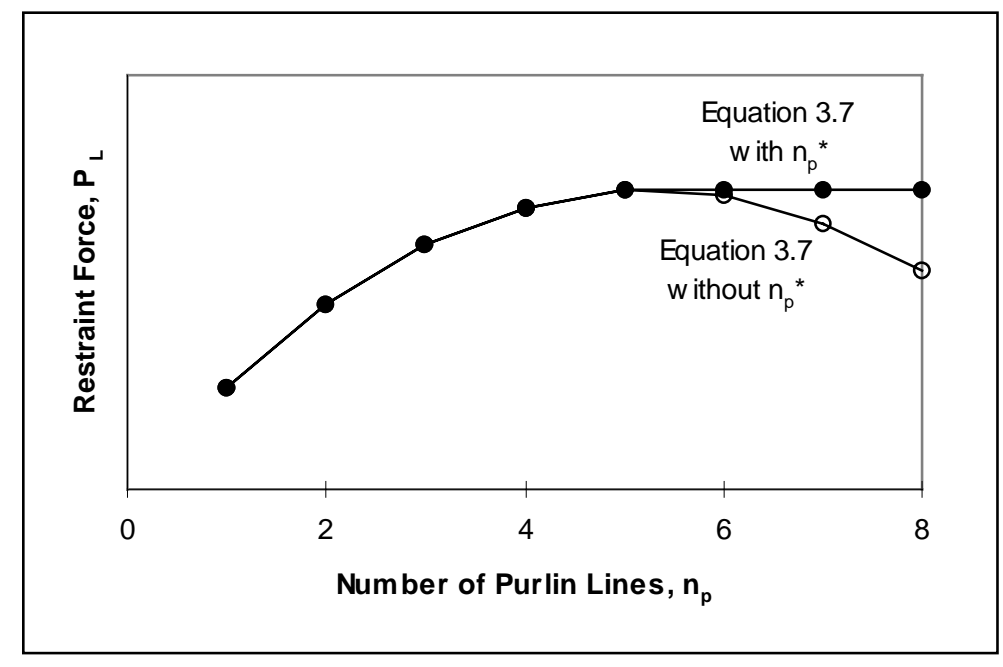

Figure 3.8 Effect of Using $n_{p}{ }^{*}$

\subsubsection{Brace Location Factor, $\mathbf{C}_{1}$}

Another key aspect to Equation 3.6 is $C_{1}$, the brace location factor. This constant factor represents the percentage of total restraint that is allocated to each brace in the system. By this logic, it is expected that the sum of the $C_{1}$ coefficients for each brace in one purlin span length is equal to unity. However, the rafter supports absorb some of the bracing for the gravity load, so this sum is less than unity for some bracing configurations. The sum is also slightly greater than unity for some configurations where a slight factor of safety was required to account for uncertainty in the results. The values for $C_{1}$ were determined from a regression analysis and are discussed further in Chapter IV. These values are given for various bracing schemes in Table 4.10. Notice that for multiple span systems, the $C_{1}$ values are larger for exterior restraints than the corresponding interior restraints, as expected from elementary mechanics. 


\subsubsection{Panel Stiffness Modifier, $\gamma$}

Equation 3.7 establishes the restraint force for the base point of $G^{\prime}=2500 \mathrm{lb} / \mathrm{in}$. To extend Equation 3.7 to the general form in Equation 3.6, a panel stiffness modifier, $\gamma$, is included. After analyzing several different cases, lateral restraint force was shown to vary linearly with the common logarithm of the roof panel stiffness over the range of common panel shear stiffnesses (refer to Figure 3.9). This lead to the following equation for the panel stiffness modifier:

$$
\gamma=C_{3} \log \left(\frac{G^{\prime}}{2500}\right)
$$

where $G^{\prime}$ is the roof panel shear stiffness (lb/in.), and $C_{3}$ is another constant determined by regression analysis of stiffness model results. In Equation 3.13, the denominator constant of 2500 has units of $\mathrm{lb} / \mathrm{in}$. to nondimensionalize the term in the log parentheses when $G^{\prime}$ is in units of $1 \mathrm{~b} / \mathrm{in}$. Equation 3.13 can be used for any units of $G^{\prime}$, if the denominator constant is first converted from $\mathrm{lb} / \mathrm{in}$. to the desired units.

Equation 3.6 is therefore based upon the point-slope method of writing the equation of a line. For roof panels stiffer than the base point value, the required restraint force is increased, and for panels less stiff than the base value, the required restraint force is decreased. Note that $\gamma=0$ for $G^{\prime}=2500 \mathrm{lb} / \mathrm{in}$., $\gamma>0$ for $G^{\prime}>2500 \mathrm{lb} / \mathrm{in}$., and $\gamma\langle 0$ for $G^{\prime}<2500 \mathrm{lb} / \mathrm{in}$. The values of $C_{3}$ are tabulated for various bracing schemes in Chapter IV. The location of a brace with respect to rafter supports and other braces determines how the restraint force varies with roof panel stiffness. The effect of $\gamma$ is to adjust the system effect factor, $\alpha$. Notice in Equation 3.6 that $\gamma$ is multiplied by $n_{p}$ instead of $n_{p}{ }^{*}$, because as panel stiffness changes, change in restraint force depends on the total number of purlins in the system and $n_{p(\max )}$ no longer applies. A roof panel with infinite shear stiffness would transfer all lateral forces to the restraints.

To utilize the panel stiffness modifier, two restrictions are required. First, $\gamma$ is valid only for $1000 \mathrm{lb} / \mathrm{in}$. $\leq G^{\prime} \leq 100,000 \mathrm{lb} / \mathrm{in}$. This is the range of linear behavior, and most roof panels have a shear stiffness within this limitation. Secondly, a maximum restraint force is set, which can never be exceeded. This maximum force is: 


$$
\left|P_{L}\right| \leq\left|P_{0} C_{1} n_{p}\right|
$$

and is the expected restraint force if system effects are ignored. Equation 3.14 applies to both tensile and compressive restraint forces. See Figure 3.9 for a typical plot of restraint force versus panel stiffness for Equation 3.6, shown with stiffness model results.

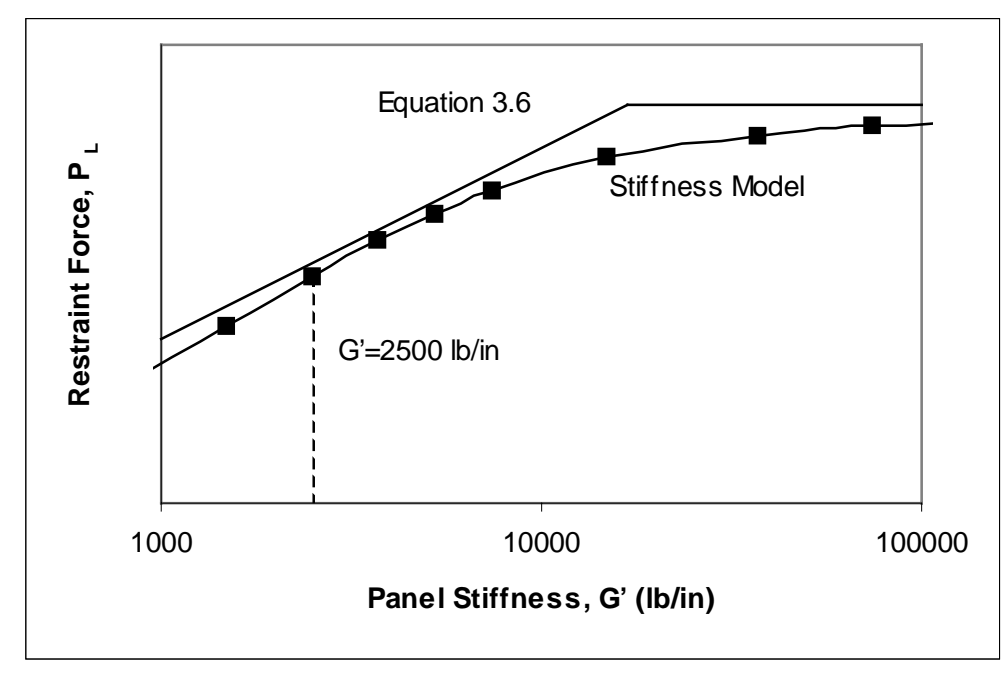

Figure 3.9 Restraint Force vs. Panel Stiffness (Proposed)

\subsubsection{Restrictions}

Restrictions must be placed on Equation 3.6 to make it applicable for design purposes. Since the stiffness models used to confirm the equation had eight restrained purlin lines or fewer, Equation 3.6 must be used with caution when $n_{p}>8$. The proposed equation is believed to apply to the design of lateral restraints in roof systems with $n_{p}>8$, but further computer testing is needed for verification. When Equation 3.6 gives a very small predicted magnitude of restraint force, $\left|P_{L}\right| \leq 100 \mathrm{lb}$, no lateral bracing is necessary. For every Z-purlin supported roof system, there is a range of roof slopes that corresponds to $\left|P_{L}\right| \leq 100 \mathrm{lb}$, and roofs systems having a roof slope within this range require no lateral restraint. 


\subsubsection{Summary of Design Equation}

The proposed design equations accurately predict the lateral bracing forces required for Z-purlin supported roof systems, for five different bracing configurations. The equation is summarized in Figure 3.12 below, where $I_{x y}$ is product moment of inertia, $I_{x}$ is $\mathrm{x}$-axis moment of inertia, $b$ is purlin flange width, $d$ is purlin depth, $t$ is purlin thickness, $w$ is distributed purlin gravity load, $L$ is purlin span length, $\theta$ is roof slope, $n_{p}$ is number of restrained purlin lines, and $G$ ' is roof panel shear stiffness. The required restraint force in any roof system equals the force on a single purlin multiplied by the number of restrained purlin lines, a brace location factor, a system effect factor, and modified by a factor for roof panel shear stiffness. The design equation addresses the deficiencies of the current AISI provisions. The treatment of roof slope and the system effect is more accurate. The proposed equations, while still depending on regression analysis, have a stronger basis in engineering principles. The new design equation accounts for roof panels of different shear stiffness, and identifies the conditions for which no lateral bracing is required. Figure 3.10 shows a typical plot comparing the proposed Equation 3.7 to the AISI Specification, Equation 3.2 with respect to slope angle $\theta$. Figure 3.11 shows a similar plot with respect to the number of restrained purlin lines.

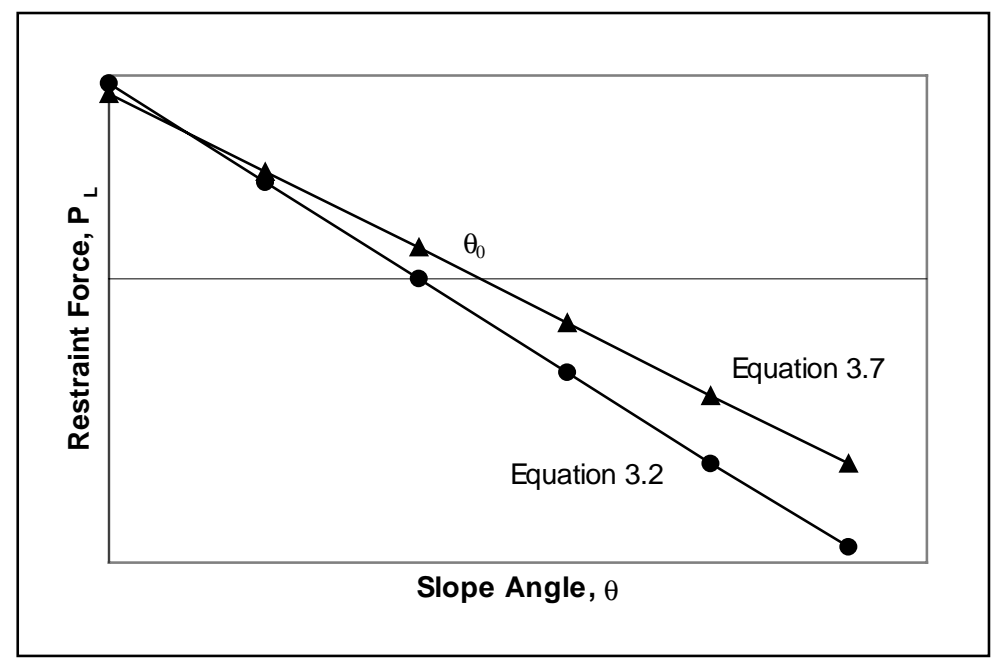

Figure 3.10 Comparison of Restraint Force vs. Roof Slope 


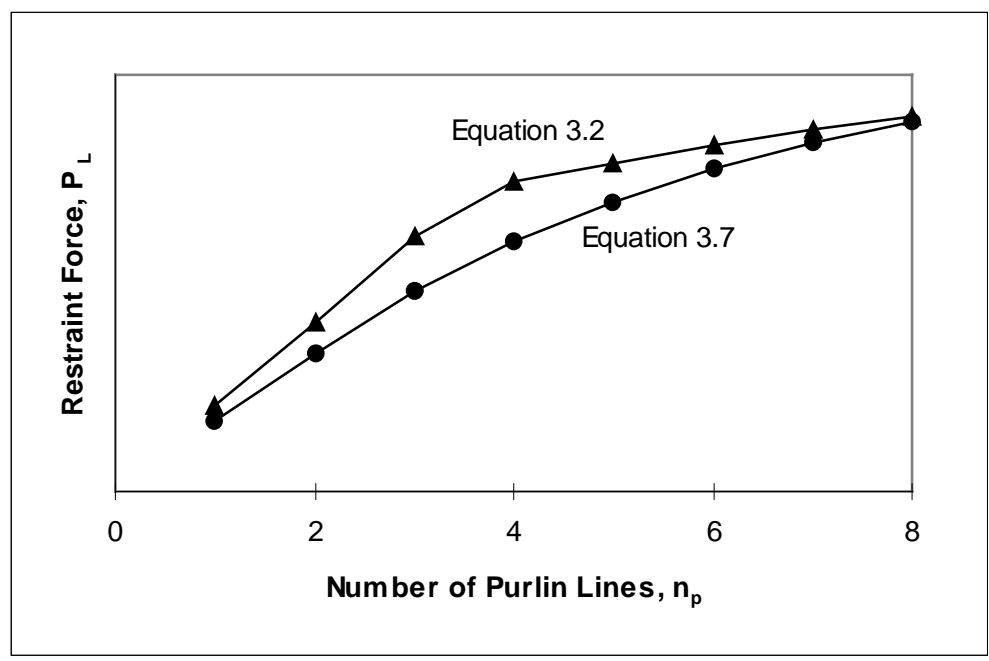

Figure 3.11 Comparison of Restraint Force vs. Number of Restrained

$$
P_{L}=P_{0} C_{1}\left(n_{p}^{*} \alpha+n_{p} \gamma\right)
$$

where:

$$
\begin{aligned}
& P_{0}=\left[\left(\frac{I_{x y}}{2 I_{x}}+\frac{b}{3 d}\right) \cos \theta-\sin \theta\right] W_{p}, \quad W_{p}=w L \\
& n_{p}^{*}=\min \left\{n_{p}, n_{p(\text { max })}\right\}, n_{p(\text { max })}=0.5+\frac{d}{2 C_{2} t} \\
& \alpha=1-C_{2}\left(\frac{t}{d}\right)\left(n_{p}^{*}-1\right), \gamma=C_{3} \log \left(\frac{G^{\prime}}{2500}\right)
\end{aligned}
$$

\section{Notes:}

1) Positive $P_{L}$ is in tension, negative $P_{L}$ is in compression.

2) Upper bound: $\left|P_{L}\right| \leq\left|n_{p} P_{0} C_{1}\right|$

3) If $\left|P_{L}\right| \leq 100 \mathrm{lb}$, no lateral bracing is necessary.

4) Applicable range of panel stiffnesses: $1000 \mathrm{lb} / \mathrm{in} \leq G^{\prime} \leq 100,000 \mathrm{lb} / \mathrm{in}$

5) $\mathrm{C}_{1}, \mathrm{C}_{2}$, and $\mathrm{C}_{3}$ are regression coefficients.

6) Models used to develop procedure had $n_{p} \leq 8$.

Figure 3.12 Summary of Design Equation 


\section{CHAPTER IV}

\section{COMPUTER TESTS AND EQUATION DEVELOPMENT}

\subsection{INTRODUCTION}

This chapter discusses the different computer tests performed on the finite element model, and the data analyses used to further develop the design equation. The objective is to fit the theoretical design equation described in Chapter III to the mathematical stiffness model described in Chapter II. An investigation into roof system behavior is made, determining the effect of each parameter upon the required lateral restraint forces. Then, a computer test matrix is developed to define the range of investigation for each parameter. The results of the computer tests are then fit to the proposed design equations using regression analysis. This statistical regression evaluates the coefficients $C_{1}, C_{2}$, and $C_{3}$ of the proposed design equations for each bracing configuration. There is also a discussion on the correlation of the resulting final design equation to the stiffness model. Finally, the proposed design equation is verified for the effects of roof slope and roof panel stiffness interaction.

\subsection{SYSTEM BEHAVIOR ANALYSIS}

Extensive studies on the system behavior of various Z-purlin roof parameters were done by Elhouar and Murray (1985) and Danza and Murray (1998). Each of these analyses investigated the effects of the following parameters on restraint forces: bracing configuration, purlin depth, purlin thickness, purlin flange width, span length, number of restrained purlin lines, and number of spans. Both studies are based upon the lateral restraint forces given by elastic stiffness models. A system behavior analysis is now done using the current model, and the findings are compared to the two previous studies. 


\subsubsection{Bracing Configuration}

Elhouar and Murray (1985) found that "Lateral restraint forces can not be mathematically related to the bracing configuration used and therefore each configuration must be considered separately." Results of the current model, as well as the Danza and Murray model, support this conclusion. The complex system interaction between purlin, roof panel, and restraint makes such a simple mathematical relation impossible. Thus, a separate regression analysis, with different resulting coefficients in the proposed design equation, must be performed for each bracing configuration.

\subsubsection{Number of Spans}

The cross-sectional shape of Z-purlins allows them to be easily lapped to create continuous spans. The observed restraint forces in a continuous span system can be quite different from those in a single span system under the same loading. Elhouar and Murray (1985) discovered that the brace force ratio, $\beta$, decreases significantly (12\% to $30 \%$ ) when the number of spans is increased from one to three, but does not change significantly as the number of spans is increased greater than three. Because of this analysis, two sets of coefficients were developed for the design equations; one for single span systems and one for multiple span systems. A three continuous span model was used to generate the multiple span coefficients in the design equation. The three span model was used because the restraint force results are conservative for systems with more than three continuous spans, and acceptable for two span systems.

Similarly, Danza and Murray (1998) developed design equations for single and multiple span systems, with a three span model representing the multiple span case. The same reasoning is used here to develop the proposed design equations. Regression analysis is used to determine different values of the coefficients $C_{1}, C_{2}$, and $C_{3}$ for single and multiple span systems. However, the present system analysis found that restraint forces for braces on the exterior of multiple span systems were almost the same $(0 \%$ to $10 \%$ less) as restraint forces for braces in the same position on single span systems, under the same loading. The primary difference between single and multiple span systems was the restraint force for interior braces on multiple span systems. These braces usually 
provide lateral restraint for a different length of purlin than in the single span case, thus causing the difference in restraint force.

\subsubsection{Number of Restrained Purlin Lines}

Due to the system effect, the required bracing force decreases as the number of restrained purlin lines is increased. As mentioned in Section 3.2, purlin web bending resistance, along with a Vierendeel truss action (between purlin, roof panel, and rafter), causes this effect. The system behavior analyses by Elhouar and Murray (1985) and Danza and Murray (1998) confirmed this finding, and discovered that the reduction in brace force can reach $70 \%$ for some cases. Analysis of the current model also agreed with the finding that increasing the number of purlins decreases the restraint force ratio. However, the current model showed that the magnitude of this reduction was a function of other parameters, specifically purlin depth and thickness.

\subsubsection{Purlin Span Length}

Elhouar and Murray (1985) discovered that varying span length had a negligible effect on the required restraint force for single span systems, and hence span length does not appear in the design equations. They did find that increasing span length increased the required restraint force for multiple span systems, often by $10 \%$ or more. Their design equations note a small dependence on span length, with the brace force ratio being proportional to up to $L^{0.25}$ for third-point restraints in multiple span systems. The system behavior analysis by Danza and Murray (1998) found that increasing purlin span length increased the required restraint force for both single and multiple span systems, with greater increases noted in multiple span systems.

Analysis of the current model found a slight increase in restraint force as span length is increased, but the effect is negligible (less than a 10\% increase) and does not merit inclusion in the proposed design equations. See Table 4.1 for examples of the variation in brace force ratio with purlin span length, for three span models. In the table, $\beta_{1}$ is the brace force ratio corresponding to $L_{1}$, and $\beta_{2}$ is the brace force ratio corresponding to $L_{2}$. Note that all of the examples are for models with eight restrained purlin lines, zero roof slope, and the purlin section identifications are those used in the 
Cold-Formed Steel Design Manual (1996). The effect of span length is only significant for interior braces in multiple span systems, and is accounted for in the proposed design equation by adjusting the regression coefficients such that a factor of safety is included. The small increase in accuracy that would result from including span length in the design equation is outweighed by the complication to the equation that would result. Thus, the only effect of span length on the proposed equation is to increase the applied gravity load, and there is no contribution to system effects.

Table 4.1 Effect of Span Length on Restraint Force

\begin{tabular}{|c|c|c|c|c|c|}
\hline Purlin Section & $\begin{array}{c}\text { Bracing } \\
\text { Configuration }\end{array}$ & $\begin{array}{c}\boldsymbol{L}_{\mathbf{1}} \\
(\mathbf{f t})\end{array}$ & $\beta_{\mathbf{1}}$ & $\begin{array}{c}\boldsymbol{L}_{\mathbf{2}} \\
(\mathbf{f t})\end{array}$ & $\beta_{\mathbf{2}}$ \\
\hline $8 \mathrm{ZS2.5x060}$ & Support Restraints & 20 & 0.120 & 25 & 0.127 \\
\hline 8ZS2.5x090 & Support Restraints & 20 & 0.090 & 25 & 0.096 \\
\hline 10ZS3x075 & Support Restraints & 30 & 0.120 & 35 & 0.129 \\
\hline 10ZS3x135 & Support Restraints & 30 & 0.073 & 35 & 0.079 \\
\hline $8 Z$ Z2.5x060 & Third-point Restraints & 20 & 0.155 & 25 & 0.161 \\
\hline 8ZS2.5x090 & Third-point Restraints & 20 & 0.134 & 25 & 0.140 \\
\hline 10ZS3x075 & Third-point Restraints & 30 & 0.151 & 35 & 0.163 \\
\hline 10ZS3x135 & Third-point Restraints & 30 & 0.118 & 35 & 0.130 \\
\hline
\end{tabular}

\subsubsection{Purlin Depth, Thickness, and Flange Width}

Elhouar and Murray (1985) investigated several purlin dimensions and section properties, and found purlin depth, thickness, and flange width to have significant effects on the required restraint force. They found that increasing purlin depth and thickness decreases lateral restraint forces, and increasing flange width increases restraint forces. The study by Danza and Murray (1998) found similar results, except that purlin thickness was shown to have a much greater effect on restraint forces. The difference in brace force ratio between relatively thick and relatively thin purlins was found to be up to $20 \%$.

The proposed model also showed these same effects with respect to purlin dimensions. The key parameter in determining the restraint force was found to be the ratio of purlin thickness to depth. As the $t / d$ ratio increases, the lateral restraint force in the system decreases (see Figure 4.1). Figure 4.1 compares the brace force ratio for 
single span systems with support restraints, for different values of $t / d$. Note that other section properties are varied for each purlin tested, including the moments of inertia. The purlin identifications are given later in Section 4.3. Increasing purlin depth increases the lateral restraint force, because purlin web bending resistance is decreased. Similarly, increasing purlin thickness decreases restraint force because purlin web bending resistance is increased. Increasing flange width increases the restraint force due to the increased torque loading.

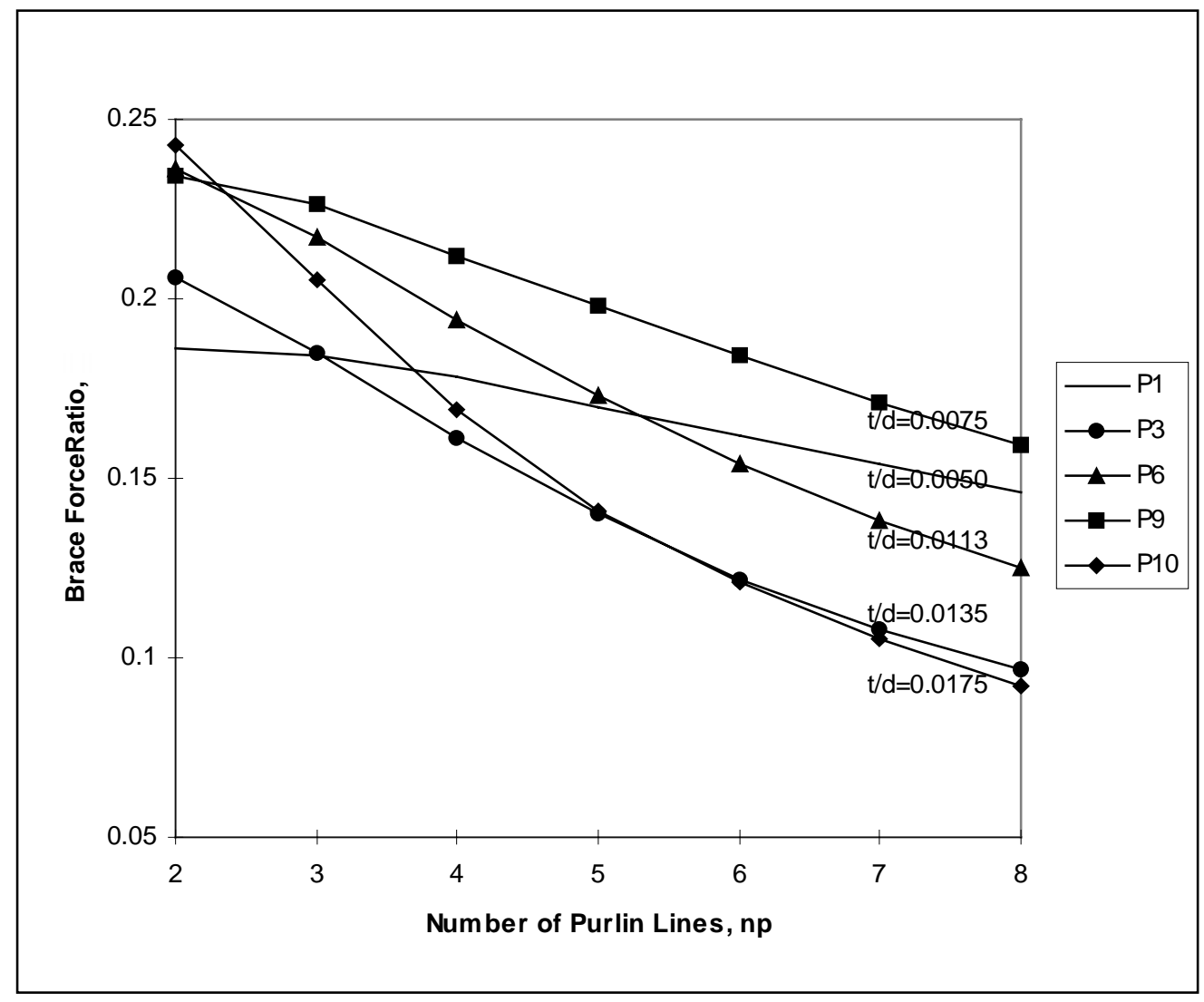

Figure 4.1 Effect of $t / d$ on Restraint Force 


\subsubsection{Purlin Moments of Inertia}

The previous system behavior analyses did not consider the effects of the moments of inertia $I_{x}$ and $I_{x y}$ of the purlin cross-section. Analysis of the current model, however, shows that increasing the ratio of $I_{x y} / I_{x}$ increases the required restraint force. The cause of this effect is the increase in the fictitious force, $W_{p} \cos \theta\left(I_{x y} / I_{x}\right)$ (see Figure 3.5 ), resulting from the asymmetry of the cross-section. Figure 4.2 shows an example of this effect, for the case of single span support restraints. The two purlins (see Section 4.3 for purlin identifications) being compared in the figure have the same $t / d$ ratio, to isolate the effect of $I_{x y} / I_{x}$ on restraint force.

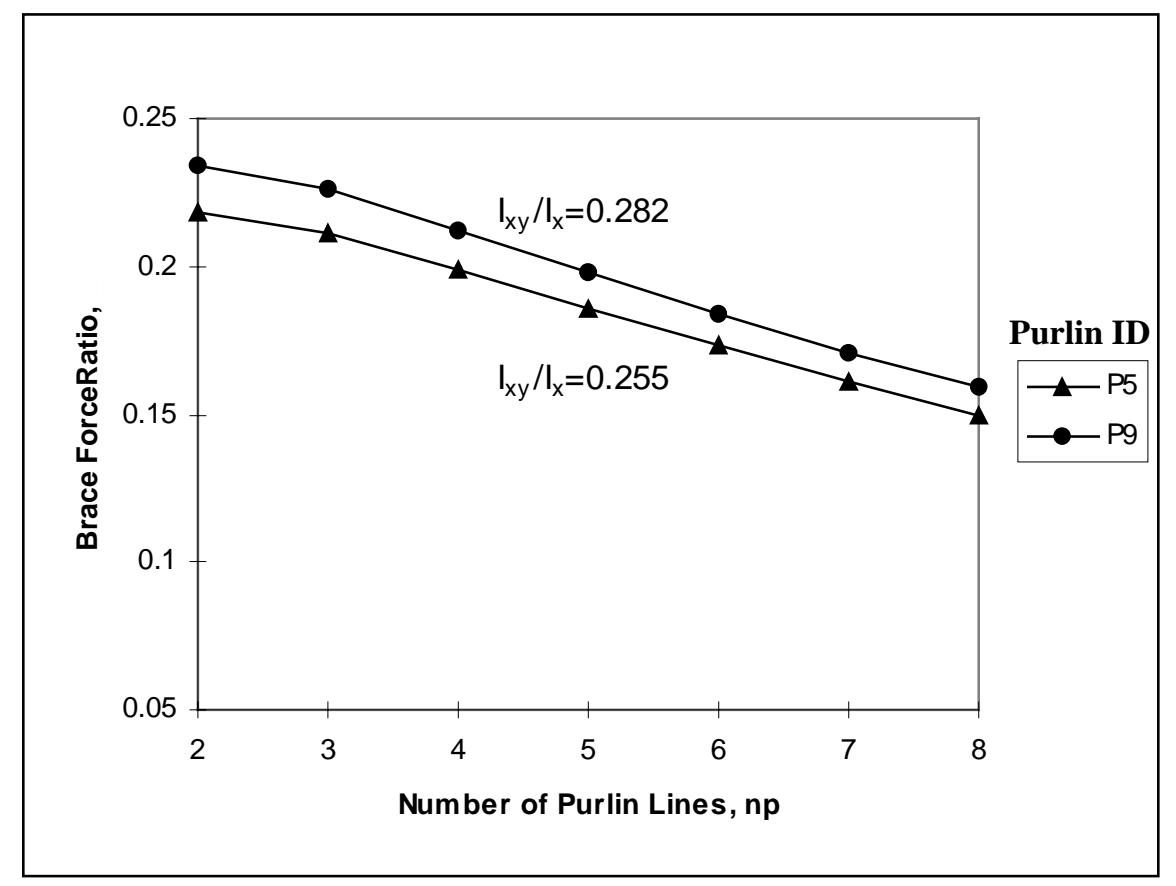

Figure 4.2 Effect of $I_{x y} / I_{x}$ on Restraint Force

\subsubsection{Roof Slope}

Elhouar and Murray (1985) did not include roof slope in their parametric study, but instead accounted for roof slope through an adjustment based on a series of five experimental tests on quarter-scale models by Seshappa and Murray (1985). Equation 
1.3 was used to correct the design equations for the effect of roof slope. They noted that as roof slope increases, the restraint force changes from tension to compression in a linear fashion with respect to $\tan \theta$. The intercept slope angle, the angle where the restraint force is zero, is given by Equation 3.5, and is a function of the number of restrained purlin lines and the bracing configuration, in addition to purlin cross-sectional properties. Equation 1.3 and Equation 3.5, in that order, are repeated here for convenience:

$$
\begin{aligned}
& P_{L}=P_{L_{O}}-W \tan \theta \\
& \theta_{0}=\tan ^{-1} \beta
\end{aligned}
$$

System behavior analysis of the current model determined that, like the previous study, restraint force changes from tension to compression as roof slope increases. The manner of this variation, however, was not found to agree with Equation 1.3. The theoretical Equation 3.9 was much more accurate in predicting the required restraint force. The intercept slope angle is then given by Equation 3.10, which is dependent only upon purlin cross-sectional properties and remains constant for any number of restrained purlin lines. Equation 3.9 and Equation 3.10, in that order, are repeated here for convenience:

$$
\begin{aligned}
P_{0} & =\left[\left(\frac{I_{x y}}{2 I_{x}}+\frac{b}{3 d}\right) \cos \theta-\sin \theta\right] W_{p} \\
\theta_{0} & =\tan ^{-1}\left(\frac{I_{x y}}{2 I_{x}}+\frac{b}{3 d}\right)
\end{aligned}
$$

Table 4.2 compares the current stiffness model results to the values of the slope intercept angle predicted by Equations 3.5 and 3.10. The table compares results from single span, support restraint systems with four or eight restrained purlin lines. Linear interpolation was used to determine the intercept slope angles for the current stiffness model. Notice that the current model results show no significant change in the intercept slope angle for $n_{p}=4$ versus $n_{p}=8$. The intercept slope angles given by Equation 3.10, for all values of $n_{p}$, are very close to the stiffness model results; the maximum difference is 1.13 degrees for purlin P10 (purlin identifications are given in Section 4.3) with eight 
restrained purlin lines. The intercept slopes given by Equation 3.5 tend to be lower than the model results by several degrees when $n_{p}=8$. However, the intercept slopes given by Equation 3.5 are often higher than the model values when $n_{p}=4$. Thus, the dependence of Equation 3.5 upon the number of restrained purlin lines is not representative of the current model behavior.

Table 4.2 Slope Intercept Comparison

\begin{tabular}{|c|c|c|c|c|c|}
\cline { 2 - 5 } \multicolumn{1}{c|}{} & \multicolumn{4}{c|}{ Slope Intercept (degrees) } \\
\hline \multirow{2}{*}{ Purlin ID } & \multicolumn{2}{|c|}{ Stiffness Model } & \multicolumn{2}{c|}{ Equation $\mathbf{3 . 5}$} & \multirow{2}{*}{ Equation 3.10 } \\
\cline { 2 - 5 } & $\mathbf{n}_{\mathbf{p}}=\mathbf{4}$ & $\mathbf{n}_{\mathbf{p}}=\mathbf{8}$ & $\mathbf{n}_{\mathbf{p}}=\mathbf{4}$ & $\mathbf{n}_{\mathbf{p}}=\mathbf{8}$ & \\
\hline P1 & 11.02 & 11.19 & 15.35 & 9.46 & 11.29 \\
\hline P3 & 11.99 & 11.96 & 10.00 & 6.11 & 12.73 \\
\hline P5 & 12.63 & 12.61 & 14.09 & 8.67 & 12.80 \\
\hline P7 & 13.69 & 13.63 & 11.81 & 7.24 & 13.74 \\
\hline P9 & 13.50 & 13.45 & 14.94 & 9.20 & 13.77 \\
\hline P10 & 14.31 & 14.16 & 10.02 & 6.12 & 15.29 \\
\hline
\end{tabular}

\subsubsection{Roof Panel Stiffness}

As noted previously, the models used by Elhouar and Murray (1985) and Danza and Murray (1998) assumed a value of $2500 \mathrm{lb} / \mathrm{in}$. for roof panel shear stiffness. Thus, panel stiffness was not included in their system behavior analyses. Analysis of the current model showed that restraint force increases significantly as roof panel shear stiffness increases. The increase in restraint force is approximately linear with respect to the common logarithm of panel stiffness, over the range of typical roof panel stiffnesses. Section 3.3.6 has a full discussion of the effect of roof panel shear stiffness upon lateral restraint forces.

\subsection{DEVELOPMENT OF COMPUTER TEST MATRIX}

Taking note of the parameters affecting required restraint forces in Z-purlin supported roof systems, a computer test matrix was developed. All of the tests in the matrix were then analyzed using the current elastic stiffness model. Five different lateral bracing configurations were examined (refer to Figure 1.3): support, third-point, 
midpoint, quarter-point, and third-point plus support restraints. Separate equations are necessary for single and multiple span conditions, so a one span and a three span model were created for each bracing configuration.

A total of ten different purlins were selected for the computer test matrix. The dimensions of these purlins are given in Table 4.3 and the corresponding section properties are shown in Table 4.4. The test purlins have six different cross-sections and five different span lengths. Purlin depth ranges from 6 in. to 12 in., flange width ranges from 2 in. to 3.25 in., thickness varies from 0.060 in. to 0.135 in., and span length varies from $20 \mathrm{ft}$ to $36 \mathrm{ft}$. These purlin dimensions were chosen as being representative of the typical range of purlins used in industry. Span lengths were selected to be appropriate for use with each section depth. Notice that the sections 10ZS3x135, 10ZS3x075, 8ZS2.5x090, and 8ZS2.5x060 each have two different span lengths. Two different purlin thicknesses were chosen for the $8 \mathrm{in}$. and $10 \mathrm{in}$. deep purlins, to examine the effects of varying the thickness to depth ratio. Flange width was not varied independently of depth, however, due to the use of standard sections. The purlins P1 and P10 were selected to represent extreme cases; P1 is a very thin and deep purlin $(t / d=0.005)$ while P10 is a very thick and shallow purlin $(t / d=0.0175)$. These extreme cases are included to ensure that the design equations accurately predict restraint forces for any typical purlin section and span length. Notice also in Table 4.4 that the $I_{x y} / I_{x}$ ratio is different for each of the six purlin sections used, to determine the effects of this parameter on restraint forces. Complete section properties for each of the purlin cross-sections are found in the Cold Formed Steel Design Manual (1996). 
Table 4.3 Purlin Dimensions

\begin{tabular}{|c|c|c|c|c|c|}
\hline ID & Section & $\begin{array}{c}\mathbf{d} \\
\text { (in.) }\end{array}$ & $\begin{array}{c}\mathbf{b} \\
\text { (in.) }\end{array}$ & $\begin{array}{c}\mathbf{t} \\
\text { (in.) }\end{array}$ & $\begin{array}{c}\mathbf{L} \\
\text { (ft) }\end{array}$ \\
\hline P1 & $12 Z$ Z3.25x060 & 12 & 3.25 & 0.060 & 36 \\
\hline P2 & $10 Z$ Z3x135 & 10 & 3.00 & 0.135 & 35 \\
\hline P3 & $10 Z S 3 \times 135$ & 10 & 3.00 & 0.135 & 30 \\
\hline P4 & $10 Z S 3 \times 075$ & 10 & 3.00 & 0.075 & 35 \\
\hline P5 & $10 Z S 3 \times 075$ & 10 & 3.00 & 0.075 & 30 \\
\hline P6 & $8 Z$ Z2.5x090 & 8 & 2.50 & 0.090 & 25 \\
\hline P7 & $8 Z$ ZS2.5x090 & 8 & 2.50 & 0.090 & 20 \\
\hline P8 & 8ZS2.5x060 & 8 & 2.50 & 0.060 & 25 \\
\hline P9 & 8ZS2.5x060 & 8 & 2.50 & 0.060 & 20 \\
\hline P10 & 6ZS2x105 & 6 & 2.00 & 0.105 & 20 \\
\hline
\end{tabular}

Table 4.4 Purlin Section Properties

\begin{tabular}{|c|c|c|c|c|c|c|c|}
\hline ID & Area (in. ${ }^{2}$ ) & $I_{x}\left(\right.$ in. $\left.^{4}\right)$ & $I_{x y}\left(\right.$ in. $\left.^{4}\right)$ & $I_{x 2}\left(\right.$ in. $\left.^{4}\right)$ & $I_{y 2}\left(\right.$ in. $\left.^{4}\right)$ & $\theta_{\mathrm{p}}(\mathrm{deg})$ & $\mathbf{J}$ (in. $\left.{ }^{4}\right)$ \\
\hline $\mathrm{P} 1$ & 1.177 & 24.62 & 5.381 & 1.12 & 25.85 & 12.90 & 0.00141 \\
\hline $\mathrm{P} 2, \mathrm{P} 3$ & 2.275 & 33.23 & 8.374 & 1.83 & 35.47 & 14.93 & 0.01382 \\
\hline $\mathrm{P} 4, \mathrm{P} 5$ & 1.279 & 18.99 & 4.834 & 1.07 & 20.29 & 15.10 & 0.00240 \\
\hline P6, P7 & 1.261 & 12.01 & 3.370 & 0.776 & 13.02 & 16.69 & 0.00340 \\
\hline P8, P9 & 0.847 & 8.15 & 2.298 & 0.532 & 8.84 & 16.79 & 0.00102 \\
\hline P10 & 1.151 & 6.17 & 2.003 & 0.491 & 6.88 & 19.42 & 0.00423 \\
\hline
\end{tabular}

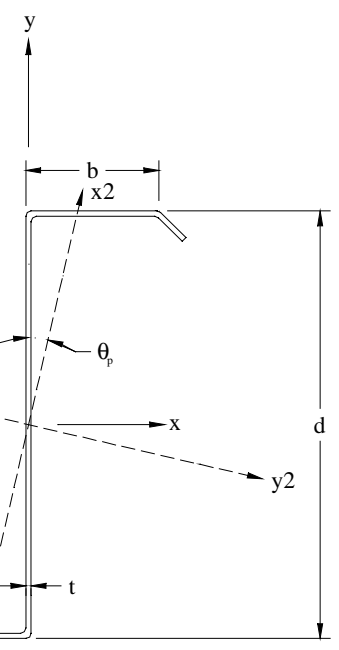


The next parameter in the test matrix is the number of parallel restrained purlin lines. In practice, the number of purlin lines between restraint anchors rarely exceeds eight. Hence, the maximum number of restrained purlin lines considered in the matrix is eight. For flat roofs (zero slope), the number of restrained purlin lines tested was one to eight, inclusive. For models with eight restrained purlin lines, the computer tests varied both the roof slope and the roof panel shear stiffness, independently of each other. Eleven different roof slopes were tested; 0:12, 1/2:12, 1:12, 2:12, .. 9:12. These roof slopes were chosen to be representative of actual Z-purlin supported roofs, and to give enough data points to accurately describe the effect of roof slope on the required restraint forces. Z-purlin supported roof systems can have slopes greater than 9:12, but the general behavior of restraint forces with roof slope can be identified without including tests at these higher roof slopes. For models with $n_{p}=8$ and $\theta=0$, six different roof panel shear stiffnesses were tested. The values of roof panel stiffness used for each span length are shown in Table 4.5, along with the corresponding areas of the Type D elements that were used for the roof panel in the current stiffness model. These values of panel shear stiffness represent typical values of actual roof panels and cover the range of log-linear behavior, $1000 \mathrm{lb} / \mathrm{in} .<G^{\prime}<100,000 \mathrm{lb} / \mathrm{in}$. All span lengths include the shear stiffness of $2500 \mathrm{lb} / \mathrm{in}$., the base point used to formulate the design equations. The set of computer test combinations for roof slope, panel shear stiffness, and number of restrained purlin lines is summarized in Table 4.6 below. The designations G1 through G6 refer to the panel shear stiffness values given in Table 4.5. The models for this set of combinations were analyzed for each bracing configuration, number of spans, and purlin in the test matrix.

Table 4.5 Panel Shear Stiffness Values

\begin{tabular}{|c|c|c|c|c|c|c|c|c|c|c|}
\hline \multirow[b]{2}{*}{ ID } & \multicolumn{2}{|c|}{$L=20 \mathrm{ft}$} & \multicolumn{2}{|c|}{$\mathrm{L}=25 \mathrm{ft}$} & \multicolumn{2}{|c|}{$\mathrm{L}=30 \mathrm{ft}$} & \multicolumn{2}{|c|}{$\mathrm{L}=35 \mathrm{ft}$} & \multicolumn{2}{|c|}{$\mathrm{L}=\mathbf{3 6} \mathrm{ft}$} \\
\hline & $\begin{array}{r}\text { Area } \\
\left(\text { in }^{2}\right)\end{array}$ & $\begin{array}{c}\mathbf{G}^{\prime} \\
(\mathbf{l b} / \mathbf{i n})\end{array}$ & $\begin{array}{c}\text { Area } \\
\left(\text { in }^{2}\right)\end{array}$ & $\begin{array}{c}\mathbf{G}^{\prime} \\
(\mathrm{lb} / \mathbf{i n})\end{array}$ & $\begin{array}{r}\text { Area } \\
\left(\text { in }^{2}\right)\end{array}$ & $\begin{array}{c}\mathbf{G}^{\prime} \\
(\mathrm{lb} / \mathbf{i n})\end{array}$ & $\begin{array}{r}\text { Area } \\
\left(\text { in }^{2}\right)\end{array}$ & $\begin{array}{c}\mathbf{G}^{\prime} \\
(\mathbf{l b} / \mathbf{i n})\end{array}$ & $\begin{array}{c}\text { Area } \\
\left(\text { in }^{2}\right)\end{array}$ & $\begin{array}{c}\mathbf{G}^{\prime} \\
(\mathbf{l b} / \mathbf{i n})\end{array}$ \\
\hline G1 & 1.0 & 76923 & 1.0 & 73529 & 1.0 & 65217 & 1.0 & 56452 & 1.0 & 56250 \\
\hline $\mathrm{G} 2$ & 0.3 & 23256 & 0.3 & 22321 & 0.3 & 20000 & 0.3 & 17157 & 0.3 & 16667 \\
\hline G3 & 0.1 & 7752 & 0.1 & 7440 & 0.1 & 6637 & 0.1 & 5719 & 0.1 & 5538 \\
\hline G4 & 0.06 & 4673 & 0.06 & 4448 & 0.07 & 4644 & 0.07 & 4005 & 0.07 & 3879 \\
\hline G5 & 0.0321 & 2500 & 0.0336 & 2495 & 0.0377 & 2500 & 0.0437 & 2500 & 0.0451 & 2500 \\
\hline G6 & 0.02 & 1560 & 0.02 & 1486 & 0.02 & 1326 & 0.02 & 1145 & 0.02 & 1109 \\
\hline
\end{tabular}


Table 4.6 Combinations of $n_{p}, \theta$, and $G$ '

\begin{tabular}{|c|c|c|c|}
\hline Combination & $\mathbf{n}_{\mathbf{p}}$ & Roof Slope & $G^{\prime}$ \\
\hline 1 & 8 & $0: 12$ & G5 \\
\hline 2 & 8 & $1 / 2: 12$ & G5 \\
\hline 3 & 8 & $1: 12$ & G5 \\
\hline 4 & 8 & $2: 12$ & G5 \\
\hline 5 & 8 & $3: 12$ & G5 \\
\hline 6 & 8 & $4: 12$ & G5 \\
\hline 7 & 8 & $5: 12$ & G5 \\
\hline 8 & 8 & $6: 12$ & G5 \\
\hline 9 & 8 & $7: 12$ & G5 \\
\hline 10 & 8 & $8: 12$ & G5 \\
\hline 11 & 8 & $9: 12$ & G5 \\
\hline 12 & 1 & $0: 12$ & G5 \\
\hline 13 & 2 & $0: 12$ & G5 \\
\hline 14 & 3 & $0: 12$ & G5 \\
\hline 15 & 4 & $0: 12$ & G5 \\
\hline 16 & 5 & $0: 12$ & G5 \\
\hline 17 & 6 & $0: 12$ & G5 \\
\hline 18 & 7 & $0: 12$ & G5 \\
\hline 19 & 8 & $0: 12$ & G1 \\
\hline 20 & 8 & $0: 12$ & $\mathrm{G} 2$ \\
\hline 21 & 8 & $0: 12$ & G3 \\
\hline 22 & 8 & $0: 12$ & G4 \\
\hline 23 & 8 & $0: 12$ & G6 \\
\hline
\end{tabular}

The current stiffness model used to represent Z-purlin supported roof systems is linear and elastic, so the relative magnitude of the applied loading is not important to the model solution. The restraint force is linearly proportional to the applied load. However, a load value must be input to analyze each model for the restraint force. For this reason, a uniform gravity load of $w=100$ plf was applied to every purlin line for all models in the test matrix.

In summary, the test matrix consists of 2300 computer model tests. This total comes from five bracing configurations (BC), two numbers of continuous spans (S), ten purlins(P), 23 parameter combinations (PC), and one loading (L): 


$$
[5 \mathrm{BC}] \times[2 \mathrm{~S}] \mathrm{x}[10 \mathrm{P}] \mathrm{x}[23 \mathrm{PC}] \mathrm{x}[1 \mathrm{~L}]=2300 \text { tests }
$$

\subsection{SOLUTION OF COMPUTER TEST MATRIX}

A commercial stiffness analysis program was used to analyze the entire computer test matrix, using the current elastic stiffness model described in Chapter II. A sample model, with input parameters and restraint force results, is presented in Appendix A. The section properties and loads used for all of the models are given in Appendix B.

The restraint force results found by solving the computer test matrix are given in Appendix C, Tables C.1 through C.19. Since the models are symmetric about the midpoint of the system, restraint forces are only given for half of the total restraints in each model. The titles of each result table in Appendix $\mathrm{C}$ give the bracing configuration, the number of spans, and the brace location, in that order. Systems with only two symmetric restraints do not have a brace location specified. Exterior denotes the restraints on the outside of each continuous purlin line, while interior refers to braces that are inside of the exterior restraints. Note that the restraint force is not tabulated for every brace location in the system. Some multiple span systems have different interior brace locations with nearly identical restraint forces. For these cases, the results were lumped together, with the largest restraint force (by magnitude) controlling. The parameter

combinations listed in the result tables are given in Table 4.6, and the purlin identifications are described in Table 4.3. The restraint forces are given in pounds, and a purlin load of $w=100$ plf was used for all models.

\subsection{STATISTICAL ANALYSES}

\subsubsection{Regression Characteristics}

Engineering principles were used to derive the form of the proposed restraint force design equation, which is summarized in Figure 3.10. The only parts of the equation that remain to be defined are the coefficients $C_{1}, C_{2}$, and $C_{3}$. These coefficients are different for each brace location in each lateral restraint configuration. As discussed in Chapter III, $C_{1}$ is the brace location factor, $C_{2}$ affects the system effect factor, and $C_{3}$ 
influences the panel stiffness modifier. The results of the computer test matrix provide enough data to determine the values of these coefficients for each brace location and configuration, but a means of statistical analysis must be chosen to process the data.

The form of the proposed design equation requires that a multivariable, nonlinear regression analysis be performed. There are ten independent variables in the equation $(b$, $d, t, I_{x y}, I_{x}, w, L, \theta, n_{p}$, and $\left.G^{\prime}\right)$ and the relationships are nonlinear. For this research, all regression analyses were done using a commercial statistical analysis program, SigmaPlot 5.0 (1999). Regression analyses were used to determine preliminary values of the three unknown coefficients, which were later adjusted to be more appropriate for design usage.

A weighted, least-squares regression was chosen to analyze the data. Because the computer test matrix includes different roof slopes, some restraint force results are positive (tension) while others are negative (compression). Also, the magnitude of some restraint force results is many times greater than others; for the test matrix, restraint force magnitudes varied from about $10,000 \mathrm{lb}$ to less than $10 \mathrm{lb}$. When an unweighted regression is performed, residuals are given equal value in the regression, regardless of the magnitude of the corresponding data point. The residual is the difference in restraint force between the stiffness model results and the design equation predictions. However, for the purposes of the restraint force design equation, accuracy is best measured by the percent error between the stiffness model results and the design equation predictions. To create design equations with the smallest percent error, a weighted regression must be used to determine the unknown coefficients. For this analysis, each residual was given a weight of $1 /\left|P_{L}\right|$, where $P_{L}$ is the restraint force given by the stiffness model. Thus, data points having a smaller magnitude of restraint force were given a larger weight in the regression.

Weighted regressions must be handled carefully to ensure that the results are not skewed by overweight on certain data points. For certain roof slopes close to the intercept value, $\theta_{o}$, the magnitude of the restraint force is close to zero (less than $10 \mathrm{lb}$ in some cases). These data points have very large weights and tend to control the 
regression, making the results unrepresentative of all the data points considered. To prevent this distortion from occurring, a select number of data points were eliminated from the regression. All data points where the magnitude of the restraint force given by the stiffness model was less than $100 \mathrm{lb}$ were discarded from the regression. Typically, these discarded data points were those where the roof slope was 3:12 (combination 5 in Table 4.6). Eliminating these points does not damage the validity of the resulting design equations, because the equations are defined such that no lateral restraint is necessary when the magnitude of the predicted restraint force is less than $100 \mathrm{lb}$.

Another group of data points was discarded from the regression analysis. This group includes all the points for models with only one restrained purlin line $\left(n_{p}=1\right.$, combination 12 in Table 4.6). Since the stiffness models used to generate these data points had only one purlin line, there was no roof panel present to span between purlin lines. The nature of the current model, with very stiff type $\mathrm{C}$ elements at the rafter supports, leads to an inordinate amount of restraint force being given to the rafter supports when there is no roof panel diaphragm action. Thus, the force in the lateral restraints is observed to be much smaller than it would be in a real system. This effect is most acute for support restraints (see Table C.1), which are located directly above the rafter supports. The stiffness model results are clearly not accurate for these data points, because the restraint force for two purlin line systems (combination 13 in Table 4.6) is

often greater than twice the restraint force for one purlin systems. This would correspond to a system effect that increases restraint force ratio, and is clearly not possible. Thus, all data points with only one purlin line are eliminated.

\subsubsection{Determination of Coefficients $C_{1}, C_{2}$, and $C_{3}$}

All of the data from the computer test matrix, minus the discarded data points mentioned previously, was then statistically analyzed using a weighted, least-squares regression. For ease of data entry, two separate regression analyses were performed; a constant panel stiffness regression and a variable panel stiffness regression. The constant panel stiffness regression included all the data points where $G^{\prime}=2500 \mathrm{lb} / \mathrm{in}$. (combinations 1 through 18 in Table 4.6). The variable panel stiffness regression included all the data 
points where $G^{\prime}$ is varied (combinations 1 and 19 through 23 in Table 4.6). The design equation summarized in Figure 3.10 was the regression equation used for both analyses.

As a means of evaluating the effectiveness of the regression model in describing the computer test data, the statistical terms $R$ and $R^{2}$ were used. $R$ is the coefficient of correlation and $R^{2}$ is the coefficient of determination; each of these measures varies from zero to one. When $R=0$, no relationship exists between the regression model and the test data, and when $R=1$, the regression model perfectly predicts the test data. For this research, values of $R^{2}$ greater than 0.90 were deemed acceptable for determining the regression coefficients. Appendix D contains a full explanation of the statistical measures calculated in the regression analysis.

To determine final coefficient values for the proposed design equation, three regression trials were performed. For the first trial, only the constant panel stiffness regression was executed, and initial values of $C_{1}$ and $C_{2}$ were calculated (see Table 4.7). A sample regression analysis for this initial trial is found in Appendix D. Notice that the $R^{2}$ values are greater than 0.97 for all restraint configurations, indicating that the regression model is highly accurate at predicting the computer test restraint forces. 
Table 4.7 First Regression Trial

\begin{tabular}{|c|c|c|c|c|}
\hline Configuration & $\mathbf{C}_{\mathbf{1}}$ & $\mathbf{C}_{\mathbf{2}}$ & $\mathbf{R}$ & $\mathbf{R}^{\mathbf{2}}$ \\
\hline Support Restraints: & & & & \\
SS & 0.4827 & 5.8234 & 0.9989 & 0.9978 \\
MS, exterior & 0.4604 & 5.9264 & 0.9990 & 0.9979 \\
MS, interior & 0.9373 & 9.1763 & 0.9851 & 0.9704 \\
\hline Third-point Restraints: & 0.4597 & 3.9651 & 0.9990 & 0.9980 \\
SS & 0.4588 & 4.2003 & 0.9989 & 0.9977 \\
MS, exterior & 0.4321 & 4.3780 & 0.9981 & 0.9961 \\
MS, interior & & & & \\
Midspan Restraints: & 0.8130 & 5.2671 & 0.9981 & 0.9962 \\
SS & 0.7674 & 5.6286 & 0.9976 & 0.9952 \\
MS, exterior & 0.7435 & 6.3627 & 0.9858 & 0.9719 \\
MS, interior & & & & \\
Quarter-point Restraints: & 0.2443 & 4.8359 & 0.9957 & 0.9913 \\
SS, exterior & 0.4255 & 3.2623 & 0.9967 & 0.9934 \\
SS, interior & 0.2416 & 4.9460 & 0.9953 & 0.9906 \\
MS, exterior $1 / 4$ span & 0.2175 & 5.1648 & 0.9941 & 0.9883 \\
MS, interior $1 / 4$ span & 0.4310 & 3.8545 & 0.9986 & 0.9972 \\
MS, 1/2 span & & & & \\
SS, exterior & 0.1584 & 3.4743 & 0.9890 & 0.9781 \\
SS, interior & 0.3456 & 2.9515 & 0.9986 & 0.9973 \\
MS, exterior support & 0.1564 & 3.4192 & 0.9919 & 0.9838 \\
MS, interior support & 0.2738 & 4.9523 & 0.9851 & 0.9704 \\
MS, third-point & 0.3457 & 3.1227 & 0.9978 & 0.9957 \\
\hline Third-point Plus Support Restraints: & & & & \\
\hline
\end{tabular}

The coefficient values determined by the first trial can be greatly simplified for design purposes. Due to the modeling process, the values are not known to a high degree of accuracy, and only two significant digits are required in the coefficient values. The $C_{2}$ values represent Z-purlin bending resistance, and restraints with corresponding locations in single and multiple span systems should have about the same resistance. Thus, these restraints are given the same $C_{2}$ value. These adjusted $C_{2}$ values were included as known values in the second regression trial, which then calculated revised $C_{1}$ values. Again, the constant panel stiffness regression was performed, and the results are shown in Table 4.8. As for the first trial, all $R^{2}$ values are greater than 0.97 , showing excellent correlation between the regression model and the computer test results. 
Table 4.8 Second Regression Trial

\begin{tabular}{|c|c|c|c|c|}
\hline Configuration & $\mathbf{C}_{\mathbf{1}}$ & $\mathbf{C}_{\mathbf{2}}$ & $\mathbf{R}$ & $\mathbf{R}^{\mathbf{2}}$ \\
\hline Support Restraints: & & & & \\
SS & 0.4858 & 5.9 & 0.9989 & 0.9978 \\
MS, exterior & 0.4594 & 5.9 & 0.9990 & 0.9979 \\
MS, interior & 0.9389 & 9.2 & 0.9851 & 0.9704 \\
\hline Third-point Restraints: & 0.4686 & 4.2 & 0.9989 & 0.9978 \\
SS & 0.4588 & 4.2 & 0.9989 & 0.9977 \\
MS, exterior & 0.4258 & 4.2 & 0.9980 & 0.9961 \\
MS, interior & & & & \\
Midspan Restraints: & 0.8358 & 5.6 & 0.9980 & 0.9961 \\
SS & 0.7656 & 5.6 & 0.9976 & 0.9952 \\
MS, exterior & 0.6981 & 5.6 & 0.9854 & 0.9710 \\
MS, interior & & & & \\
Quarter-point Restraints: & 0.2477 & 5.0 & 0.9956 & 0.9913 \\
SS, exterior & 0.4369 & 3.6 & 0.9966 & 0.9931 \\
SS, interior & 0.2427 & 5.0 & 0.9953 & 0.9906 \\
MS, exterior $1 / 4$ span & 0.2145 & 5.0 & 0.9941 & 0.9883 \\
MS, interior $1 / 4$ span & 0.4222 & 3.6 & 0.9985 & 0.9971 \\
MS, 1/2 span & & & & \\
SS, exterior & 0.1587 & 3.5 & 0.9890 & 0.9781 \\
SS, interior & 0.3469 & 3.0 & 0.9986 & 0.9973 \\
MS, exterior support & 0.1574 & 3.5 & 0.9919 & 0.9838 \\
MS, interior support & 0.2749 & 5.0 & 0.9851 & 0.9704 \\
MS, third-point & 0.3425 & 3.0 & 0.9978 & 0.9957 \\
\hline
\end{tabular}

Since the regression coefficients are not known to more than two significant digits of accuracy, the resulting $C_{1}$ values from the second trial were adjusted to the nearest appropriate value for design purposes. The coefficient $C_{1}$ is the brace location factor, which controls the percentage of total restraint force that is allocated to a particular restraint. All $C_{1}$ values were increased in the adjustment, because increasing this coefficient always produces a more conservative prediction for restraint forces. For the third trial, the variable panel stiffness regression was performed. The adjusted values for $C_{1}$ and $C_{2}$ were taken as known quantities, and initial values for the coefficient $C_{3}$ were determined (see Table 4.9). The coefficient $C_{3}$ controls the panel stiffness modifier (see Equation 3.13). The $R^{2}$ values for this trial are greater than 0.90 for all restraint 
configurations, with three exceptions. These three exceptions all have $R^{2}$ values above 0.89 , and are close enough to 0.90 to be acceptable for the final design equation.

Table 4.9 Third Regression Trial

\begin{tabular}{|l|c|c|c|c|c|}
\hline Configuration & $\mathbf{C}_{\mathbf{1}}$ & $\mathbf{C}_{\mathbf{2}}$ & $\mathbf{C}_{\mathbf{3}}$ & $\mathbf{R}$ & $\mathbf{R}^{\mathbf{2}}$ \\
\hline Support Restraints: & & & & & \\
SS & 0.50 & 5.9 & 0.2912 & 0.9905 & 0.9812 \\
MS, exterior & 0.50 & 5.9 & 0.3623 & 0.9901 & 0.9803 \\
MS, interior & 1.00 & 9.2 & 0.4198 & 0.9915 & 0.9830 \\
\hline Third-point Restraints: & & & & & \\
SS & 0.50 & 4.2 & 0.2130 & 0.9943 & 0.9886 \\
MS, exterior & 0.50 & 4.2 & 0.2632 & 0.9914 & 0.9830 \\
MS, interior & 0.45 & 4.2 & 0.3269 & 0.9850 & 0.9701 \\
\hline Midspan Restraints: & & & & & \\
SS & 0.85 & 5.6 & 0.3168 & 0.9852 & 0.9706 \\
MS, exterior & 0.80 & 5.6 & 0.3958 & 0.9711 & 0.9430 \\
MS, interior & 0.75 & 5.6 & 0.4673 & 0.9479 & 0.8986 \\
\hline Quarter-point Restraints: & & & & & \\
SS, exterior & 0.25 & 5.0 & 0.3305 & 0.9704 & 0.9416 \\
SS, interior & 0.45 & 3.6 & 0.1067 & 0.9458 & 0.8946 \\
MS, exterior $1 / 4$ span & 0.25 & 5.0 & 0.3585 & 0.9589 & 0.9194 \\
MS, interior $1 / 4$ span & 0.22 & 5.0 & 0.4223 & 0.9448 & 0.8927 \\
MS, 1/2 span & 0.45 & 3.6 & 0.2569 & 0.9783 & 0.9571 \\
\hline Third-point Plus Support Restraints: & & & & & \\
SS, exterior & 0.17 & 3.5 & 0.3566 & 0.9537 & 0.9096 \\
SS, interior & 0.35 & 3.0 & 0.0221 & 0.9852 & 0.9706 \\
MS, exterior support & 0.17 & 3.5 & 0.3553 & 0.9664 & 0.9338 \\
MS, interior support & 0.30 & 5.0 & 0.4564 & 0.9743 & 0.9492 \\
MS, third-point & 0.35 & 3.0 & 0.0718 & 0.9709 & 0.9426 \\
\hline
\end{tabular}

After the third regression trial, the final values of the regression coefficients were determined by adjusting the $C_{3}$ values. Again, these values need only have two significant digits of accuracy, and are adjusted to values that are appropriate for use in the design equation. The final regression coefficient values are presented in Table 4.10. 
Table 4.10 Final Regression Coefficient Values

\begin{tabular}{|l|l|l|l|}
\hline Configuration & $\mathbf{C}_{\mathbf{1}}$ & $\mathbf{C}_{\mathbf{2}}$ & $\mathbf{C}_{\mathbf{3}}$ \\
\hline Support Restraints: & & & \\
SS & 0.50 & 5.9 & 0.35 \\
MS, exterior & 0.50 & 5.9 & 0.35 \\
MS, interior & 1.00 & 9.2 & 0.45 \\
\hline Third-point Restraints: & 0.50 & & \\
SS & 0.50 & 4.2 & 0.25 \\
MS, exterior & 0.45 & 4.2 & 0.25 \\
MS, interior & & & 0.35 \\
\hline Midspan Restraints: & 0.85 & 5.6 & \\
SS & 0.80 & 5.6 & 0.35 \\
MS, exterior & 0.75 & 5.6 & 0.35 \\
MS, interior & & & 0.45 \\
\hline Quarter-point Restraints: & 0.25 & 5.0 & 0.35 \\
SS, exterior & 0.45 & 3.6 & 0.15 \\
SS, interior & 0.25 & 5.0 & 0.40 \\
MS, exterior $1 / 4$ span & 0.22 & 5.0 & 0.40 \\
MS, interior $1 / 4$ span & 0.45 & 3.6 & 0.25 \\
MS, 1/2 span & & & \\
SS, exterior & 0.17 & 3.5 & 0.35 \\
SS, interior & 0.35 & 3.0 & 0.05 \\
MS, exterior support & 0.17 & 3.5 & 0.35 \\
MS, interior support & 0.30 & 5.0 & 0.45 \\
MS, third-point & 0.35 & 3.0 & 0.10 \\
\hline Third-point Plus Support Restraints: & & & \\
\hline
\end{tabular}

\subsection{VERIFIFICATION OF PANEL STIFFNESS AND ROOF SLOPE INTERACTION}

The computer test matrix discussed in Section 4.3 does not include a series of data points where roof slope is varied for values of roof panel shear stiffness other than $G^{\prime}=2500 \mathrm{lb} / \mathrm{in}$. The proposed design equation, given in Figure 3.10, must accurately predict the effects on restraint force of the interaction between roof slope and roof panel shear stiffness. To minimize the total data collection time, only four different computer test series were used to verify the proposed design equation for the combined interaction of roof panel stiffness and roof slope. The four test series are described in Table 4.11 and 
note that for all tests, $n_{p}=8$, the loading is $w=100$ plf, and the purlin identifications are found in Table 4.4. These four series did not require an extensive number of computer test runs, but the results give a representative description of the interaction behavior. The data points for each test series in this verification, along with restraint force results in $1 b$, are shown in Table 4.12.

Table 4.11 Test Series for Roof Slope and Panel Stiffness Interaction

\begin{tabular}{|c|l|c|}
\hline Test Series & \multicolumn{1}{|c|}{ Bracing Configuration } & Purlin \\
\hline 1 & Single Span, Support Restraints & P6 \\
\hline 2 & Multiple Span, Third-point Restraints, Interior & P5 \\
\hline 3 & Single Span, Quarter-point Restraints, Interior & P9 \\
\hline 4 & $\begin{array}{c}\text { Multiple Span, Third-point Plus Support Restraints, } \\
\text { Interior Support }\end{array}$ & P2 \\
\hline
\end{tabular}

Table 4.12 Results of Roof Slope and Panel Stiffness Interaction Tests

\begin{tabular}{|c|c|c|c|c|c|c|}
\hline Data Point & Roof Slope & $\begin{array}{c}\text { Panel } \\
\text { Stiffness }\end{array}$ & $\begin{array}{c}\text { Test Series } \\
\mathbf{1}\end{array}$ & $\begin{array}{c}\text { Test Series } \\
\mathbf{2}\end{array}$ & $\begin{array}{c}\text { Test Series } \\
\mathbf{3}\end{array}$ & Test Series \\
\hline 1 & & G1 & 2206 & 2495 & 1710 & 1834 \\
\hline 2 & $0: 12$ & G2 & 2046 & 2370 & 1775 & 1612 \\
\hline 3 & $0: 12$ & G3 & 1720 & 2118 & 1689 & 1241 \\
\hline 4 & $0: 12$ & G4 & 1507 & 2060 & 1600 & 1094 \\
\hline 5 & $0: 12$ & G5 & 1246 & 1768 & 1460 & 894 \\
\hline 6 & $0: 12$ & G6 & 1021 & 1530 & 1345 & 591 \\
\hline 7 & $1 / 2: 12$ & G1 & 1806 & 2011 & 1401 & 1471 \\
\hline 8 & $1 / 2: 12$ & G2 & 1678 & 1913 & 1456 & 1292 \\
\hline 9 & $1 / 2: 12$ & G3 & 1417 & 1714 & 1390 & 996 \\
\hline 10 & $1 / 2: 12$ & G4 & 1244 & 1621 & 1321 & 878 \\
\hline 11 & $1 / 2: 12$ & G5 & 1030 & 1438 & 1211 & 717 \\
\hline 12 & $1 / 2: 12$ & G6 & 846 & 1250 & 1120 & 473 \\
\hline 13 & $1: 12$ & G1 & 1421 & 1639 & 1104 & 1118 \\
\hline 14 & $1: 12$ & G2 & 1325 & 1466 & 1149 & 981 \\
\hline 15 & $1: 12$ & G3 & 1125 & 1319 & 1103 & 758 \\
\hline 16 & $1: 12$ & G4 & 991 & 1251 & 1052 & 668 \\
\hline 17 & $1: 12$ & G5 & 823 & 1116 & 971 & 546 \\
\hline 18 & $1: 12$ & G6 & 678 & 977 & 903 & 358 \\
\hline 19 & $2: 12$ & G1 & 560 & 596 & 442 & 348 \\
\hline 20 & $2: 12$ & G2 & 535 & 572 & 464 & 305 \\
\hline 21 & $2: 12$ & G3 & 472 & 530 & 461 & 240 \\
\hline 22 & $2: 12$ & G4 & 424 & 510 & 451 & 213 \\
\hline 23 & $2: 12$ & G5 & 359 & 472 & 434 & 174 \\
\hline
\end{tabular}


Table 4.12 Results of Roof Slope and Panel Stiffness Interaction Tests, Continued

\begin{tabular}{|c|c|c|c|c|c|c|}
\hline 24 & $2: 12$ & G6 & 300 & 432 & 418 & 109 \\
\hline 25 & $3: 12$ & G1 & -181 & -401 & -130 & -331 \\
\hline 26 & $3: 12$ & G2 & -146 & -373 & -126 & -293 \\
\hline 27 & $3: 12$ & G3 & -91 & -305 & -92 & -219 \\
\hline 28 & $3: 12$ & G4 & -65 & -274 & -65 & -192 \\
\hline 29 & $3: 12$ & G5 & -40 & -212 & -27 & -157 \\
\hline 30 & $3: 12$ & G6 & -24 & -150 & - & -113 \\
\hline 31 & $4: 12$ & G1 & -965 & -1255 & -734 & -1037 \\
\hline 32 & $4: 12$ & G2 & -865 & -1182 & -750 & -913 \\
\hline 33 & $4: 12$ & G3 & -686 & -1019 & -677 & -694 \\
\hline 34 & $4: 12$ & G4 & -581 & -943 & -613 & -609 \\
\hline 35 & $4: 12$ & G5 & -463 & -794 & -517 & -498 \\
\hline 36 & $4: 12$ & G6 & -368 & -643 & -441 & -341 \\
\hline 37 & $5: 12$ & G1 & -1608 & -2139 & -1230 & -1634 \\
\hline 38 & $5: 12$ & G2 & -1456 & -2019 & -1262 & -1440 \\
\hline 39 & $5: 12$ & G3 & -1174 & -1760 & -1157 & -1138 \\
\hline 40 & $5: 12$ & G4 & -1006 & -1639 & -1062 & -966 \\
\hline 41 & $5: 12$ & G5 & -810 & -1401 & -918 & -790 \\
\hline 42 & $5: 12$ & G6 & -651 & -1159 & -803 & -537 \\
\hline 43 & $6: 12$ & G1 & -2283 & -2955 & -1750 & -2241 \\
\hline 44 & $6: 12$ & G2 & -2076 & -2792 & -1800 & -1974 \\
\hline 45 & $6: 12$ & G3 & -1687 & -2444 & -1662 & -1508 \\
\hline 46 & $6: 12$ & G4 & -1451 & -2281 & -1534 & -1326 \\
\hline 47 & $6: 12$ & G5 & -1175 & -1961 & -1340 & -1085 \\
\hline 48 & $6: 12$ & G6 & -948 & -1634 & -1185 & -734 \\
\hline 49 & $7: 12$ & G1 & -2904 & -3615 & -2229 & -2804 \\
\hline 50 & $7: 12$ & G2 & -2646 & -3418 & -2294 & -2468 \\
\hline 51 & 7:12 & G3 & -2159 & -2996 & -2125 & -1887 \\
\hline 52 & $7: 12$ & G4 & -1861 & -2798 & -1968 & -1659 \\
\hline 53 & $7: 12$ & G5 & -1511 & -2411 & -1728 & -1357 \\
\hline 54 & $7: 12$ & G6 & -1221 & -2015 & -1537 & -916 \\
\hline 55 & $8: 12$ & G1 & -3461 & -4293 & -2658 & -3309 \\
\hline 56 & $8: 12$ & G2 & -3158 & -4060 & -2739 & -2913 \\
\hline 57 & $8: 12$ & G3 & -2583 & -3564 & -2542 & -2228 \\
\hline 58 & $8: 12$ & G4 & -2229 & -3332 & -2359 & -1959 \\
\hline 59 & $8: 12$ & G5 & -1812 & -2877 & -2078 & -1602 \\
\hline 60 & $8: 12$ & G6 & -1466 & -2411 & -1853 & -1080 \\
\hline 61 & $9: 12$ & G1 & -3973 & -4915 & -3053 & -3710 \\
\hline 62 & $9: 12$ & G2 & -3629 & -4650 & -3146 & -3268 \\
\hline 63 & $9: 12$ & G3 & -2973 & -4086 & -2925 & -2501 \\
\hline 64 & $9: 12$ & G4 & -2568 & -3822 & -2717 & -2200 \\
\hline 65 & $9: 12$ & G5 & -2090 & -3305 & -2399 & -1802 \\
\hline 66 & $9: 12$ & G6 & -1692 & -2775 & -2144 & -1213 \\
\hline
\end{tabular}

To compare the results of the verification tests to the proposed design equation, a regression analysis was performed. The regression performed on the verification test 
results was a weighted, variable panel stiffness regression. The regression equation took the values for $C_{1}$ and $C_{2}$ given in Table 4.10 as known quantities and then solved for the coefficient $C_{3}$ (the panel stiffness modifier coefficient). For each verification test, the statistical measures $R$ and $R^{2}$, defined previously, were obtained to evaluate the strength of the correlation between the computer test results and the proposed design equation. Table 4.13 shows the regression results of the verification tests and compares the $C_{3}$ values to those of the final coefficient values in the proposed design equation, which are presented in Table 4.10 .

Table 4.13 Comparison of Verification Tests to Design Equation

\begin{tabular}{|c|c|c|c|}
\hline Comparison & $\mathbf{C}_{\mathbf{3}}$ & $\mathbf{R}$ & $\mathbf{R}^{\mathbf{2}}$ \\
\hline Test Series 1: & & & 0.9934 \\
Verification Regression & 0.3827 & 0.9967 & \\
Design Equation & 0.35 & & 0.9916 \\
\hline Test Series 2: & 0.5033 & 0.9958 & \\
Verification Regression & 0.35 & & 0.9944 \\
Design Equation & 0.3810 & 0.9972 & \\
\hline Test Series 3: & 0.15 & & 0.9795 \\
Verification Regression & & & \\
Design Equation & 0.4922 & 0.9897 & \\
\hline Test Series 4: & 0.45 & & \\
Verification Regression & & & \\
Design Equation &
\end{tabular}

The results of the verification test regression show $R^{2}$ values that are all greater than 0.97 , indicating a strong correlation between the regression model and the computer test results. The values of the coefficient $C_{3}$ determined by the verification test regression are all higher than the values used in the proposed design equation. The reason for this discrepancy is that each of the verification tests considered only one purlin cross-section and span length, whereas the previous regression analyses considered ten different purlins. Thus, the coefficient $C_{3}$ shows slight variation with section properties, but this variation does not merit an adjustment to the form of the design equation. The 
two sets of coefficient values are similar enough that the validity of the proposed design equation for roof slope and roof panel stiffness interaction is confirmed. 


\section{CHAPTER V}

\section{APPLICATION OF DESIGN PROCEDURE}

\subsection{INTRODUCTION}

This chapter explains the application of the proposed design procedure to the estimation of lateral restraint forces in Z-purlin supported roof systems. The proposed procedure is summarized in Figure 5.1 and the design equation coefficients are given in Table 5.1. Three design examples, representative of typical Z-purlin roof systems, are presented to illustrate the design procedure.

Table 5.1 Design Equation Coefficient Values

\begin{tabular}{|l|c|c|c|}
\hline Configuration & $\mathbf{C}_{\mathbf{1}}$ & $\mathbf{C}_{\mathbf{2}}$ & $\mathbf{C}_{\mathbf{3}}$ \\
\hline Support Restraints: & & & \\
SS & 0.50 & 5.9 & 0.35 \\
MS, exterior & 0.50 & 5.9 & 0.35 \\
MS, interior & 1.00 & 9.2 & 0.45 \\
\hline Third-point Restraints: & 0.50 & & \\
SS & 0.50 & 4.2 & 0.25 \\
MS, exterior & 0.45 & 4.2 & 0.25 \\
MS, interior & & & 0.35 \\
\hline Midspan Restraints: & 0.85 & 5.6 & \\
SS & 0.80 & 5.6 & 0.35 \\
MS, exterior & 0.75 & 5.6 & 0.35 \\
MS, interior & 0.25 & & 0.45 \\
\hline Quarter-point Restraints: & 0.45 & 5.0 & 0.35 \\
SS, exterior & 0.25 & 3.6 & 0.15 \\
SS, interior & 0.22 & 5.0 & 0.40 \\
MS, exterior $1 / 4$ span & 5.0 & 0.40 \\
MS, interior $1 / 4$ span & 0.45 & 3.6 & 0.25 \\
MS, 1/2 span & & & \\
SS, exterior & 0.17 & 3.5 & 0.35 \\
SS, interior & 0.35 & 3.0 & 0.05 \\
MS, exterior support & 0.17 & 3.5 & 0.35 \\
MS, interior support & 0.30 & 5.0 & 0.45 \\
MS, third-point & 0.35 & 3.0 & 0.10 \\
\hline Third-point Plus Support Restraints: & & & \\
\hline
\end{tabular}




$$
P_{L}=P_{0} C_{1}\left(n_{p}^{*} \alpha+n_{p} \gamma\right)
$$

where:

$$
\begin{aligned}
& P_{0}=\left[\left(\frac{I_{x y}}{2 I_{x}}+\frac{b}{3 d}\right) \cos \theta-\sin \theta\right] W_{p} \\
& W_{p}=w L \\
& \alpha=1-C_{2}\left(\frac{t}{d}\right)\left(n_{p}^{*}-1\right) \\
& n_{p}^{*}=\min \left\{n_{p}, n_{p(\max )}\right\} \\
& n_{p(\max )}=0.5+\frac{d}{2 C_{2} t} \\
& \gamma=C_{3} \log \left(\frac{G^{\prime}}{2500}\right)
\end{aligned}
$$

and

$n_{p}=$ number of parallel, restrained purlin lines

$b=$ purlin flange width

$d=$ purlin depth

$t=$ purlin thickness

$I_{x y}=$ the product moment of inertia

$I_{x}=$ the moment of inertia with respect to the centroidal axis perpendicular to the web of the Z-section

$\theta=$ roof slope (from horizontal)

$w=$ distributed gravity load along each purlin (force/length)

$L=$ span length

$G^{\prime}=$ roof panel shear stiffness (lb/in.)

\section{Notes:}

1) Positive $P_{L}$ is in tension, negative $P_{L}$ is in compression.

2) Upper bound: $\left|P_{L}\right| \leq\left|n_{p} P_{0} C_{1}\right|$

3) If $\left|P_{L}\right| \leq 100 \mathrm{lb}$, no lateral bracing is necessary.

4) Applicable range of panel stiffnesses: $1000 \mathrm{lb} / \mathrm{in} \leq G^{\prime} \leq 100,000 \mathrm{lb} / \mathrm{in}$

5) $\mathrm{C}_{1}, \mathrm{C}_{2}$, and $\mathrm{C}_{3}$ are regression coefficients.

6) Models used to develop procedure had $n_{p} \leq 8$.

Figure 5.1 Summary of Proposed Design Procedure 


\subsection{Design Examples}

Example 1: Determine restraint forces for a three continuous span system having six parallel purlin lines and support restraints. The purlin section is $8 \mathrm{ZS} 2.5 \mathrm{x} 075$, the span length is $22.5 \mathrm{ft}$, and purlin lines are spaced $5 \mathrm{ft}$ apart. The roof slope is 1:12 (9.46 degrees) and the roof panel shear stiffness is $2500 \mathrm{lb} / \mathrm{in}$. A uniform gravity load of $20 \mathrm{psf}$ is applied to the system.

Solution: The design equation is given in Figure 5.1:

$$
P_{L}=P_{0} C_{1}\left(n_{p}^{*} \alpha+n_{p} \gamma\right)
$$

From Table 5.1, for multiple span systems with support restraints:

Exterior restraints: $C_{1}=0.50, C_{2}=5.9, C_{3}=0.35$

Interior restraints: $C_{1}=1.00, C_{2}=9.2, C_{3}=0.45$

For the purlin section 8ZS2.5x075, Table I-16 of the Cold-Formed Steel Design Manual, (1996) gives the following section properties:

$$
d=8 \text { in., } b=2.5 \text { in., } t=0.075 \text { in., } I_{x y}=2.840 \text { in. }^{4}, I_{x}=10.10 \text { in. }^{4}
$$

with

$$
P_{0}=\left[\left(\frac{I_{x y}}{2 I_{x}}+\frac{b}{3 d}\right) \cos \theta-\sin \theta\right] W_{p}
$$

The $\bar{w}=20 \mathrm{psf}$ gravity load is evenly distributed to all purlin lines:

$$
w=\frac{\bar{w} a\left(n_{p}-1\right)}{n_{p}}=\frac{(20 \mathrm{psf})(5 \mathrm{ft})(6-1)}{6}=83.3 \mathrm{plf}
$$

and

$$
W_{p}=w L=(83.3 \mathrm{plf})(22.5 \mathrm{ft})=1875 \mathrm{lb}
$$

thus,

$$
P_{0}=\left[\left(\frac{2.840 \mathrm{in.}^{4}}{2\left(10.10 \mathrm{in.}^{4}\right)}+\frac{2.5 \mathrm{in} .}{3(8 \mathrm{in} .)}\right) \cos 9.46^{0}-\sin 9.46^{0}\right](1875 \mathrm{lb})=144.5 \mathrm{lb}
$$


with

$$
\alpha=1-C_{2}\left(\frac{t}{d}\right)\left(n_{p}^{*}-1\right)
$$

and

$$
n_{p}^{*}=\min \left\{n_{p}, n_{p(\max )}\right\}, \quad n_{p(\max )}=0.5+\frac{d}{2 C_{2} t}
$$

For the exterior restraints:

$$
\begin{aligned}
& n_{p(\max )}=0.5+\frac{8 \text { in. }}{2(5.9)(0.075 \text { in. })}=9.54>6 \rightarrow n_{p}^{*}=6 \\
& \alpha=1-5.9\left(\frac{0.075 \text { in. }}{8 \text { in. }}\right)(6-1)=0.723
\end{aligned}
$$

For the interior restraints:

$$
\begin{aligned}
& n_{p(\max )}=0.5+\frac{8 \text { in. }}{2(9.2)(0.075 \text { in. })}=5.80<6 \rightarrow n_{p}^{*}=5.80 \\
& \alpha=1-9.2\left(\frac{0.075 \text { in. }}{8 \text { in. }}\right)(5.80-1)=0.586
\end{aligned}
$$

The roof panel shear stiffness modifier:

$$
\gamma=C_{3} \log \left(\frac{G^{\prime}}{2500 \mathrm{lb} / \mathrm{in} .}\right), G^{\prime}=2500 \mathrm{lb} / \mathrm{in} . \rightarrow \gamma=0
$$

Finally, the design restraint forces are:

Exterior restraints: $P_{L}=(144.5 \mathrm{lb})(0.50)[(6)(0.723)+(6)(0)]=313 \mathrm{lb}(\mathrm{T})$

Interior restraints: $P_{L}=(144.5 \mathrm{lb})(1.00)[(5.80)(0.586)+(6)(0)]=491 \mathrm{lb}(\mathrm{T})$ 
Shown graphically, the results are:

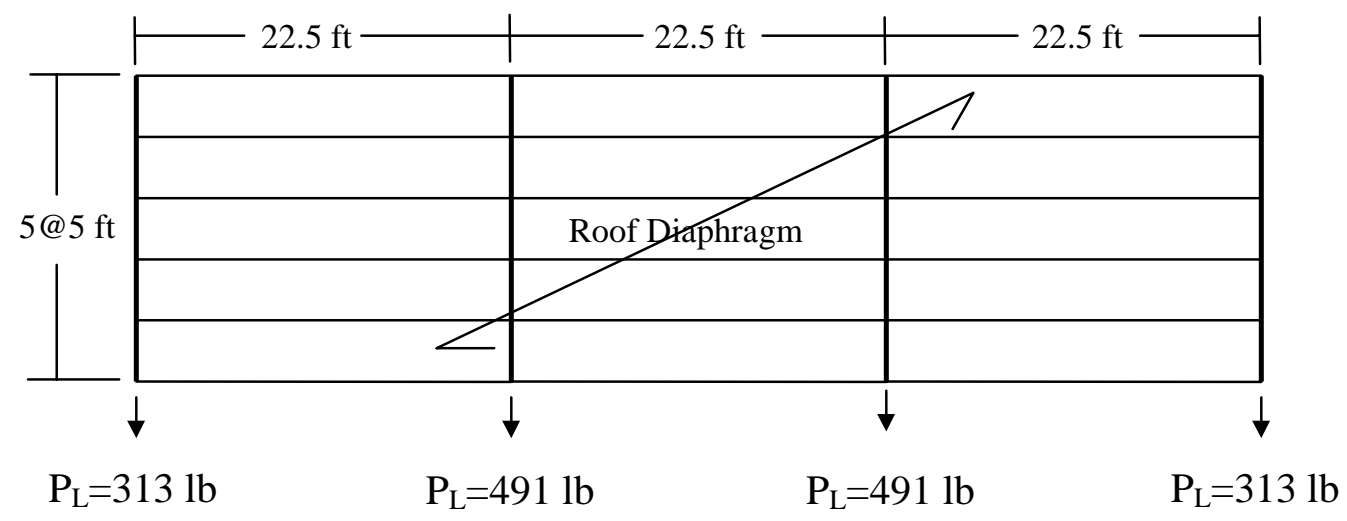

Figure 5.2 Restraint Forces for Example 1

Example 2: Determine restraint forces for a single span system having eight parallel purlin lines and quarter-point restraints. The purlin section is $10 \mathrm{ZS} 3 \times 105$, the span length is $30 \mathrm{ft}$, and purlin lines are spaced $5 \mathrm{ft}$ apart. The system has a roof slope of 5:12 (26.57 degrees) and the panel shear stiffness is 10,000 lb/in. A uniform gravity load of $30 \mathrm{psf}$ is applied to the system.

Solution: The design equation is given in Figure 5.1:

$$
P_{L}=P_{0} C_{1}\left(n_{p}^{*} \alpha+n_{p} \gamma\right)
$$

From Table 5.1, for single span systems with quarter-point restraints:

Exterior restraints: $C_{1}=0.25, C_{2}=5.0, C_{3}=0.35$

Interior restraints: $C_{1}=0.45, C_{2}=3.6, C_{3}=0.15$

For the purlin section 10ZS3x105, Table I-16 of the Cold-Formed Steel Design Manual, (1996) gives the following section properties:

$$
d=10 \text { in., } b=3 \text { in., } t=0.105 \text { in., } I_{x y}=6.640 \mathrm{in}^{4}, I_{x}=26.21 \mathrm{in}^{4}
$$

with

$$
P_{0}=\left[\left(\frac{I_{x y}}{2 I_{x}}+\frac{b}{3 d}\right) \cos \theta-\sin \theta\right] W_{p}
$$


The $\bar{w}=30$ psf gravity load is evenly distributed to all purlin lines:

$$
w=\frac{\bar{w} a\left(n_{p}-1\right)}{n_{p}}=\frac{(30 \mathrm{psf})(5 \mathrm{ft})(8-1)}{8}=131.3 \mathrm{plf}
$$

and

$$
W_{p}=w L=(131.3 \text { plf })(30 \mathrm{ft})=3938 \mathrm{lb}
$$

thus,

$$
P_{0}=\left[\left(\frac{6.640 \text { in. }^{4}}{2\left(26.21 \text { in. }^{4}\right)}+\frac{3 \text { in. }}{3(10 \mathrm{in} .)}\right) \cos 26.57^{0}-\sin 26.57^{0}\right](3938 \mathrm{lb})=-963.1 \mathrm{lb}
$$

with

$$
\alpha=1-C_{2}\left(\frac{t}{d}\right)\left(n_{p}^{*}-1\right)
$$

and

$$
n_{p}^{*}=\min \left\{n_{p}, n_{p(\max )}\right\}, n_{p(\max )}=0.5+\frac{d}{2 C_{2} t}
$$

The roof panel shear stiffness modifier:

$$
\gamma=C_{3} \log \left(\frac{G^{\prime}}{2500 \mathrm{lb} / \mathrm{in} .}\right)
$$

For the exterior restraints:

$$
\begin{aligned}
& n_{p(\max )}=0.5+\frac{8 \text { in. }}{2(5.9)(0.075 \text { in. })}=9.54>6 \rightarrow n_{p}^{*}=6 \\
& \alpha=1-5.0\left(\frac{0.105 \text { in. }}{10 \text { in. }}\right)(8-1)=0.633 \\
& \gamma=C_{3} \log \left(\frac{G^{\prime}}{2500 \mathrm{lb} / \mathrm{in} .}\right)=(0.35) \log \left(\frac{10,000 \mathrm{lb} / \mathrm{in} .}{2500 \mathrm{lb} / \mathrm{in} .}\right)=0.211
\end{aligned}
$$

For the interior restraints:

$$
\begin{aligned}
& n_{p(\max )}=0.5+\frac{10 \text { in. }}{2(3.6)(0.105 \text { in. })}=13.78>8 \rightarrow n_{p}^{*}=8 \\
& \alpha=1-3.6\left(\frac{0.105 \text { in. }}{10 \text { in. }}\right)(8-1)=0.735
\end{aligned}
$$




$$
\gamma=C_{3} \log \left(\frac{G^{\prime}}{2500 \mathrm{lb} / \mathrm{in} .}\right)=(0.15) \log \left(\frac{10,000 \mathrm{lb} / \mathrm{in} .}{2500 \mathrm{lb} / \mathrm{in} .}\right)=0.090
$$

Finally, the design restraint forces are:

Exterior restraints: $P_{L}=(-963.1 \mathrm{lb})(0.25)[(8)(0.633)+(8)(0.211)]=-1626 \mathrm{lb}(\mathrm{C})$

Check $\left|P_{L}\right| \leq\left|n_{p} P_{0} C_{1}\right|$ :

$$
\left|P_{L}\right|=1626 \mathrm{lb} \leq\left|n_{p} P_{0} C_{1}\right|=(8)(963.1 \mathrm{lb})(0.25)=1926 \mathrm{lb} \rightarrow \mathrm{OK}
$$

Interior restraints: $P_{L}=(-963.1 \mathrm{lb})(0.45)[(8)(0.735)+(8)(0.090)]=-2860 \mathrm{lb}(\mathrm{C})$

$$
\begin{aligned}
& \text { Check }\left|P_{L}\right| \leq\left|n_{p} P_{0} C_{1}\right|: \\
& \left|P_{L}\right|=2860 \mathrm{lb} \leq\left|n_{p} P_{0} C_{1}\right|=(8)(963.1 \mathrm{lb})(0.45)=3467 \mathrm{lb} \rightarrow \mathrm{OK}
\end{aligned}
$$

Shown graphically, the results are:

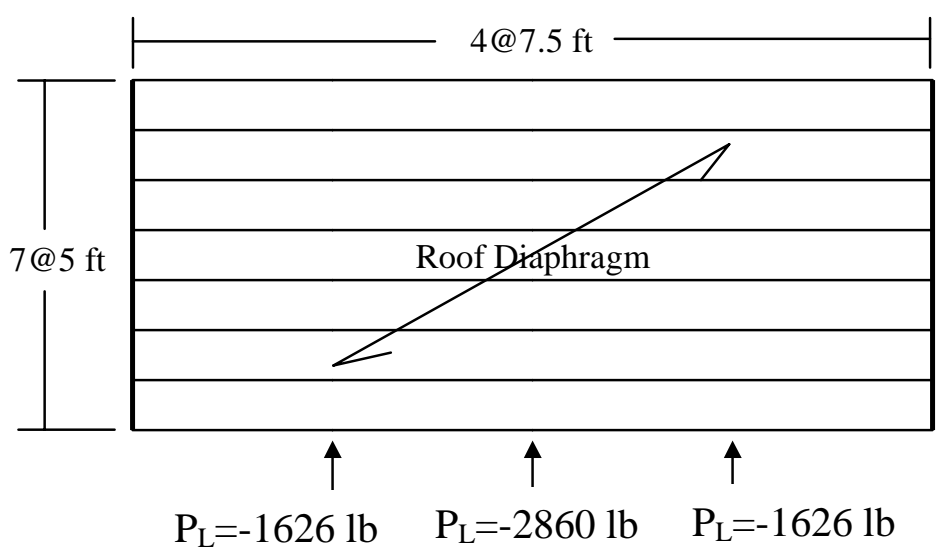

Figure 5.3 Restraint Forces for Example 2

Example 3: Determine restraint forces for a single span system having three parallel purlin lines and third-point plus support restraints. The purlin section is $8 \mathrm{ZS} 2.5 \times 090$, the span length is $25 \mathrm{ft}$, and purlin lines are spaced $5 \mathrm{ft}$ apart. The roof slope is 3:12 and the panel shear stiffness is $2500 \mathrm{lb} / \mathrm{in}$. A uniform gravity load of $20 \mathrm{psf}$ is applied to the system.

Solution: The design equation is given in Figure 5.1: 


$$
P_{L}=P_{0} C_{1}\left(n_{p}^{*} \alpha+n_{p} \gamma\right)
$$

From Table 5.1, for multiple span systems with support restraints:

Exterior restraints: $C_{1}=0.17, C_{2}=3.5, C_{3}=0.35$

Interior restraints: $C_{1}=0.35, C_{2}=3.0, C_{3}=0.05$

For the purlin section 8ZS2.5x090, Table I-16 of the Cold-Formed Steel Design Manual, (1996) gives the following section properties:

$$
d=8 \text { in., } b=2.5 \text { in., } t=0.090 \text { in., } I_{x y}=3.370 \text { in. }^{4}, I_{x}=12.01 \text { in. }^{4}
$$

with

$$
P_{0}=\left[\left(\frac{I_{x y}}{2 I_{x}}+\frac{b}{3 d}\right) \cos \theta-\sin \theta\right] W_{p}
$$

The $\bar{w}=20$ psf gravity load is evenly distributed to all purlin lines:

$$
w=\frac{\bar{w} a\left(n_{p}-1\right)}{n_{p}}=\frac{(20 \mathrm{psf})(5 \mathrm{ft})(3-1)}{3}=66.7 \mathrm{plf}
$$

and

$$
W_{p}=w L=(66.7 \mathrm{plf})(25 \mathrm{ft})=1667 \mathrm{lb}
$$

thus,

$$
P_{0}=\left[\left(\frac{3.370 \mathrm{in}^{4}}{2\left(12.01 \mathrm{in}^{4}\right)}+\frac{2.5 \mathrm{in}}{3(8 \mathrm{in})}\right) \cos 14.04^{0}-\sin 14.04^{0}\right](1667 \mathrm{lb})=-9.2 \mathrm{lb}
$$

with

$$
\alpha=1-C_{2}\left(\frac{t}{d}\right)\left(n_{p}^{*}-1\right)
$$

and

$$
n_{p}^{*}=\min \left\{n_{p}, n_{p(\max )}\right\}, n_{p(\max )}=0.5+\frac{d}{2 C_{2} t}
$$

For the exterior restraints:

$$
n_{p(\max )}=0.5+\frac{8 \text { in. }}{2(3.5)(0.090 \text { in. })}=13.19>3 \rightarrow n_{p}^{*}=3
$$




$$
\alpha=1-3.5\left(\frac{0.090 \text { in. }}{8 \text { in. }}\right)(3-1)=0.921
$$

For the interior restraints:

$$
\begin{aligned}
& n_{p(\max )}=0.5+\frac{8 \text { in. }}{2(3.0)(0.090 \text { in. })}=15.31<3 \rightarrow n_{p}^{*}=3 \\
& \alpha=1-3.0\left(\frac{0.090 \text { in. }}{8 \text { in. }}\right)(3-1)=0.933
\end{aligned}
$$

The roof panel shear stiffness modifier:

$$
\gamma=C_{3} \log \left(\frac{G^{\prime}}{2500 \mathrm{lb} / \mathrm{in} .}\right) G^{\prime}=2500 \mathrm{lb} / \mathrm{in} . \rightarrow \gamma=0
$$

Finally, the final design restraint forces are:

Exterior restraints: $P_{L}=(-9.2 \mathrm{lb})(0.17)[(3)(0.921)+(3)(0)]=-4 \mathrm{lb}$

Interior restraints: $P_{L}=(-9.2 \mathrm{lb})(0.35)[(3)(0.933)+(3)(0)]=-9 \mathrm{lb}$

Since $\left|P_{L}\right| \leq 100 \mathrm{lb}$ for all restraints in the system, no lateral restraint is necessary. 


\section{CHAPTER VI}

\section{SUMMARY, CONCLUSIONS, AND RECOMMENDATIONS}

\subsection{SUMMARY}

A design procedure for the prediction of lateral restraint forces in Z-purlin supported, sloped roofs under gravity loads has been formulated in this research. The procedure applies to both single and multiple span systems for five lateral restraint configurations: support, third-point, midspan, quarter-point, and third-point plus support restraints. To develop the design procedure, a mathematical model was created to collect restraint force data, because experimental research on sloped roofs is both difficult and costly to perform. A first order, linear, elastic stiffness model was used to represent the Z-purlin roof system as a space truss. The model was based on that used by Elhouar and Murray (1985) to develop the current design equations in the American Iron and Steel Institute Specification for the Design of Cold-Formed Steel Structural Members (1996).

The data resulting from the stiffness model was used to develop theoretical expressions to predict restraint force. A new treatment of purlin forces and system effects in Z-purlin roof systems led to a new form of restraint force design equation. The proposed equation postulates that the predicted restraint force in any given system is equal to the force on a single purlin multiplied by the total number of purlins, a brace location factor, a reduction factor caused by system effects, and modified by a factor for roof panel stiffness. The equation predicts the restraint force for any value of roof panel shear stiffness between $1000 \mathrm{lb} / \mathrm{in}$. and 100,000 lb/in. The treatment of roof slope in the proposed equation is more accurate than the current specification, and the intercept slope angle (where restraint force is zero) depends only upon purlin cross-sectional properties. The proposed equation also identifies a range of roof slopes for which a given roof system does not require any lateral restraint.

The theoretical equation was developed with three coefficients that are dependent

on the bracing configuration. The values of these coefficients were determined by 
analyses of the restraint force data collected from the stiffness model. A weighted, leastsquares regression was utilized, and the effectiveness of the regression model was measured by $R^{2}$, the coefficient of determination.

\subsection{CONCLUSIONS}

A design procedure has been formulated to predict the required restraint force for Z-purlin supported roof systems under gravity loads. The equation accounts for roof systems of any slope and panel shear stiffness (between $1000 \mathrm{lb} / \mathrm{in}$. and 100,000 lb/in.). The procedure applies to single and multiple span systems with the following bracing configurations: support, third-point, midspan, quarter-point, and third-point plus support restraints. The form of the design equation is based on statics, and was verified by comparison to results of elastic stiffness models. Coefficients, to account for variations in system interactions, were determined by a statistical analysis of the model results and depend on the bracing configuration. The proposed procedure is summarized in Figure 5.1 and the coefficients are given in Table 5.1.

For accuracy, $n_{p(\max )}$ should be left in decimal form instead of rounding to whole numbers. This equation applies only to gravity loads, not uplift, and is only valid for systems with all purlin top flanges facing in the same direction (see Figure 3.2). The proposed procedure applies to both standing seam and through-fastened roof systems. Note that all of the relationships in the procedure are dimensionless, except for the roof panel shear stiffness. The panel stiffness modifier, $\gamma$, was calibrated such that $G$ is in lb/in.).

\subsection{RECOMMENDATIONS}

The American Iron and Steel Institute's Specification for the Design of ColdFormed Steel Structural Members (1996) has provisions for the prediction of restraint forces for Z-purlin supported roofs under gravity loads. This research has developed a design procedure for the prediction of restraint forces for all of the bracing configurations addressed by the AISI Provisions (support, third-point, and midspan restraints) and the 
research by Danza and Murray in 1998 (quarter-point and third-point plus support restraints). The empirical equations contained in the AISI Provisions and the Danza and Murray research lack a strong connection to engineering principles, and each work presents different forms for the final solution. The design procedure proposed here is unified for all bracing configurations and is a more accurate representation of Z-purlin roof systems. It is recommended that the current AISI Provisions be revised to include the proposed design equation. Also, the proposed design procedure should be verified for use with roof systems consisting of more than eight purlin lines, by comparison to experimental or model testing. 


\section{REFERENCES}

Cold-Formed Steel Design Manual, (1996). American Iron and Steel Institute, Washington, D. C.

Curtis, L. E. and Murray, T. M. (1983). "Simple Span Z-purlin Tests to Determine Restraint force Accumulation," Fears Structural Engineering Laboratory Report No. FSEL/MBMA 83-02, University of Oklahoma, Norman, Oklahoma, 197 pages.

Danza, M. A. and Murray, T. M. (1998). "Lateral Restraint Forces in Quarter-point and Third-point Plus Support Braced Z-purlin Supported Roof Systems," Research Report CE/VPI-ST-99/07, Department of Civil and Environmental Engineering, Virginia Polytechnic Institute and State University, Blacksburg, Virginia, 129 pages.

Elhouar, S. and Murray, T. M. (1985). "Prediction of Lateral Restraint Forces for Zpurlin Supported Roof Systems," Fears Structural Engineering Laboratory Report No. FSEL/AISI 85-01, University of Oklahoma, Norman, Oklahoma, 107 pages.

Fenske, T. E. and Yener, M. (1990). "Analysis and Design of Light Gage Steel Roof Systems," Thin-Walled Structures, 10(3), 221-234.

Fisher, J. M. and LaBoube R. A. A Guide for Designing with Standing Seam Roof Panels (1997). AISI Design Guide CF97-1, American Iron and Steel Institute, Washington, D.C.

Ghazanfari, A. and Murray, T. M. (1982). "Simple Span Z-purlin Tests with Various Restraint Systems," Fears Structural Engineering Laboratory Report No. FSEL/MBMA 82-01A, University of Oklahoma, Norman, Oklahoma, 47 pages.

Ghazanfari, A. and Murray, T. M. (1983). "Prediction of Lateral Restraint Forces of Single Span Z-purlins with Experimental Verification," Fears Structural Engineering Laboratory Report No. FSEL/MBMA 83-04, University of Oklahoma, Norman, Oklahoma, 131 pages.

Heinz, D. A. (1994). "Application of Generalized Beam Theory to the Design of ThinWalled Purlins," Thin-Walled Structures, 19(2-4), 311-335.

Lucas, F. G., Al-Bermani, G. A., and Kitipornchai, S. (1997). "Modelling of ColdFormed Purlin-Sheeting Systems," Thin-Walled Structures, 27(3), 223-243.

Needham, J. R. (1981). "Review of the Bending Mechanics of Cold-Formed Z-purlins," Department of Civil Engineering, University of Kansas. 


\section{REFERENCES, CONTINUED}

Rivard, P. and Murray, T. M. (1986). "Anchorage Forces in Two Purlin Line Standing Seam Z-purlin Supported Roof Systems," Fears Structural Engineering Laboratory Report No. FSEL/MBMA 86-01, University of Oklahoma, Norman, Oklahoma, 178 pages.

Seshappa, V. and Murray, T. M. (1985). "Experimental Studies of Z-purlin Supported Roof Systems Using Quarter Scale Models," Fears Structural Engineering Laboratory Report No. FSEL/MBMA 85-02, University of Oklahoma, Norman, Oklahoma, 81 pages.

SigmaPlot (1999). Version 5.0, SPSS, Inc., Chicago, Illinois

Specification for the Design of Cold-Formed Steel Structural Members (1996). American Iron and Steel Institute, Washington, D.C.

Zetlin, L. and Winter, G. (1955). "Unsymmetrical Bending of Beams with and without Lateral Bracing," Proceedings of the American Society of Civil Engineers, Vol. 81, 774-1 to $774-20$. 
APPENDIX A: STIFFNESS MODEL EXAMPLE 
This appendix describes how to construct a typical stiffness model used in this research. For the example roof system shown in Figure A.1, the section properties for each element in the model are given, along with calculations for determining the applied loads. Then, analysis results given and compared to the restraint forces predicted by the proposed design procedure. Refer to Chapter II for a full discussion of the stiffness model.

Given: A single span system with four purlin lines and third-point restraints. The purlin cross-section is 10ZS3x075, span length is $30 \mathrm{ft}$, and purlin lines are spaced $5 \mathrm{ft}$ apart. The roof slope is 1:12 and the roof panel shear stiffness is $2500 \mathrm{lb} / \mathrm{in}$. The applied gravity load is $w=100$ plf along each purlin line.

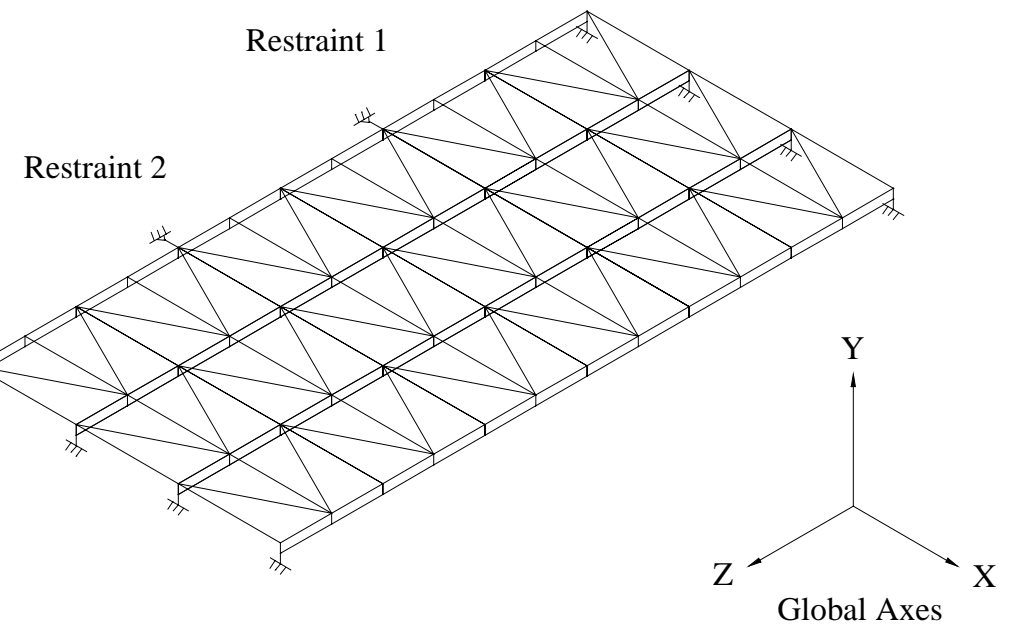

Figure A.1 Example Model

Model Parameters: For the purlin section 10ZS3x075, Table I-16 of the Cold-Formed Steel Design Manual, (1996) gives the following section properties:

$$
\begin{aligned}
& d=10 \text { in., } b=3 \text { in., } t=0.075 \text { in., Area=1.279 in. }{ }^{2}, I_{x 2}=1.07 \text { in. }^{4}, I_{y 2}=20.29 \text { in. }^{4}, \\
& \theta=74.90 \text { degrees, } J=0.00240 \text { in. }^{4}
\end{aligned}
$$

Based on these section properties, the element properties are: 
Table A.1 Section Properties for Example Model

\begin{tabular}{|c|c|c|c|c|}
\hline Element Type & Area $\left(\right.$ in. $\left.^{2}\right)$ & $\mathrm{I}_{\mathrm{yy}}\left(\right.$ in. $\left.^{4}\right)$ & $\mathrm{I}_{\mathrm{zz}}$ (in. $\left.{ }^{4}\right)$ & $\mathrm{J}$ (in. $\left.{ }^{4}\right)$ \\
\hline A & 1.279 & 1.07 & 20.29 & 10 \\
\hline B & 2.25 & 0.00240 & 0.001055 & 1.07 \\
\hline C & 13.50 & 0.00240 & 1 & 1.07 \\
\hline D & 0.0377 & 0.001 & 0.001 & 0.001 \\
\hline E & 0.333 & 0.001 & 0.001 & 0.001 \\
\hline F & 2.25 & 0.00240 & 0.00527 & 1.07 \\
\hline
\end{tabular}

The $\mathrm{x}$-axis rotation for type A elements is: $270+\theta=270+74.90=344.9$ degrees

Loading: Distributed load applied to type A elements along the principal axes:

$$
\begin{aligned}
& w_{y}=w \cdot \cos \theta \cdot \cos \theta_{p}=(-100 \mathrm{plf}) \cos \left(4.76^{\circ}\right) \cos \left(15.10^{\circ}\right)=-0.0096 \mathrm{k} / \mathrm{ft} \\
& w_{z}=w \cdot \cos \theta \cdot \sin \theta_{p}=(-100 \mathrm{plf}) \cos \left(4.76^{\circ}\right) \sin \left(15.10^{\circ}\right)=-0.0026 \mathrm{k} / \mathrm{ft}
\end{aligned}
$$

Distributed downslope load: $w_{d s}=w \sin \theta=(-100 \mathrm{plf}) \sin \left(4.76^{\circ}\right)=-0.008 \mathrm{k} / \mathrm{ft}$

Total torque acting on each purlin line:

$$
T=\frac{b w_{w e b} L}{3}=\frac{(0.25 \mathrm{ft})(-0.100 \mathrm{k} / \mathrm{ft}) \cos \left(4.76^{\circ}\right)(30 \mathrm{ft})}{3}=-0.249 \mathrm{k} \cdot \mathrm{ft}
$$

Point torque on inside joints: $\frac{T}{24}=\frac{-0.249 \mathrm{k} \cdot \mathrm{ft}}{24}=-0.0104 \mathrm{k} \cdot \mathrm{ft}$

Point torque on outside joints: $\frac{T}{48}=\frac{-0.249 \mathrm{k} \cdot \mathrm{ft}}{48}=-0.0052 \mathrm{k} \cdot \mathrm{ft}$

Analysis Results: Due to symmetry, the two braces have the same restraint force:

Restraints 1 \& 2: $P_{L}=734 \mathrm{lb}$.

\section{Results of Proposed Design Procedure:}

Restraints $1 \& 2: P_{L}=780 \mathrm{lb}$. 
APPENDIX B: MODEL LOADS AND SECTION PROPERTIES 
Table B.1 Model Loading

\begin{tabular}{|c|c|c|c|c|c|c|c|c|}
\hline \multirow[t]{2}{*}{ Purlin ID } & \multirow[t]{2}{*}{$\begin{array}{l}\text { Roof } \\
\text { Slope }\end{array}$} & \multirow[t]{2}{*}{$\begin{array}{c}\theta \\
(\operatorname{deg})\end{array}$} & \multirow[t]{2}{*}{$\begin{array}{c}w_{\mathrm{ds}} \\
(\mathbf{k} / \mathbf{f t})\end{array}$} & \multirow[t]{2}{*}{$\begin{array}{c}\mathbf{w}_{\mathbf{y}} \\
(\mathbf{k} / \mathbf{f t})\end{array}$} & \multirow[t]{2}{*}{$\begin{array}{c}\mathbf{w}_{\mathbf{z}} \\
(\mathbf{k} / \mathbf{f t})\end{array}$} & \multirow[t]{2}{*}{$\begin{array}{l}\text { Dist. T } \\
\text { (k-ft/ft) }\end{array}$} & \multicolumn{2}{|c|}{$\begin{array}{c}\text { Inside Point T } \\
\text { (k-ft) }\end{array}$} \\
\hline & & & & & & & $\mathbf{L}_{1}$ & $\mathbf{L}_{2}$ \\
\hline & $0: 12$ & 0 & 0 & -0.097 & -0.022 & -0.00903 & -0.014 & \\
\hline \multirow{2}{*}{$\begin{array}{c}\text { P1 } \\
\left(\mathrm{L}_{1}=36 \mathrm{ft}\right)\end{array}$} & $1 / 2: 12$ & 2.39 & -0.004 & -0.097 & -0.022 & -0.00902 & -0.014 & \\
\hline & $1: 12$ & 4.76 & -0.008 & -0.097 & -0.022 & -0.00900 & -0.013 & \\
\hline \multirow{8}{*}{$\begin{array}{l}\mathrm{x} \text {-axis rotate } \\
=347.1 \mathrm{deg}\end{array}$} & $2: 12$ & 9.46 & -0.016 & -0.096 & -0.022 & -0.00891 & -0.013 & \\
\hline & $3: 12$ & 14.04 & -0.024 & -0.095 & -0.022 & -0.00876 & -0.013 & \\
\hline & $4: 12$ & 18.43 & -0.032 & -0.092 & -0.021 & -0.00856 & -0.013 & \\
\hline & $5: 12$ & 22.62 & -0.039 & -0.090 & -0.021 & -0.00833 & -0.012 & \\
\hline & $6: 12$ & 26.57 & -0.045 & -0.087 & -0.020 & -0.00807 & -0.012 & \\
\hline & $7: 12$ & 30.26 & -0.050 & -0.084 & -0.019 & -0.00780 & -0.012 & \\
\hline & $8: 12$ & 33.69 & -0.056 & -0.081 & -0.019 & -0.00751 & -0.011 & \\
\hline & $9: 12$ & 36.87 & -0.060 & -0.078 & -0.018 & -0.00722 & -0.011 & \\
\hline \multirow{4}{*}{$\begin{array}{c}\text { P2, P3 } \\
\left(\mathrm{L}_{1}=35 \mathrm{ft}\right) \\
\left(\mathrm{L}_{2}=30 \mathrm{ft}\right)\end{array}$} & $0: 12$ & 0 & 0 & -0.097 & -0.026 & -0.00833 & -0.012 & -0.010 \\
\hline & $1 / 2: 12$ & 2.39 & -0.004 & -0.097 & -0.026 & -0.00833 & -0.012 & -0.010 \\
\hline & $1: 12$ & 4.76 & -0.008 & -0.096 & -0.026 & -0.00830 & -0.012 & -0.010 \\
\hline & $2: 12$ & 9.46 & -0.016 & -0.095 & -0.025 & -0.00822 & -0.012 & -0.010 \\
\hline \multirow{7}{*}{$\begin{array}{l}\mathrm{x} \text {-axis rotate } \\
=345.1 \mathrm{deg}\end{array}$} & $3: 12$ & 14.04 & -0.024 & -0.094 & -0.025 & -0.00808 & -0.012 & -0.010 \\
\hline & $4: 12$ & 18.43 & -0.032 & -0.092 & -0.024 & -0.00791 & -0.012 & -0.010 \\
\hline & $5: 12$ & 22.62 & -0.039 & -0.089 & -0.024 & -0.00769 & -0.011 & -0.010 \\
\hline & $6: 12$ & 26.57 & -0.045 & -0.086 & -0.023 & -0.00745 & -0.011 & -0.009 \\
\hline & $7: 12$ & 30.26 & -0.050 & -0.083 & -0.022 & -0.00720 & -0.010 & -0.009 \\
\hline & $8: 12$ & 33.69 & -0.056 & -0.080 & -0.021 & -0.00693 & -0.010 & -0.009 \\
\hline & $9: 12$ & 36.87 & -0.060 & -0.077 & -0.021 & -0.00667 & -0.010 & -0.008 \\
\hline \multirow{4}{*}{$\begin{array}{c}\text { P4, P5 } \\
\left(\mathrm{L}_{1}=35 \mathrm{ft}\right) \\
\left(\mathrm{L}_{2}=30 \mathrm{ft}\right)\end{array}$} & $0: 12$ & 0 & 0 & -0.097 & -0.026 & -0.00833 & -0.012 & -0.010 \\
\hline & $1 / 2: 12$ & 2.39 & -0.004 & -0.096 & -0.026 & -0.00833 & -0.012 & -0.010 \\
\hline & $1: 12$ & 4.76 & -0.008 & -0.096 & -0.026 & -0.00830 & -0.012 & -0.010 \\
\hline & $2: 12$ & 9.46 & -0.016 & -0.095 & -0.026 & -0.00822 & -0.012 & -0.010 \\
\hline \multirow{7}{*}{$\begin{array}{l}\mathrm{x} \text {-axis rotate } \\
=344.9 \mathrm{deg}\end{array}$} & $3: 12$ & 14.04 & -0.024 & -0.094 & -0.025 & -0.00808 & -0.012 & -0.010 \\
\hline & $4: 12$ & 18.43 & -0.032 & -0.092 & -0.025 & -0.00791 & -0.012 & -0.010 \\
\hline & $5: 12$ & 22.62 & -0.039 & -0.089 & -0.024 & -0.00769 & -0.011 & -0.010 \\
\hline & $6: 12$ & 26.57 & -0.045 & -0.086 & -0.023 & -0.00745 & -0.011 & -0.009 \\
\hline & $7: 12$ & 30.26 & -0.050 & -0.083 & -0.023 & -0.00720 & -0.010 & -0.009 \\
\hline & $8: 12$ & 33.69 & -0.056 & -0.080 & -0.022 & -0.00693 & -0.010 & -0.009 \\
\hline & $9: 12$ & 36.87 & -0.060 & -0.077 & -0.021 & -0.00667 & -0.010 & -0.008 \\
\hline \multirow{4}{*}{$\begin{array}{c}\text { P6, P7 } \\
\left(\mathrm{L}_{1}=25 \mathrm{ft}\right) \\
\left(\mathrm{L}_{2}=20 \mathrm{ft}\right)\end{array}$} & $0: 12$ & 0 & 0 & -0.096 & -0.029 & -0.00694 & -0.007 & -0.006 \\
\hline & $1 / 2: 12$ & 2.39 & -0.004 & -0.096 & -0.029 & -0.00694 & -0.007 & -0.006 \\
\hline & $1: 12$ & 4.76 & -0.008 & -0.095 & -0.029 & -0.00692 & -0.007 & -0.006 \\
\hline & $2: 12$ & 9.46 & -0.016 & -0.094 & -0.028 & -0.00685 & -0.007 & -0.006 \\
\hline \multirow{7}{*}{$\begin{array}{l}\mathrm{x} \text {-axis rotate } \\
=343.3 \mathrm{deg}\end{array}$} & $3: 12$ & 14.04 & -0.024 & -0.093 & -0.028 & -0.00674 & -0.007 & -0.006 \\
\hline & $4: 12$ & 18.43 & -0.032 & -0.091 & -0.027 & -0.00659 & -0.007 & -0.005 \\
\hline & $5: 12$ & 22.62 & -0.039 & -0.088 & -0.027 & -0.00641 & -0.007 & -0.005 \\
\hline & $6: 12$ & 26.57 & -0.045 & -0.086 & -0.026 & -0.00621 & -0.006 & -0.005 \\
\hline & $7: 12$ & 30.26 & -0.050 & -0.083 & -0.025 & -0.00600 & -0.006 & -0.005 \\
\hline & $8: 12$ & 33.69 & -0.056 & -0.080 & -0.024 & -0.00578 & -0.006 & -0.005 \\
\hline & $9: 12$ & 36.87 & -0.060 & -0.077 & -0.023 & -0.00556 & -0.006 & -0.005 \\
\hline
\end{tabular}


Table B.1 Model Loading, Continued

\begin{tabular}{|c|c|c|c|c|c|c|c|c|}
\hline P8, P9 & $0: 12$ & 0 & 0 & -0.096 & -0.029 & -0.00694 & -0.007 & -0.006 \\
$\left(\mathrm{~L}_{1}=25 \mathrm{ft}\right)$ & $1 / 2: 12$ & 2.39 & -0.004 & -0.096 & -0.029 & -0.00694 & -0.007 & -0.006 \\
$\left(\mathrm{~L}_{2}=20 \mathrm{ft}\right)$ & $1: 12$ & 4.76 & -0.008 & -0.095 & -0.029 & -0.00692 & -0.007 & -0.006 \\
& $2: 12$ & 9.46 & -0.016 & -0.094 & -0.028 & -0.00685 & -0.007 & -0.006 \\
x-axis rotate & $3: 12$ & 14.04 & -0.024 & -0.093 & -0.028 & -0.00674 & -0.007 & -0.006 \\
$=343.2 \mathrm{deg}$ & $4: 12$ & 18.43 & -0.032 & -0.091 & -0.027 & -0.00659 & -0.007 & -0.005 \\
& $5: 12$ & 22.62 & -0.039 & -0.088 & -0.027 & -0.00641 & -0.007 & -0.005 \\
& $6: 12$ & 26.57 & -0.045 & -0.086 & -0.026 & -0.00621 & -0.006 & -0.005 \\
& $7: 12$ & 30.26 & -0.050 & -0.083 & -0.025 & -0.00600 & -0.006 & -0.005 \\
& $8: 12$ & 33.69 & -0.056 & -0.080 & -0.024 & -0.00578 & -0.006 & -0.005 \\
& $9: 12$ & 36.87 & -0.060 & -0.077 & -0.023 & -0.00556 & -0.006 & -0.005 \\
\hline P10 & $0: 12$ & 0 & 0 & -0.094 & -0.033 & -0.00556 & -0.005 & \\
$\left(\mathrm{~L}_{1}=20 \mathrm{ft}\right)$ & $1 / 2: 12$ & 2.39 & -0.004 & -0.094 & -0.033 & -0.00555 & -0.005 & \\
& $1: 12$ & 4.76 & -0.008 & -0.094 & -0.033 & -0.00554 & -0.005 & \\
$\mathrm{x}$-axis rotate & $2: 12$ & 9.46 & -0.016 & -0.093 & -0.033 & -0.00548 & -0.005 & \\
$=340.6 \mathrm{deg}$ & $3: 12$ & 14.04 & -0.024 & -0.091 & -0.032 & -0.00539 & -0.004 & \\
& $4: 12$ & 18.43 & -0.032 & -0.089 & -0.032 & -0.00527 & -0.004 & \\
& $5: 12$ & 22.62 & -0.039 & -0.087 & -0.031 & -0.00513 & -0.004 & \\
& $6: 12$ & 26.57 & -0.045 & -0.084 & -0.030 & -0.00497 & -0.004 & \\
& $7: 12$ & 30.26 & -0.050 & -0.081 & -0.029 & -0.00480 & -0.004 & \\
& $8: 12$ & 33.69 & -0.056 & -0.078 & -0.028 & -0.00462 & -0.004 & \\
& $9: 12$ & 36.87 & -0.060 & -0.075 & -0.027 & -0.00444 & -0.004 & \\
\hline
\end{tabular}

Notes: 1) Distributed loads $w_{y}$ and $w_{z}$ are applied to type A elements, along the principal axes of the cross-section, which are given by the $\mathrm{x}$-axis rotation.

2) Distributed load $w_{d s}$ is the downslope component of the gravity load.

3) $T$ is the torque loading - the point torque for joints on the outside of each purlin line is half of the tabulated point torque for joints on the inside

4) $L_{1}$ and $L_{2}$ are the span lengths that were tested for the given purlin crosssection.

5) The gravity load per purlin is $w=100$ plf.

6) Purlin identifications are given in Table 4.3 
Table B.2 Model Section Properties

\begin{tabular}{|c|c|c|c|c|c|c|c|c|c|c|c|}
\hline ID & $\begin{array}{l}\text { Elem. } \\
\text { Type }\end{array}$ & $\begin{array}{l}\text { Area } \\
\left(\text { in. }^{2}\right)\end{array}$ & $\begin{array}{c}\mathbf{I}_{\mathrm{yy}} \\
\left.\text { (in. }{ }^{2}\right)\end{array}$ & $\begin{array}{c}\mathbf{I}_{\mathrm{zz}} \\
\left(\text { in. }^{4}{ }^{2}\right)\end{array}$ & $\underset{\left(\text { in. }^{4}\right)}{\mathbf{J}}$ & ID & $\begin{array}{l}\text { Elem. } \\
\text { Type }\end{array}$ & $\begin{array}{l}\text { Area } \\
\left(\text { in. }{ }^{2}\right)\end{array}$ & $\begin{array}{c}\mathbf{I}_{\mathrm{yy}_{4}} \\
\left.\text { (in. }{ }^{2}\right)\end{array}$ & $\begin{array}{c}I_{\mathrm{zz}} \\
\left.\text { (in. }{ }^{4}\right)\end{array}$ & $\underset{\left(\text { in. }{ }^{4}\right)}{\mathbf{J}}$ \\
\hline \multirow{6}{*}{ P1 } & $\mathrm{A}$ & 1.177 & 1.12 & 25.85 & 10 & \multirow{6}{*}{ P6 } & $\mathrm{A}$ & 1.261 & 0.776 & 13.02 & 10 \\
\hline & B & 2.16 & 0.00141 & 0.000648 & 1.12 & & B & 2.25 & 0.00340 & 0.001519 & 0.776 \\
\hline & $\mathrm{C}$ & 12.96 & 0.00141 & 1 & 1.12 & & $\mathrm{C}$ & 13.50 & 0.00340 & 1 & 0.776 \\
\hline & D & 0.0451 & 0.001 & 0.001 & 0.001 & & D & 0.0336 & 0.001 & 0.001 & 0.001 \\
\hline & $\mathrm{E}$ & 0.333 & 0.001 & 0.001 & 0.001 & & E & 0.333 & 0.001 & 0.001 & 0.001 \\
\hline & $\mathrm{F}$ & 2.16 & 0.00141 & 0.000324 & 1.12 & & $\mathrm{~F}$ & 2.25 & 0.00340 & 0.000759 & 0.776 \\
\hline \multirow{6}{*}{$\mathbf{P 2}$} & A & 2.275 & 1.83 & 35.47 & 10 & \multirow{6}{*}{ P7 } & A & 1.261 & 0.776 & 13.02 & 10 \\
\hline & B & 4.73 & 0.0138 & 0.007176 & 1.83 & & B & 1.80 & 0.00340 & 0.001215 & 0.776 \\
\hline & $\mathrm{C}$ & 28.35 & 0.0138 & 1 & 1.83 & & $\mathrm{C}$ & 10.80 & 0.00340 & 1 & 0.776 \\
\hline & D & 0.0437 & 0.001 & 0.001 & 0.001 & & D & 0.0321 & 0.001 & 0.001 & 0.001 \\
\hline & E & 0.333 & 0.001 & 0.001 & 0.001 & & E & 0.333 & 0.001 & 0.001 & 0.001 \\
\hline & $\mathrm{F}$ & 4.73 & 0.0138 & 0.007176 & 1.83 & & $\mathrm{~F}$ & 1.80 & 0.00340 & 0.000608 & 0.776 \\
\hline \multirow{6}{*}{ P3 } & $\mathrm{A}$ & 2.275 & 1.83 & 35.47 & 10 & \multirow{6}{*}{ P8 } & $\mathrm{A}$ & 0.847 & 0.532 & 8.84 & 10 \\
\hline & B & 4.05 & 0.0138 & 0.006151 & 1.83 & & B & 1.50 & 0.00102 & 0.000450 & 0.532 \\
\hline & $\mathrm{C}$ & 24.30 & 0.0138 & 1 & 1.83 & & $\mathrm{C}$ & 9.00 & 0.00102 & 1 & 0.532 \\
\hline & D & 0.0377 & 0.001 & 0.001 & 0.001 & & D & 0.0336 & 0.001 & 0.001 & 0.001 \\
\hline & $\mathrm{E}$ & 0.333 & 0.001 & 0.001 & 0.001 & & $\mathrm{E}$ & 0.333 & 0.001 & 0.001 & 0.001 \\
\hline & $\mathrm{F}$ & 4.05 & 0.0138 & 0.003075 & 1.83 & & $\mathrm{~F}$ & 1.50 & 0.00102 & 0.000225 & 0.532 \\
\hline \multirow{6}{*}{ P4 } & $\bar{A}$ & 1.279 & 1.07 & 20.29 & 10 & \multirow{6}{*}{ P9 } & $\bar{A}$ & 0.847 & 0.532 & 8.84 & 10 \\
\hline & B & 2.63 & 0.00240 & 0.00123 & 1.07 & & B & 1.20 & 0.00102 & 0.000360 & 0.532 \\
\hline & $\mathrm{C}$ & 15.75 & 0.00240 & 1 & 1.07 & & $\mathrm{C}$ & 7.20 & 0.00102 & 1 & 0.532 \\
\hline & D & 0.0437 & 0.001 & 0.001 & 0.001 & & D & 0.0321 & 0.001 & 0.001 & 0.001 \\
\hline & $\mathrm{E}$ & 0.333 & 0.001 & 0.001 & 0.001 & & E & 0.333 & 0.001 & 0.001 & 0.001 \\
\hline & $\mathrm{F}$ & 2.63 & 0.00240 & 0.000615 & 1.07 & & $\mathrm{~F}$ & 1.20 & 0.00102 & 0.000180 & 0.532 \\
\hline \multirow{6}{*}{ P5 } & A & 1.279 & 1.07 & 20.29 & 10 & \multirow{6}{*}{ P10 } & A & 1.151 & 0.491 & 6.88 & 10 \\
\hline & B & 2.25 & 0.00240 & 0.001055 & 1.07 & & B & 2.10 & 0.00423 & 0.00193 & 0.491 \\
\hline & $\mathrm{C}$ & 13.50 & 0.00240 & 1 & 1.07 & & $\mathrm{C}$ & 12.60 & 0.00423 & 1 & 0.491 \\
\hline & D & 0.0377 & 0.001 & 0.001 & 0.001 & & D & 0.0321 & 0.001 & 0.001 & 0.001 \\
\hline & E & 0.333 & 0.001 & 0.001 & 0.001 & & E & 0.333 & 0.001 & 0.001 & 0.001 \\
\hline & $\mathrm{F}$ & 2.25 & 0.00240 & 0.000527 & 1.07 & & $\mathrm{~F}$ & 2.10 & 0.00423 & 0.000965 & 0.491 \\
\hline
\end{tabular}

Note: Purlin identifications are given in Table 4.3 
APPENDIX C: RESTRAINT FORCE DATA FROM STIFFNESS MODEL 
This appendix contains tables that give the restraint force results from the current stiffness model for every computer test in the test matrix. The stiffness model is described in Chapter II and the computer test matrix is described in Section 4.3. The test combinations are given in Table 4.6. A more extensive explanation of these tables is presented in Section 4.4. Note that all restraint forces are given in pounds.

Table C.1 Support Restraints, Single Span

\begin{tabular}{|c|c|c|c|c|c|c|c|c|c|c|}
\hline \multicolumn{1}{c|}{} & \multicolumn{9}{|c|}{ Purlin Designation } \\
\hline Combination & P1 & $\mathbf{P 2}$ & $\mathbf{P 3}$ & $\mathbf{P 4}$ & $\mathbf{P 5}$ & $\mathbf{P 6}$ & $\mathbf{P 7}$ & P8 & P9 & P10 \\
\hline $\mathbf{1}$ & 2108 & 1370 & 1160 & 2169 & 1802 & 1246 & 996 & 1597 & 1269 & 736 \\
\hline $\mathbf{2}$ & 1753 & 1095 & 941 & 1764 & 1463 & 1030 & 824 & 1339 & 1048 & 611 \\
\hline $\mathbf{3}$ & 1207 & 828 & 716 & 1370 & 1135 & 821 & 658 & 1066 & 834 & 494 \\
\hline $\mathbf{4}$ & 320 & 234 & 229 & 583 & 480 & 359 & 292 & 483 & 358 & 258 \\
\hline $\mathbf{5}$ & -529 & -272 & -190 & -254 & -219 & -41 & -29 & -19 & -53 & 6 \\
\hline $\mathbf{6}$ & -1427 & -814 & -634 & -966 & -814 & -466 & -367 & -550 & -486 & -206 \\
\hline $\mathbf{7}$ & -2171 & -1262 & -999 & -1712 & -1432 & -810 & -697 & -987 & -847 & -430 \\
\hline $\mathbf{8}$ & -2945 & -1716 & -1381 & -2393 & -2006 & -1177 & -934 & -1446 & -1221 & -634 \\
\hline $\mathbf{9}$ & -3661 & -2148 & -1733 & -2943 & -2461 & -1515 & -1203 & -1868 & -1567 & -823 \\
\hline $\mathbf{1 0}$ & -4209 & -2527 & -2050 & -3516 & -2939 & -1812 & -1442 & -2248 & -1879 & -992 \\
\hline $\mathbf{1 1}$ & -4801 & -2826 & -2293 & -4035 & -3377 & -2092 & -1665 & -2597 & -2166 & -1147 \\
\hline $\mathbf{1 3}$ & 25 & 25 & 21 & 24 & 21 & 18 & 15 & 21 & 19 & 16 \\
\hline $\mathbf{1 4}$ & 669 & 715 & 617 & 771 & 653 & 589 & 464 & 600 & 468 & 486 \\
\hline $\mathbf{1 5}$ & 993 & 968 & 833 & 1125 & 951 & 815 & 646 & 865 & 677 & 614 \\
\hline $\mathbf{1 6}$ & 1280 & 1130 & 967 & 1421 & 1196 & 972 & 772 & 1080 & 848 & 676 \\
\hline $\mathbf{1 7}$ & 1532 & 1232 & 1050 & 1666 & 1397 & 1079 & 859 & 1253 & 988 & 707 \\
\hline $\mathbf{1 8}$ & 1751 & 1342 & 1102 & 1867 & 1560 & 1154 & 921 & 1392 & 1101 & 723 \\
\hline $\mathbf{1 9}$ & 1941 & 1370 & 1136 & 2032 & 1693 & 1208 & 964 & 1504 & 1194 & 732 \\
\hline $\mathbf{2 0}$ & 2717 & 2514 & 2224 & 3044 & 2590 & 2206 & 1777 & 2350 & 1847 & 1561 \\
\hline $\mathbf{2 1}$ & 2652 & 2255 & 2009 & 2903 & 2478 & 2046 & 1654 & 2177 & 1777 & 1387 \\
\hline $\mathbf{2 2}$ & 2488 & 1793 & 1612 & 2582 & 2217 & 1720 & 1398 & 1939 & 1609 & 1086 \\
\hline $\mathbf{2 3}$ & 1876 & 1018 & 912 & 1694 & 1470 & 1021 & 826 & 1370 & 1090 & 613 \\
\hline & & & & & & & & & \\
\hline
\end{tabular}


Table C.2 Support Restraints, Multiple Span, Exterior

\begin{tabular}{|c|c|c|c|c|c|c|c|c|c|c|}
\hline \multicolumn{1}{c|}{} & \multicolumn{9}{|c|}{ Purlin Designation } \\
\hline Combination & $\mathbf{P 1}$ & $\mathbf{P 2}$ & $\mathbf{P 3}$ & $\mathbf{P 4}$ & $\mathbf{P 5}$ & $\mathbf{P 6}$ & $\mathbf{P 7}$ & P8 & P9 & P10 \\
\hline $\mathbf{1}$ & 2044 & 1342 & 1120 & 2031 & 1671 & 1185 & 922 & 1490 & 1166 & 740 \\
\hline $\mathbf{2}$ & 1585 & 1083 & 906 & 1652 & 1356 & 984 & 764 & 1234 & 960 & 625 \\
\hline $\mathbf{3}$ & 1139 & 831 & 699 & 1284 & 1050 & 788 & 610 & 987 & 759 & 512 \\
\hline $\mathbf{4}$ & 248 & 273 & 239 & 548 & 438 & 355 & 272 & 437 & 318 & 289 \\
\hline $\mathbf{5}$ & -605 & -206 & -159 & -234 & -212 & -17 & -22 & -39 & -64 & 51 \\
\hline $\mathbf{6}$ & -1502 & -716 & -580 & -900 & -766 & -413 & -332 & -541 & -468 & -150 \\
\hline $\mathbf{7}$ & -2250 & -1138 & -929 & -1596 & -1343 & -741 & -589 & -956 & -802 & -362 \\
\hline $\mathbf{8}$ & -3024 & -1571 & -1288 & -2236 & -1876 & -1079 & -856 & -1389 & -1149 & -555 \\
\hline $\mathbf{9}$ & -3739 & -1977 & -1623 & -2829 & -2304 & -1394 & -1103 & -1788 & -1470 & -734 \\
\hline $\mathbf{1 0}$ & -4290 & -2338 & -1922 & -3282 & -2746 & -1675 & -1325 & -2147 & -1757 & -895 \\
\hline $\mathbf{1 1}$ & -4881 & -2620 & -2155 & -3773 & -3153 & -1936 & -1529 & -2476 & -2022 & -1043 \\
\hline $\mathbf{1 2}$ & 24 & 25 & 21 & 24 & 21 & 18 & 15 & 21 & 18 & 15 \\
\hline $\mathbf{1 3}$ & 557 & 665 & 574 & 665 & 567 & 540 & 427 & 530 & 416 & 479 \\
\hline $\mathbf{1 4}$ & 848 & 930 & 798 & 999 & 854 & 775 & 611 & 793 & 625 & 619 \\
\hline $\mathbf{1 5}$ & 1131 & 1102 & 937 & 1296 & 1101 & 935 & 734 & 1012 & 796 & 685 \\
\hline $\mathbf{1 6}$ & 1398 & 1208 & 1019 & 1544 & 1301 & 1039 & 813 & 1184 & 928 & 716 \\
\hline $\mathbf{1 7}$ & 1641 & 1273 & 1069 & 1745 & 1456 & 1107 & 864 & 1314 & 1029 & 730 \\
\hline $\mathbf{1 8}$ & 1855 & 1314 & 1100 & 1903 & 1577 & 1153 & 899 & 1413 & 1106 & 738 \\
\hline $\mathbf{2 0}$ & 2455 & 2551 & 2275 & 2849 & 2482 & 2282 & 1866 & 2343 & 1885 & 1850 \\
\hline $\mathbf{2 1}$ & 2366 & 2255 & 1999 & 2694 & 2328 & 2041 & 1652 & 2177 & 1736 & 1524 \\
\hline $\mathbf{2 2}$ & 2245 & 1772 & 1570 & 2417 & 2079 & 1675 & 1344 & 1939 & 1532 & 1132 \\
\hline $\mathbf{2 3}$ & 2171 & 1585 & 1404 & 2269 & 1950 & 1451 & 1158 & 1761 & 1386 & 945 \\
\hline & 1702 & 988 & 865 & 1577 & 1350 & 963 & 756 & 1268 & 986 & 612 \\
\hline
\end{tabular}

Table C.3 Support Restraints, Multiple Span, Interior

\begin{tabular}{|c|c|c|c|c|c|c|c|c|c|c|}
\hline \multirow[b]{2}{*}{ Combination } & \multicolumn{10}{|c|}{ Purlin Designation } \\
\hline & P1 & P2 & P3 & P4 & P5 & P6 & P7 & P8 & P9 & P10 \\
\hline 1 & 3656 & 1981 & 1525 & 3383 & 2634 & 1707 & 1235 & 2307 & 1712 & 1035 \\
\hline 2 & 2804 & 1609 & 1231 & 2744 & 2124 & 1417 & 1017 & 1900 & 1394 & 884 \\
\hline 3 & 1975 & 1247 & 946 & 2123 & 1628 & 1136 & 804 & 1507 & 1085 & 737 \\
\hline 4 & 317 & 453 & 320 & 882 & 635 & 516 & 339 & 640 & 410 & 443 \\
\hline 5 & -1270 & -242 & -231 & -432 & -414 & -24 & -68 & -116 & -182 & 131 \\
\hline 6 & -2926 & -968 & -802 & -1555 & -1311 & -590 & -492 & -909 & -798 & -135 \\
\hline 7 & -4320 & -1574 & -1281 & -2719 & -2245 & -1062 & -853 & -1571 & -1318 & -413 \\
\hline 8 & -5749 & -2207 & -1781 & -3803 & -3099 & -1555 & -1219 & -2254 & -1848 & -669 \\
\hline 9 & -7068 & -2784 & -2234 & -4794 & -3793 & -2005 & 1556 & -2885 & -2336 & -906 \\
\hline 10 & -8098 & -3310 & -2648 & -5570 & -4514 & -2413 & -1866 & -3452 & -2781 & -1118 \\
\hline 11 & -9180 & -3714 & -2968 & -6388 & -5165 & -2785 & -2143 & -3972 & -3184 & -1314 \\
\hline 12 & 49 & 53 & 45 & 50 & 44 & 37 & 31 & 42 & 37 & 32 \\
\hline 13 & 1287 & 1222 & 958 & 1448 & 1193 & 958 & 711 & 1072 & 784 & 799 \\
\hline 14 & 1885 & 1605 & 1255 & 2061 & 1650 & 1315 & 953 & 1491 & 1095 & 964 \\
\hline 15 & 2372 & 1785 & 1388 & 2493 & 1980 & 1485 & 1077 & 1770 & 1303 & 1015 \\
\hline 16 & 2774 & 1880 & 1456 & 2810 & 2216 & 1583 & 1147 & 1968 & 1452 & 1032 \\
\hline 17 & 3114 & 1933 & 1493 & 3050 & 2394 & 1644 & 1191 & 2113 & 1563 & 1037 \\
\hline 18 & 3401 & 1959 & 1510 & 3232 & 2527 & 1680 & 1216 & 2220 & 1645 & 1035 \\
\hline 19 & 5233 & 5202 & 4369 & 6010 & 4969 & 4338 & 3302 & 4490 & 3359 & 3438 \\
\hline 20 & 5020 & 4288 & 3629 & 5539 & 4602 & 3816 & 2915 & 4204 & 3159 & 2790 \\
\hline 21 & 4419 & 2963 & 2506 & 4504 & 3751 & 2835 & 2154 & 3476 & 2610 & 1867 \\
\hline 22 & 4111 & 2519 & 2123 & 4043 & 3368 & 2292 & 1728 & 2980 & 2231 & 1455 \\
\hline 23 & 2669 & 1271 & 1043 & 2305 & 1901 & 1264 & 922 & 1811 & 1329 & 787 \\
\hline
\end{tabular}


Table C.4 Third-point Restraints, Single Span

\begin{tabular}{|c|c|c|c|c|c|c|c|c|c|c|}
\hline \multicolumn{1}{c|}{} & \multicolumn{9}{|c|}{ Purlin Designation } \\
\hline Combination & $\mathbf{P 1}$ & $\mathbf{P 2}$ & $\mathbf{P 3}$ & $\mathbf{P 4}$ & $\mathbf{P 5}$ & $\mathbf{P 6}$ & $\mathbf{P 7}$ & P8 & P9 & P10 \\
\hline $\mathbf{1}$ & 2335 & 1775 & 1526 & 2346 & 1977 & 1508 & 1208 & 1779 & 1406 & 1081 \\
\hline $\mathbf{2}$ & 1825 & 1431 & 1238 & 1910 & 1611 & 1254 & 1006 & 1478 & 1166 & 913 \\
\hline $\mathbf{3}$ & 1328 & 1098 & 958 & 1487 & 1255 & 1007 & 810 & 1189 & 933 & 748 \\
\hline $\mathbf{4}$ & 337 & 352 & 338 & 640 & 543 & 455 & 375 & 540 & 420 & 423 \\
\hline $\mathbf{5}$ & -612 & -278 & -197 & -261 & -214 & -13 & 0 & -17 & -27 & 74 \\
\hline $\mathbf{6}$ & -1615 & -961 & -768 & -1027 & -858 & -517 & -401 & -609 & -500 & -218 \\
\hline $\mathbf{7}$ & -2447 & -1506 & -1226 & -1825 & -1539 & -932 & -722 & -1093 & -890 & -528 \\
\hline $\mathbf{8}$ & -3312 & -2095 & -1719 & -2569 & -2149 & -1355 & -1067 & -1604 & -1291 & -811 \\
\hline $\mathbf{9}$ & -4112 & -2640 & -2164 & -3161 & -2727 & -1758 & -1386 & -2074 & -1668 & -1073 \\
\hline $\mathbf{1 0}$ & -4727 & -3106 & -2575 & -3765 & -3160 & -2111 & -1665 & -2496 & -2002 & -1308 \\
\hline $\mathbf{1 1}$ & -5385 & -3479 & -2888 & -4335 & -3638 & -2445 & -1929 & -2884 & -2314 & -1524 \\
\hline $\mathbf{1 2}$ & 267 & 304 & 262 & 308 & 263 & 242 & 193 & 242 & 190 & 212 \\
\hline $\mathbf{1 3}$ & 615 & 608 & 530 & 670 & 580 & 507 & 411 & 536 & 430 & 420 \\
\hline $\mathbf{1 4}$ & 945 & 894 & 779 & 1021 & 878 & 751 & 607 & 806 & 643 & 605 \\
\hline $\mathbf{1 5}$ & 1258 & 1141 & 992 & 1344 & 1150 & 962 & 776 & 1050 & 835 & 755 \\
\hline $\mathbf{1 6}$ & 1554 & 1349 & 1170 & 1638 & 1396 & 1140 & 918 & 1269 & 1007 & 874 \\
\hline $\mathbf{1 7}$ & 1832 & 1522 & 1316 & 1902 & 1614 & 1289 & 1035 & 1462 & 1159 & 965 \\
\hline $\mathbf{1 8}$ & 2092 & 1663 & 1433 & 2138 & 1808 & 1410 & 1131 & 1632 & 1291 & 1032 \\
\hline $\mathbf{2 0}$ & 2720 & 2518 & 2236 & 3047 & 2596 & 2215 & 1786 & 2355 & 1852 & 1576 \\
\hline $\mathbf{2 1}$ & 2663 & 2306 & 2062 & 2919 & 2498 & 2078 & 1683 & 2273 & 1794 & 1444 \\
\hline $\mathbf{2 2}$ & 2524 & 2000 & 1784 & 2651 & 2285 & 1825 & 1484 & 2090 & 1659 & 1254 \\
\hline $\mathbf{2 3}$ & 2450 & 1897 & 1684 & 2527 & 2183 & 1676 & 1361 & 1957 & 1558 & 1166 \\
\hline & 2070 & 1630 & 1405 & 2042 & 1758 & 1381 & 1106 & 1613 & 1283 & 1041 \\
\hline
\end{tabular}

Table C.5 Third-point Restraints, Multiple Span, Exterior

\begin{tabular}{|c|c|c|c|c|c|c|c|c|c|c|}
\hline \multicolumn{1}{c|}{} & \multicolumn{10}{c|}{ Purlin Designation } \\
\hline Combination & P1 & P2 & P3 & P4 & P5 & P6 & P7 & P8 & P9 & P10 \\
\hline $\mathbf{1}$ & 2276 & 1786 & 1512 & 2304 & 1923 & 1486 & 1168 & 1716 & 1348 & 1105 \\
\hline $\mathbf{2}$ & 1773 & 1452 & 1233 & 1879 & 1567 & 1240 & 975 & 1428 & 1117 & 941 \\
\hline $\mathbf{3}$ & 1284 & 1127 & 963 & 1465 & 1222 & 1002 & 788 & 1149 & 893 & 782 \\
\hline $\mathbf{4}$ & 307 & 402 & 359 & 639 & 530 & 469 & 370 & 528 & 396 & 466 \\
\hline $\mathbf{5}$ & -628 & -214 & -155 & -241 & -205 & 16 & 13 & -7 & -30 & 128 \\
\hline $\mathbf{6}$ & -1614 & -877 & -707 & -989 & -830 & -471 & -369 & -575 & -484 & -156 \\
\hline $\mathbf{7}$ & -2434 & -1421 & -1154 & -1775 & -1486 & -871 & -684 & -1040 & -856 & -458 \\
\hline $\mathbf{8}$ & -3285 & -1978 & -1631 & -2490 & -2085 & -1283 & -1008 & -1530 & -1247 & -734 \\
\hline $\mathbf{9}$ & -4071 & -2508 & -2071 & -3067 & -2568 & -1672 & -1313 & -1981 & -1609 & -989 \\
\hline $\mathbf{1 0}$ & -4674 & -2973 & -2457 & -3664 & -3067 & -2014 & -1584 & -2386 & -1930 & -1218 \\
\hline $\mathbf{1 1}$ & -5324 & -3336 & -2760 & -4219 & -3530 & -2336 & -1836 & -2759 & -2229 & -1429 \\
\hline $\mathbf{1 2}$ & 270 & 317 & 272 & 319 & 270 & 252 & 198 & 249 & 191 & 223 \\
\hline $\mathbf{1 3}$ & 645 & 625 & 544 & 691 & 597 & 520 & 421 & 549 & 442 & 436 \\
\hline $\mathbf{1 4}$ & 983 & 916 & 795 & 1045 & 896 & 764 & 616 & 818 & 652 & 627 \\
\hline $\mathbf{1 5}$ & 1286 & 1164 & 1006 & 1361 & 1160 & 972 & 779 & 1052 & 836 & 781 \\
\hline $\mathbf{1 6}$ & 1563 & 1371 & 1179 & 1642 & 1392 & 1144 & 912 & 1257 & 995 & 901 \\
\hline $\mathbf{1 8}$ & 1820 & 1539 & 1317 & 1891 & 1594 & 1284 & 1019 & 1435 & 1133 & 990 \\
\hline $\mathbf{1 9}$ & 2056 & 1677 & 1427 & 2111 & 1770 & 1397 & 1103 & 1587 & 1249 & 1058 \\
\hline $\mathbf{2 0}$ & 2723 & 2664 & 2329 & 3090 & 2611 & 2290 & 1815 & 2372 & 1839 & 1798 \\
\hline $\mathbf{2 1}$ & 2657 & 2390 & 2106 & 2932 & 2495 & 2119 & 1691 & 2276 & 1776 & 1586 \\
\hline $\mathbf{2 2}$ & 2487 & 2034 & 1787 & 2626 & 2250 & 1827 & 1462 & 2065 & 1621 & 1321 \\
\hline $\mathbf{2 3}$ & 2402 & 1920 & 1679 & 2494 & 2139 & 1663 & 1329 & 1920 & 1509 & 1209 \\
\hline & 1998 & 1628 & 1386 & 1994 & 1699 & 1354 & 1064 & 1562 & 1222 & 1054 \\
\hline
\end{tabular}


Table C.6 Third-point Restraints, Multiple Span, Interior

\begin{tabular}{|c|c|c|c|c|c|c|c|c|c|c|}
\hline \multicolumn{1}{c|}{} & \multicolumn{9}{c|}{ Purlin Designation } \\
\hline Combination & $\mathbf{P 1}$ & $\mathbf{P 2}$ & $\mathbf{P 3}$ & $\mathbf{P 4}$ & $\mathbf{P 5}$ & $\mathbf{P 6}$ & $\mathbf{P 7}$ & P8 & P9 & P10 \\
\hline $\mathbf{1}$ & 2099 & 1705 & 1394 & 2169 & 1768 & 1378 & 1045 & 1581 & 1207 & 1053 \\
\hline $\mathbf{2}$ & 1621 & 1395 & 1140 & 1768 & 1437 & 1153 & 871 & 1313 & 994 & 903 \\
\hline $\mathbf{3}$ & 1155 & 1094 & 893 & 1379 & 1115 & 934 & 702 & 1054 & 787 & 758 \\
\hline $\mathbf{4}$ & 226 & 434 & 345 & 606 & 471 & 447 & 327 & 478 & 332 & 477 \\
\hline $\mathbf{5}$ & -664 & -150 & -126 & -226 & -212 & 43 & 8 & -20 & -64 & 177 \\
\hline $\mathbf{6}$ & -1597 & -763 & -628 & -930 & -794 & -415 & -339 & -547 & -478 & -104 \\
\hline $\mathbf{7}$ & -2378 & -1268 & -1039 & -1666 & -1401 & -782 & -623 & -981 & -823 & -381 \\
\hline $\mathbf{8}$ & -3183 & -1790 & -1472 & -2343 & -1961 & -1163 & -917 & -1435 & -1181 & -635 \\
\hline $\mathbf{9}$ & -3927 & -2279 & -1873 & -2887 & -2411 & -1518 & -1190 & -1854 & -1512 & -870 \\
\hline $\mathbf{1 0}$ & -4503 & -2715 & -2229 & -3451 & -2877 & -1834 & -1434 & -2230 & -1809 & -1082 \\
\hline $\mathbf{1 1}$ & -5116 & -3051 & -2505 & -3970 & -3304 & -2128 & -1660 & -2576 & -2082 & -1276 \\
\hline $\mathbf{1 2}$ & 220 & 287 & 242 & 276 & 226 & 221 & 166 & 211 & 154 & 206 \\
\hline $\mathbf{1 3}$ & 584 & 600 & 509 & 652 & 550 & 490 & 384 & 509 & 395 & 429 \\
\hline $\mathbf{1 4}$ & 880 & 884 & 743 & 984 & 823 & 721 & 559 & 757 & 583 & 616 \\
\hline $\mathbf{1 5}$ & 1153 & 1121 & 935 & 1281 & 1063 & 911 & 702 & 971 & 745 & 762 \\
\hline $\mathbf{1 7}$ & 1408 & 1315 & 1092 & 1544 & 1276 & 1068 & 821 & 1160 & 891 & 872 \\
\hline $\mathbf{1 8}$ & 1657 & 1471 & 1218 & 1777 & 1465 & 1196 & 915 & 1324 & 1015 & 951 \\
\hline $\mathbf{1 9}$ & 1886 & 1604 & 1318 & 1987 & 1629 & 1299 & 989 & 1464 & 1120 & 1011 \\
\hline $\mathbf{2 0}$ & 2541 & 2677 & 2295 & 2958 & 2495 & 2258 & 1765 & 2291 & 1760 & 1870 \\
\hline $\mathbf{2 1}$ & 2467 & 2395 & 2056 & 2809 & 2370 & 2073 & 1620 & 2182 & 1676 & 1630 \\
\hline $\mathbf{2 2}$ & 2310 & 1992 & 1700 & 2509 & 2118 & 1752 & 1363 & 1957 & 1503 & 1314 \\
\hline $\mathbf{2 3}$ & 2227 & 1860 & 1580 & 2371 & 2000 & 1572 & 1217 & 1800 & 1380 & 1179 \\
\hline & 1807 & 1516 & 1252 & 1836 & 1530 & 1235 & 935 & 1417 & 1074 & 988 \\
\hline
\end{tabular}

Table C.7 Midpoint Restraint, Single Span

\begin{tabular}{|c|c|c|c|c|c|c|c|c|c|c|}
\hline \multirow[b]{2}{*}{ Combination } & \multicolumn{10}{|c|}{ Purlin Designation } \\
\hline & P1 & P2 & P3 & P4 & P5 & P6 & P7 & P8 & P9 & P10 \\
\hline 1 & 4045 & 2603 & 2240 & 3771 & 3164 & 2257 & 1817 & 2835 & 2249 & 1548 \\
\hline 2 & 3162 & 2101 & 1819 & 3071 & 2579 & 1877 & 1515 & 2357 & 1867 & 1308 \\
\hline 3 & 2303 & 1618 & 1414 & 2395 & 2014 & 1512 & 1223 & 1896 & 1498 & 1075 \\
\hline 4 & 587 & 532 & 503 & 1037 & 878 & 690 & 569 & 863 & 671 & 612 \\
\hline 5 & -1054 & -397 & -276 & -417 & -337 & -12 & 8 & -22 & -35 & 117 \\
\hline 6 & -2790 & -1386 & -1107 & -1641 & -1362 & -761 & -589 & -964 & -787 & -298 \\
\hline 7 & -4228 & -2191 & -1783 & -2928 & -2438 & -1370 & -1076 & -1734 & -1404 & -739 \\
\hline 8 & -5725 & -3039 & -2497 & -4115 & -3431 & -2016 & -1590 & -2546 & -2052 & -1152 \\
\hline 9 & -7110 & -3821 & -3156 & -5212 & -4349 & -2610 & -2064 & -3294 & -2649 & -1534 \\
\hline 10 & -8167 & -4529 & -3749 & -6049 & -5045 & -3144 & -2491 & -3966 & -3186 & -1848 \\
\hline 11 & -9312 & -5074 & -4206 & -6965 & -5814 & -3643 & -2887 & -4584 & -3679 & -2165 \\
\hline 12 & 445 & 516 & 444 & 521 & 441 & 410 & 323 & 407 & 315 & 360 \\
\hline 13 & 1090 & 997 & 870 & 1149 & 997 & 846 & 688 & 924 & 747 & 681 \\
\hline 14 & 1708 & 1452 & 1266 & 1766 & 1521 & 1244 & 1008 & 1397 & 1120 & 963 \\
\hline 15 & 2274 & 1816 & 1579 & 2307 & 1971 & 1560 & 1261 & 1797 & 1433 & 1171 \\
\hline 16 & 2786 & 2099 & 1818 & 2769 & 2351 & 1807 & 1459 & 2132 & 1696 & 1320 \\
\hline 17 & 3249 & 2315 & 2000 & 3160 & 2671 & 1998 & 1611 & 2410 & 1915 & 1425 \\
\hline 18 & 3668 & 2479 & 2137 & 3491 & 2940 & 2144 & 1728 & 2642 & 2098 & 1498 \\
\hline 19 & 5367 & 4653 & 4163 & 5927 & 5060 & 4220 & 3412 & 4598 & 3621 & 2864 \\
\hline 20 & 5144 & 3936 & 3563 & 5458 & 4696 & 3738 & 3046 & 4291 & 3398 & 2416 \\
\hline 21 & 4644 & 3101 & 2800 & 4595 & 3996 & 2993 & 2454 & 3682 & 2941 & 1908 \\
\hline 22 & 4398 & 2863 & 2568 & 4243 & 3700 & 2622 & 2148 & 3295 & 2642 & 1715 \\
\hline 23 & 3329 & 2327 & 2020 & 3080 & 2671 & 2009 & 1624 & 2461 & 1972 & 1475 \\
\hline
\end{tabular}


Table C.8 Midpoint Restraints, Multiple Span, Exterior

\begin{tabular}{|c|c|c|c|c|c|c|c|c|c|c|}
\hline \multicolumn{1}{c|}{} & \multicolumn{9}{|c|}{ Purlin Designation } \\
\hline Combination & $\mathbf{P 1}$ & $\mathbf{P 2}$ & $\mathbf{P 3}$ & $\mathbf{P 4}$ & $\mathbf{P 5}$ & $\mathbf{P 6}$ & $\mathbf{P 7}$ & P8 & P9 & P10 \\
\hline $\mathbf{1}$ & 3679 & 2502 & 2081 & 3489 & 2857 & 2085 & 1614 & 2533 & 1969 & 1512 \\
\hline $\mathbf{2}$ & 2856 & 2041 & 1701 & 2849 & 2329 & 1743 & 1348 & 2107 & 1629 & 1293 \\
\hline $\mathbf{3}$ & 2055 & 1596 & 1334 & 2224 & 1814 & 1413 & 1091 & 1696 & 1301 & 1080 \\
\hline $\mathbf{4}$ & 456 & 599 & 512 & 976 & 785 & 674 & 515 & 778 & 571 & 657 \\
\hline $\mathbf{5}$ & -1074 & -256 & -194 & -357 & -312 & 40 & 20 & -13 & -60 & 203 \\
\hline $\mathbf{6}$ & -2684 & -1166 & -944 & -1485 & -1243 & -635 & -505 & -850 & -726 & -178 \\
\hline $\mathbf{7}$ & -4026 & -1909 & -1559 & -2667 & -2215 & -1187 & -936 & -1539 & -1276 & -582 \\
\hline $\mathbf{8}$ & -5415 & -2692 & -2204 & -3757 & -3112 & -1770 & -1389 & -2262 & -1851 & -952 \\
\hline $\mathbf{9}$ & -6698 & -3415 & -2801 & -4626 & -3830 & -2306 & -1807 & -2927 & -2380 & -1295 \\
\hline $\mathbf{1 0}$ & -7687 & -4066 & -3338 & -5533 & -4576 & -2789 & -2183 & -3526 & -2856 & -1603 \\
\hline $\mathbf{1 1}$ & -8748 & -4560 & -3747 & -6367 & -5262 & -3232 & -2528 & -4077 & -3293 & -1886 \\
\hline $\mathbf{1 2}$ & 383 & 478 & 406 & 468 & 389 & 372 & 285 & 361 & 268 & 338 \\
\hline $\mathbf{1 3}$ & 1047 & 968 & 833 & 1107 & 949 & 811 & 647 & 874 & 701 & 676 \\
\hline $\mathbf{1 4}$ & 1635 & 1418 & 1212 & 1701 & 1443 & 1191 & 944 & 1320 & 1044 & 958 \\
\hline $\mathbf{1 5}$ & 2155 & 1769 & 1502 & 2205 & 1851 & 1484 & 1167 & 1679 & 1319 & 1160 \\
\hline $\mathbf{1 6}$ & 2612 & 2036 & 1717 & 2623 & 2185 & 1704 & 1334 & 1967 & 1539 & 1301 \\
\hline $\mathbf{1 7}$ & 3014 & 2235 & 1876 & 2967 & 2456 & 1868 & 1456 & 2197 & 1715 & 1397 \\
\hline $\mathbf{1 8}$ & 3365 & 2388 & 1994 & 3251 & 2676 & 1993 & 1548 & 2383 & 1856 & 1466 \\
\hline $\mathbf{1 9}$ & 5193 & 4894 & 4254 & 5866 & 4950 & 4293 & 4524 & 4524 & 3486 & 3297 \\
\hline $\mathbf{2 0}$ & 4919 & 4004 & 3514 & 5306 & 4509 & 3697 & 4150 & 4150 & 3213 & 2630 \\
\hline $\mathbf{2 1}$ & 4330 & 3044 & 2660 & 4345 & 3718 & 2850 & 3450 & 3450 & 2686 & 1953 \\
\hline $\mathbf{2 2}$ & 4057 & 2782 & 2417 & 3974 & 3402 & 2457 & 3036 & 3036 & 2365 & 1714 \\
\hline $\mathbf{2 3}$ & 2955 & 2201 & 1855 & 2808 & 2378 & 1839 & 2203 & 2203 & 1704 & 1419 \\
\hline
\end{tabular}

Table C.9 Midpoint Restraint, Multiple Span, Interior

\begin{tabular}{|c|c|c|c|c|c|c|c|c|c|c|}
\hline \multicolumn{1}{c|}{} & \multicolumn{10}{c|}{ Purlin Designation } \\
\hline Combination & P1 & P2 & P3 & P4 & P5 & P6 & P7 & P8 & P9 & P10 \\
\hline $\mathbf{1}$ & 3400 & 2366 & 1911 & 3274 & 2620 & 1924 & 1438 & 2330 & 1761 & 1435 \\
\hline $\mathbf{2}$ & 2628 & 1942 & 1567 & 2679 & 2135 & 1614 & 1201 & 1939 & 1453 & 1235 \\
\hline $\mathbf{3}$ & 1876 & 1531 & 1234 & 2097 & 1661 & 1314 & 972 & 1561 & 1155 & 1042 \\
\hline $\mathbf{4}$ & 375 & 614 & 491 & 936 & 715 & 643 & 462 & 720 & 495 & 656 \\
\hline $\mathbf{5}$ & -1063 & -174 & -149 & -301 & -290 & 67 & 21 & -6 & -79 & 242 \\
\hline $\mathbf{6}$ & -2568 & -1012 & -828 & -1352 & -1146 & -546 & -445 & -774 & -682 & -106 \\
\hline $\mathbf{7}$ & -3831 & -1700 & -1386 & -2450 & -2038 & -1049 & -830 & -1410 & -1183 & -475 \\
\hline $\mathbf{8}$ & -5129 & -2422 & -1971 & -3463 & -2861 & -1578 & -1233 & -2072 & -1703 & -814 \\
\hline $\mathbf{9}$ & -6329 & -3089 & -2512 & -4275 & -3523 & -2066 & -1604 & -2683 & -2182 & -1127 \\
\hline $\mathbf{1 0}$ & -7261 & -3690 & -2999 & -5118 & -4208 & -2505 & -1938 & -3233 & -2613 & -1410 \\
\hline $\mathbf{1 1}$ & -8252 & -4149 & -3371 & -5893 & -4837 & -2909 & -2245 & -3738 & -3008 & 1669 \\
\hline $\mathbf{1 2}$ & 320 & 436 & 366 & 415 & 335 & 333 & 245 & 313 & 220 & 312 \\
\hline $\mathbf{1 3}$ & 986 & 926 & 784 & 1053 & 889 & 767 & 600 & 822 & 646 & 656 \\
\hline $\mathbf{1 4}$ & 1519 & 1363 & 1142 & 1619 & 1348 & 1127 & 871 & 1240 & 957 & 931 \\
\hline $\mathbf{1 5}$ & 1989 & 1699 & 1409 & 2091 & 1722 & 1398 & 1070 & 1570 & 1203 & 1123 \\
\hline $\mathbf{1 6}$ & 2409 & 1950 & 1603 & 2481 & 2025 & 1598 & 1213 & 1832 & 1397 & 1254 \\
\hline $\mathbf{1 7}$ & 2782 & 2135 & 1743 & 2801 & 2269 & 1744 & 1315 & 2040 & 1550 & 1342 \\
\hline $\mathbf{1 9}$ & 3110 & 2267 & 1840 & 3061 & 2463 & 1847 & 1386 & 2201 & 1667 & 1397 \\
\hline $\mathbf{2 0}$ & 4863 & 4992 & 4246 & 5673 & 4773 & 4280 & 3320 & 4421 & 3381 & 3447 \\
\hline $\mathbf{2 1}$ & 4610 & 4031 & 3453 & 5147 & 4335 & 3651 & 2831 & 4032 & 3080 & 2706 \\
\hline $\mathbf{2 2}$ & 4056 & 2956 & 2521 & 4172 & 3520 & 2736 & 2113 & 3297 & 2517 & 1932 \\
\hline $\mathbf{2 3}$ & 2654 & 2669 & 2262 & 3782 & 3189 & 2315 & 1777 & 2857 & 2176 & 1661 \\
\hline & & 2042 & 1675 & 2570 & 2129 & 1670 & 1247 & 1991 & 1490 & 1328 \\
\hline
\end{tabular}


Table C.10 Quarter-point Restraints, Single Span, Exterior

\begin{tabular}{|c|c|c|c|c|c|c|c|c|c|c|}
\hline \multicolumn{1}{c|}{} & \multicolumn{9}{|c|}{ Purlin Designation } \\
\hline Combination & $\mathbf{P 1}$ & $\mathbf{P 2}$ & $\mathbf{P 3}$ & $\mathbf{P 4}$ & $\mathbf{P 5}$ & $\mathbf{P 6}$ & $\mathbf{P 7}$ & P8 & P9 & P10 \\
\hline $\mathbf{1}$ & 1235 & 967 & 774 & 1268 & 996 & 737 & 549 & 869 & 643 & 521 \\
\hline $\mathbf{2}$ & 975 & 795 & 635 & 1050 & 820 & 618 & 459 & 728 & 534 & 442 \\
\hline $\mathbf{3}$ & 723 & 629 & 500 & 838 & 648 & 503 & 371 & 591 & 429 & 364 \\
\hline $\mathbf{4}$ & 217 & 256 & 198 & 413 & 304 & 246 & 176 & 286 & 195 & 211 \\
\hline $\mathbf{5}$ & -267 & -64 & -61 & -41 & -63 & 25 & 8 & 24 & -7 & 47 \\
\hline $\mathbf{6}$ & -779 & -405 & -337 & -425 & -374 & -210 & -170 & -254 & -220 & -90 \\
\hline $\mathbf{7}$ & -1204 & -683 & -563 & -829 & -700 & -402 & -317 & -483 & -396 & -236 \\
\hline $\mathbf{8}$ & -1645 & -977 & -800 & -1201 & -1001 & -605 & -470 & -723 & -580 & -370 \\
\hline $\mathbf{9}$ & -2053 & -1248 & -1020 & -1498 & -1242 & -792 & -612 & -945 & -750 & -493 \\
\hline $\mathbf{1 0}$ & -2367 & -1492 & -1217 & -1809 & -1492 & -960 & -740 & -1144 & -902 & -604 \\
\hline $\mathbf{1 1}$ & -2705 & -1678 & -1368 & -2094 & -1723 & -1115 & -857 & -1328 & -1043 & -706 \\
\hline $\mathbf{1 2}$ & 184 & 216 & 185 & 218 & 182 & 171 & 132 & 169 & 130 & 147 \\
\hline $\mathbf{1 3}$ & 450 & 422 & 342 & 493 & 392 & 323 & 241 & 349 & 256 & 252 \\
\hline $\mathbf{1 5}$ & 601 & 560 & 449 & 662 & 518 & 421 & 311 & 456 & 332 & 324 \\
\hline $\mathbf{1 6}$ & 732 & 671 & 538 & 802 & 628 & 504 & 375 & 553 & 405 & 384 \\
\hline $\mathbf{1 7}$ & 862 & 766 & 615 & 933 & 733 & 578 & 431 & 645 & 474 & 433 \\
\hline $\mathbf{1 8}$ & 991 & 847 & 679 & 1055 & 830 & 642 & 479 & 728 & 538 & 471 \\
\hline $\mathbf{1 9}$ & 1116 & 913 & 732 & 1167 & 918 & 694 & 518 & 803 & 594 & 500 \\
\hline $\mathbf{2 0}$ & 1566 & 1651 & 1350 & 1819 & 1481 & 1269 & 974 & 1319 & 999 & 918 \\
\hline $\mathbf{2 1}$ & 1475 & 1446 & 1178 & 1684 & 1359 & 1126 & 853 & 1205 & 901 & 785 \\
\hline $\mathbf{2 2}$ & 1364 & 1161 & 955 & 1482 & 1199 & 941 & 712 & 1067 & 797 & 634 \\
\hline $\mathbf{2 3}$ & 1313 & 1070 & 882 & 1394 & 1130 & 872 & 637 & 980 & 733 & 573 \\
\hline & 1061 & 860 & 703 & 1061 & 859 & 663 & 495 & 770 & 574 & 503 \\
\hline
\end{tabular}

Table C.11 Quarter-point Restraint, Single Span, Interior

\begin{tabular}{|c|c|c|c|c|c|c|c|c|c|c|}
\cline { 2 - 14 } \multicolumn{1}{c|}{} & \multicolumn{10}{c|}{ Purlin Designation } \\
\hline Combination & P1 & P2 & P3 & P4 & P5 & P6 & P7 & P8 & P9 & P10 \\
\hline $\mathbf{1}$ & 2197 & 1687 & 1505 & 2179 & 1933 & 1505 & 1252 & 1771 & 1460 & 1102 \\
\hline $\mathbf{2}$ & 1702 & 1348 & 1216 & 1757 & 1569 & 1247 & 1042 & 1466 & 1211 & 930 \\
\hline $\mathbf{3}$ & 1222 & 1023 & 939 & 1343 & 1215 & 998 & 841 & 1172 & 971 & 763 \\
\hline $\mathbf{4}$ & 263 & 290 & 315 & 519 & 502 & 440 & 388 & 513 & 434 & 431 \\
\hline $\mathbf{5}$ & -654 & -336 & -218 & -366 & -259 & -38 & 0 & 52 & -27 & 76 \\
\hline $\mathbf{6}$ & -1625 & -1003 & -786 & -1108 & -899 & -547 & -413 & -653 & -517 & -221 \\
\hline $\mathbf{7}$ & -2427 & -1543 & -1249 & -1888 & -1572 & -960 & -750 & -1143 & -918 & -536 \\
\hline $\mathbf{8}$ & -3264 & -2114 & -1736 & -2607 & -2192 & -1399 & -1106 & -1661 & -1340 & -825 \\
\hline $\mathbf{9}$ & -4038 & -2642 & -2187 & -3176 & -2684 & -1802 & -1434 & -2137 & -1728 & -1091 \\
\hline $\mathbf{1 0}$ & -4626 & -3116 & -2592 & -3773 & -3200 & -2164 & -1729 & -2565 & -2078 & -1330 \\
\hline $\mathbf{1 1}$ & -5265 & -3473 & -2898 & -4322 & -3674 & -2497 & -2000 & -2958 & -2399 & -1550 \\
\hline $\mathbf{1 2}$ & 209 & 222 & 194 & 228 & 201 & 181 & 150 & 185 & 151 & 162 \\
\hline $\mathbf{1 3}$ & 388 & 454 & 428 & 435 & 427 & 410 & 361 & 412 & 368 & 368 \\
\hline $\mathbf{1 4}$ & 727 & 744 & 699 & 782 & 752 & 684 & 593 & 718 & 623 & 579 \\
\hline $\mathbf{1 5}$ & 1076 & 1013 & 937 & 1134 & 1060 & 923 & 788 & 997 & 847 & 750 \\
\hline $\mathbf{1 6}$ & 1398 & 1240 & 1132 & 1451 & 1329 & 1119 & 946 & 1239 & 1039 & 882 \\
\hline $\mathbf{1 7}$ & 1689 & 1424 & 1287 & 1728 & 1561 & 1278 & 1072 & 1445 & 1202 & 979 \\
\hline $\mathbf{1 8}$ & 1955 & 1571 & 1409 & 1969 & 1761 & 1404 & 1173 & 1621 & 1341 & 1050 \\
\hline $\mathbf{1 9}$ & 2314 & 1816 & 1813 & 2474 & 2239 & 1907 & 1629 & 2078 & 1710 & 1343 \\
\hline $\mathbf{2 0}$ & 2380 & 1832 & 1806 & 2492 & 2282 & 1908 & 1644 & 2133 & 1775 & 1331 \\
\hline $\mathbf{2 1}$ & 2321 & 1779 & 1676 & 2365 & 2161 & 1750 & 1498 & 2023 & 1689 & 1226 \\
\hline $\mathbf{2 2}$ & 2274 & 1742 & 1614 & 2293 & 2089 & 1673 & 1391 & 1919 & 1600 & 1166 \\
\hline $\mathbf{2 3}$ & 2005 & 1603 & 1411 & 1973 & 1757 & 1398 & 1157 & 1630 & 1345 & 1066 \\
\hline
\end{tabular}


Table C.12 Quarter-point Restraints, Multiple Span, Exterior ${ }^{1 / 4}$ Span

\begin{tabular}{|c|c|c|c|c|c|c|c|c|c|c|}
\hline \multicolumn{1}{c|}{} & \multicolumn{9}{c|}{ Purlin Designation } \\
\hline Combination & $\mathbf{P 1}$ & $\mathbf{P 2}$ & $\mathbf{P 3}$ & $\mathbf{P 4}$ & $\mathbf{P 5}$ & $\mathbf{P 6}$ & $\mathbf{P 7}$ & P8 & P9 & P10 \\
\hline $\mathbf{1}$ & 1190 & 956 & 762 & 1216 & 957 & 719 & 531 & 826 & 614 & 532 \\
\hline $\mathbf{2}$ & 933 & 787 & 626 & 1002 & 784 & 603 & 443 & 690 & 509 & 454 \\
\hline $\mathbf{3}$ & 682 & 624 & 494 & 794 & 617 & 491 & 359 & 559 & 407 & 379 \\
\hline $\mathbf{4}$ & 180 & 258 & 200 & 377 & 281 & 242 & 171 & 266 & 182 & 229 \\
\hline $\mathbf{5}$ & -300 & -55 & -53 & -67 & -77 & 27 & 9 & 14 & -13 & 69 \\
\hline $\mathbf{6}$ & -806 & -389 & -321 & -444 & -380 & -201 & -163 & -254 & -219 & -66 \\
\hline $\mathbf{7}$ & -1227 & -662 & -542 & -839 & -698 & -388 & -304 & -474 & -390 & -208 \\
\hline $\mathbf{8}$ & -1664 & -950 & -773 & -1204 & -991 & -585 & -452 & -705 & -567 & -339 \\
\hline $\mathbf{9}$ & -2067 & -1216 & -987 & -1495 & -1226 & -767 & -589 & -918 & -731 & -460 \\
\hline $\mathbf{1 0}$ & -2378 & -1455 & -1180 & -1799 & -1470 & -930 & -712 & -1109 & -878 & -569 \\
\hline $\mathbf{1 1}$ & -2712 & -1638 & -1327 & -2079 & -1694 & -1081 & -825 & -1285 & -1013 & -669 \\
\hline $\mathbf{1 2}$ & 187 & 225 & 191 & 223 & 187 & 176 & 136 & 173 & 133 & 156 \\
\hline $\mathbf{1 3}$ & 444 & 420 & 344 & 479 & 387 & 322 & 243 & 343 & 257 & 261 \\
\hline $\mathbf{1 4}$ & 594 & 556 & 449 & 641 & 509 & 418 & 312 & 447 & 332 & 335 \\
\hline $\mathbf{1 5}$ & 724 & 666 & 537 & 777 & 617 & 500 & 373 & 539 & 401 & 396 \\
\hline $\mathbf{1 6}$ & 848 & 760 & 612 & 903 & 716 & 571 & 426 & 625 & 465 & 445 \\
\hline $\mathbf{1 7}$ & 969 & 839 & 674 & 1019 & 807 & 631 & 469 & 702 & 523 & 483 \\
\hline $\mathbf{1 8}$ & 1083 & 903 & 723 & 1123 & 887 & 680 & 504 & 769 & 572 & 511 \\
\hline $\mathbf{1 9}$ & 1574 & 1650 & 1364 & 1818 & 1484 & 1291 & 986 & 1322 & 994 & 1008 \\
\hline $\mathbf{2 0}$ & 1466 & 1409 & 1161 & 1648 & 1339 & 1119 & 849 & 1191 & 889 & 825 \\
\hline $\mathbf{2 1}$ & 1331 & 1134 & 935 & 1426 & 1161 & 920 & 695 & 1036 & 774 & 650 \\
\hline $\mathbf{2 2}$ & 1273 & 1050 & 864 & 1338 & 1090 & 820 & 618 & 946 & 705 & 585 \\
\hline $\mathbf{2 3}$ & 1015 & 858 & 694 & 1022 & 825 & 648 & 479 & 739 & 546 & 514 \\
\hline
\end{tabular}

Table C.13 Quarter-point Restraint, Multiple Span, Interior 1/4 Span

\begin{tabular}{|c|c|c|c|c|c|c|c|c|c|c|}
\hline & \multicolumn{10}{|c|}{ Purlin Designation } \\
\hline Combination & P1 & $\mathbf{P 2}$ & P3 & P4 & P5 & P6 & P7 & P8 & P9 & P10 \\
\hline 1 & 1032 & 836 & 642 & 1065 & 818 & 615 & 435 & 708 & 509 & 475 \\
\hline 2 & 794 & 687 & 525 & 871 & 664 & 515 & 361 & 587 & 417 & 408 \\
\hline 3 & 562 & 543 & 412 & 682 & 514 & 418 & 289 & 470 & 327 & 343 \\
\hline 4 & 99 & 221 & 160 & 303 & 214 & 202 & 132 & 211 & 131 & 214 \\
\hline 5 & -371 & -75 & -65 & -132 & -121 & 15 & -10 & -28 & -49 & 77 \\
\hline 6 & -828 & -362 & -290 & -470 & -388 & -186 & -150 & -260 & -224 & -41 \\
\hline 7 & -1214 & -600 & -478 & -820 & -664 & -345 & -271 & -453 & -372 & -165 \\
\hline 8 & -1607 & -847 & -676 & -1143 & -918 & -516 & -396 & -652 & -527 & -278 \\
\hline 9 & -1971 & -1080 & -860 & -1404 & -1128 & -673 & -511 & -840 & -670 & -383 \\
\hline 10 & -2256 & -1291 & -1025 & -1672 & -1345 & -815 & -614 & -1010 & -799 & -477 \\
\hline 11 & -2558 & -1453 & -1152 & -1920 & -1543 & -946 & -709 & -1165 & -917 & -564 \\
\hline 12 & 146 & 204 & 167 & 187 & 150 & 151 & 110 & 141 & 103 & 148 \\
\hline 13 & 372 & 375 & 296 & 422 & 330 & 283 & 204 & 295 & 211 & 244 \\
\hline 14 & 488 & 489 & 383 & 555 & 430 & 363 & 260 & 381 & 272 & 308 \\
\hline 15 & 599 & 583 & 456 & 673 & 522 & 433 & 310 & 461 & 331 & 361 \\
\hline 16 & 714 & 665 & 519 & 786 & 610 & 493 & 352 & 536 & 386 & 403 \\
\hline 17 & 827 & 733 & 570 & 889 & 689 & 543 & 387 & 603 & 434 & 434 \\
\hline 18 & 933 & 791 & 611 & 983 & 758 & 584 & 414 & 660 & 475 & 458 \\
\hline 19 & 1397 & 1575 & 1289 & 1667 & 1235 & 1235 & 934 & 1234 & 921 & 1030 \\
\hline 20 & 1292 & 1312 & 1067 & 1504 & 1050 & 1050 & 783 & 1096 & 808 & 817 \\
\hline 21 & 1171 & 1017 & 823 & 1285 & 832 & 832 & 612 & 934 & 682 & 612 \\
\hline 22 & 1115 & 931 & 748 & 1194 & 724 & 724 & 527 & 836 & 608 & 537 \\
\hline 23 & 850 & 736 & 571 & 863 & 541 & 541 & 380 & 616 & 439 & 450 \\
\hline
\end{tabular}


Table C.14 Quarter-point Restraints, Multiple Span, $1 / 2$ Span

\begin{tabular}{|c|c|c|c|c|c|c|c|c|c|c|}
\hline \multicolumn{1}{c|}{} & \multicolumn{9}{c|}{ Purlin Designation } \\
\hline Combination & $\mathbf{P 1}$ & $\mathbf{P 2}$ & $\mathbf{P 3}$ & $\mathbf{P 4}$ & $\mathbf{P 5}$ & $\mathbf{P 6}$ & $\mathbf{P 7}$ & P8 & P9 & P10 \\
\hline $\mathbf{1}$ & 2137 & 1719 & 1473 & 2176 & 1862 & 1466 & 1169 & 1690 & 1351 & 1113 \\
\hline $\mathbf{2}$ & 1659 & 1409 & 1202 & 1778 & 1517 & 1225 & 977 & 1405 & 1120 & 951 \\
\hline $\mathbf{3}$ & 1194 & 1114 & 941 & 1399 & 1180 & 991 & 791 & 1131 & 896 & 795 \\
\hline $\mathbf{4}$ & 273 & 452 & 373 & 642 & 511 & 482 & 376 & 518 & 399 & 501 \\
\hline $\mathbf{5}$ & -622 & -207 & -146 & -259 & -210 & 60 & 29 & 19 & -32 & 186 \\
\hline $\mathbf{6}$ & -1558 & -842 & -680 & -972 & -817 & -457 & -361 & -572 & -483 & -135 \\
\hline $\mathbf{7}$ & -2336 & -1361 & -1117 & -1719 & -1453 & -847 & -672 & -1031 & -856 & -434 \\
\hline $\mathbf{8}$ & -3144 & -1906 & -1576 & -2409 & -2040 & -1258 & -999 & -1515 & -1248 & -708 \\
\hline $\mathbf{9}$ & -3890 & -2411 & -2001 & -2957 & -2507 & -1637 & -1301 & -1960 & -1608 & -961 \\
\hline $\mathbf{1 0}$ & -4462 & -2865 & -2384 & -3531 & -2995 & -1979 & -1572 & -2360 & -1932 & -1188 \\
\hline $\mathbf{1 1}$ & -5079 & -3209 & -2674 & -4058 & -3444 & -2292 & -1822 & -2728 & -2230 & -1397 \\
\hline $\mathbf{1 2}$ & 204 & 229 & 200 & 236 & 201 & 186 & 148 & 186 & 146 & 163 \\
\hline $\mathbf{1 3}$ & 476 & 528 & 468 & 546 & 487 & 451 & 373 & 463 & 380 & 395 \\
\hline $\mathbf{1 4}$ & 821 & 848 & 741 & 927 & 811 & 726 & 592 & 763 & 619 & 617 \\
\hline $\mathbf{1 5}$ & 1136 & 1117 & 962 & 1266 & 1089 & 946 & 773 & 1013 & 827 & 787 \\
\hline $\mathbf{1 6}$ & 1413 & 1329 & 1137 & 1552 & 1327 & 1122 & 914 & 1228 & 998 & 909 \\
\hline $\mathbf{1 8}$ & 1680 & 1495 & 1278 & 1794 & 1536 & 1266 & 1023 & 1411 & 1138 & 997 \\
\hline $\mathbf{1 9}$ & 1920 & 1619 & 1389 & 1996 & 1713 & 1379 & 1106 & 1564 & 1255 & 1066 \\
\hline $\mathbf{2 0}$ & 2321 & 2030 & 2030 & 2613 & 2290 & 2055 & 1674 & 2130 & 1694 & 1668 \\
\hline $\mathbf{2 1}$ & 2386 & 1955 & 1955 & 2625 & 2320 & 2022 & 1660 & 2174 & 1744 & 1562 \\
\hline $\mathbf{2 2}$ & 2298 & 1711 & 1711 & 2432 & 2149 & 1782 & 1458 & 2017 & 1622 & 1324 \\
\hline $\mathbf{2 3}$ & 2236 & 1619 & 1619 & 2330 & 2054 & 1632 & 1327 & 1883 & 1513 & 1216 \\
\hline & 1904 & 1356 & 1356 & 1916 & 1659 & 1341 & 1067 & 1543 & 1225 & 1058 \\
\hline
\end{tabular}

Table C.15 Third-point plus Support Restraint, Single Span, Exterior

\begin{tabular}{|c|c|c|c|c|c|c|c|c|c|c|}
\hline \multirow[b]{2}{*}{ Combination } & \multicolumn{10}{|c|}{ Purlin Designation } \\
\hline & P1 & P2 & P3 & P4 & P5 & P6 & P7 & P8 & P9 & P10 \\
\hline 1 & 829 & 587 & 500 & 881 & 728 & 537 & 424 & 659 & 509 & 313 \\
\hline 2 & 638 & 462 & 395 & 714 & 587 & 440 & 346 & 541 & 414 & 255 \\
\hline 3 & 452 & 341 & 294 & 551 & 448 & 346 & 271 & 427 & 321 & 199 \\
\hline 4 & 80 & 74 & 72 & 226 & 172 & 138 & 106 & 175 & 119 & 86 \\
\hline 5 & -276 & -159 & -123 & -118 & -119 & -43 & -39 & -45 & -58 & -32 \\
\hline 6 & -648 & -403 & -326 & -414 & -370 & -232 & -190 & -276 & -243 & -132 \\
\hline 7 & -961 & -605 & -496 & -719 & -628 & -390 & -316 & -468 & -398 & -237 \\
\hline 8 & -1281 & -817 & -670 & -1001 & -867 & -554 & -447 & -667 & -558 & -333 \\
\hline 9 & -1577 & -1007 & -831 & -1230 & -1061 & -704 & -567 & -850 & -705 & -421 \\
\hline 10 & -1809 & -1181 & -976 & -1464 & -1259 & -840 & -674 & -1015 & -836 & -500 \\
\hline 11 & -2053 & -1316 & -1089 & -1679 & -1441 & -945 & -773 & -1166 & -957 & -573 \\
\hline 12 & 23 & 17 & 15 & 23 & 20 & 17 & 14 & 20 & 18 & 14 \\
\hline 13 & 155 & 149 & 131 & 187 & 156 & 139 & 109 & 143 & 108 & 96 \\
\hline 14 & 254 & 245 & 215 & 309 & 258 & 226 & 178 & 239 & 181 & 151 \\
\hline 15 & 369 & 336 & 292 & 439 & 367 & 308 & 243 & 338 & 258 & 200 \\
\hline 16 & 491 & 417 & 360 & 566 & 471 & 381 & 301 & 432 & 331 & 241 \\
\hline 17 & 611 & 485 & 416 & 682 & 566 & 443 & 350 & 517 & 398 & 272 \\
\hline 18 & 724 & 542 & 463 & 787 & 652 & 495 & 391 & 593 & 457 & 296 \\
\hline 19 & 1016 & 1063 & 919 & 1206 & 1016 & 908 & 723 & 935 & 729 & 671 \\
\hline 20 & 946 & 936 & 815 & 1115 & 935 & 821 & 650 & 861 & 666 & 585 \\
\hline 21 & 891 & 758 & 673 & 1009 & 852 & 709 & 565 & 787 & 609 & 467 \\
\hline 22 & 867 & 687 & 613 & 960 & 814 & 636 & 508 & 736 & 571 & 398 \\
\hline 23 & 728 & 427 & 384 & 716 & 616 & 443 & 355 & 574 & 449 & 255 \\
\hline
\end{tabular}


Table C.16 Third-point plus Support Restraints, Single Span, Interior

\begin{tabular}{|c|c|c|c|c|c|c|c|c|c|c|}
\hline \multicolumn{1}{c|}{} & \multicolumn{9}{c|}{ Purlin Designation } \\
\hline Combination & $\mathbf{P 1}$ & $\mathbf{P 2}$ & $\mathbf{P 3}$ & $\mathbf{P 4}$ & $\mathbf{P 5}$ & $\mathbf{P 6}$ & $\mathbf{P 7}$ & P8 & P9 & P10 \\
\hline $\mathbf{1}$ & 1734 & 1592 & 1365 & 1853 & 1569 & 1295 & 1030 & 1409 & 1110 & 1003 \\
\hline $\mathbf{2}$ & 1362 & 1287 & 1111 & 1514 & 1284 & 1079 & 861 & 1175 & 926 & 848 \\
\hline $\mathbf{3}$ & 1000 & 994 & 866 & 1181 & 1006 & 871 & 698 & 949 & 748 & 699 \\
\hline $\mathbf{4}$ & 278 & 334 & 315 & 518 & 450 & 404 & 331 & 442 & 349 & 401 \\
\hline $\mathbf{5}$ & -412 & -229 & -156 & -195 & -148 & 4 & 17 & 8 & 7 & 82 \\
\hline $\mathbf{6}$ & -1146 & -829 & -658 & -793 & -649 & -422 & -318 & -454 & -356 & -184 \\
\hline $\mathbf{7}$ & -1750 & -1317 & -1067 & -1423 & -1177 & -768 & -590 & -831 & -653 & -468 \\
\hline $\mathbf{8}$ & -2383 & -1834 & -1498 & -2004 & -1665 & -1135 & -878 & -1229 & -967 & -727 \\
\hline $\mathbf{9}$ & -2968 & -2309 & -1897 & -2462 & -2050 & -1473 & -1144 & -1596 & -1256 & -967 \\
\hline $\mathbf{1 0}$ & -3412 & -2737 & -2256 & -2946 & -2455 & -1777 & -1384 & -1926 & -1516 & -1182 \\
\hline $\mathbf{1 1}$ & -3896 & -3060 & -2527 & -3390 & -2828 & -2006 & -1603 & -2230 & -1754 & -1380 \\
\hline $\mathbf{1 2}$ & 267 & 304 & 262 & 308 & 263 & 242 & 193 & 242 & 190 & 212 \\
\hline $\mathbf{1 3}$ & 534 & 573 & 495 & 596 & 511 & 458 & 367 & 466 & 371 & 397 \\
\hline $\mathbf{1 4}$ & 775 & 815 & 705 & 857 & 733 & 653 & 523 & 666 & 529 & 561 \\
\hline $\mathbf{1 5}$ & 991 & 1025 & 886 & 1090 & 932 & 823 & 660 & 844 & 670 & 696 \\
\hline $\mathbf{1 6}$ & 1189 & 1206 & 1042 & 1304 & 1113 & 972 & 778 & 1006 & 798 & 806 \\
\hline $\mathbf{1 7}$ & 1378 & 1359 & 1172 & 1503 & 1280 & 1099 & 878 & 1155 & 914 & 891 \\
\hline $\mathbf{1 8}$ & 1560 & 1487 & 1279 & 1686 & 1432 & 1206 & 962 & 1289 & 1018 & 955 \\
\hline $\mathbf{1 9}$ & 1725 & 1592 & 1420 & 1894 & 1620 & 1372 & 1110 & 1453 & 1147 & 999 \\
\hline $\mathbf{2 0}$ & 1773 & 1644 & 1459 & 1935 & 1660 & 1403 & 1137 & 1493 & 1184 & 1039 \\
\hline $\mathbf{2 1}$ & 1768 & 1637 & 1434 & 1913 & 1640 & 1377 & 1111 & 1479 & 1173 & 1037 \\
\hline $\mathbf{2 2}$ & 1756 & 1620 & 1412 & 1893 & 1621 & 1344 & 1080 & 1454 & 1152 & 1023 \\
\hline $\mathbf{2 3}$ & 1665 & 1547 & 1320 & 1763 & 1497 & 1247 & 990 & 1356 & 1068 & 993 \\
\hline
\end{tabular}

Table C.17 Third-point plus Support Restraints, Multiple Span, Exterior Support

\begin{tabular}{|c|c|c|c|c|c|c|c|c|c|c|}
\hline & \multicolumn{10}{|c|}{ Purlin Designation } \\
\hline Combination & P1 & $\mathbf{P 2}$ & P3 & P4 & P5 & P6 & P7 & P8 & P9 & P10 \\
\hline 1 & 791 & 605 & 508 & 855 & 709 & 537 & 419 & 637 & 495 & 338 \\
\hline 2 & 605 & 481 & 405 & 690 & 570 & 441 & 343 & 521 & 402 & 281 \\
\hline 3 & 423 & 361 & 305 & 530 & 434 & 348 & 269 & 410 & 311 & 225 \\
\hline 4 & 59 & 97 & 86 & 209 & 162 & 144 & 107 & 165 & 112 & 114 \\
\hline 5 & -289 & -133 & -106 & -129 & -125 & -34 & -35 & -50 & -62 & -2 \\
\hline 6 & -651 & -374 & -307 & -419 & -371 & -221 & -183 & -274 & -243 & -102 \\
\hline 7 & -957 & -575 & -474 & -719 & -626 & -376 & -307 & -462 & -396 & -206 \\
\hline 8 & -1269 & -782 & -647 & -996 & -860 & -538 & -435 & -655 & -552 & -301 \\
\hline 9 & -1558 & -974 & -806 & -1221 & -1051 & -686 & -552 & -833 & -696 & -389 \\
\hline 10 & -1784 & -1145 & -949 & -1452 & -1246 & -819 & -658 & -993 & -826 & -468 \\
\hline 11 & -2022 & -1280 & -1061 & -1663 & -1425 & -942 & -755 & -1144 & -945 & -540 \\
\hline 12 & 24 & 17 & 16 & 23 & 20 & 17 & 14 & 20 & 18 & 14 \\
\hline 13 & 154 & 164 & 140 & 187 & 156 & 143 & 111 & 142 & 108 & 112 \\
\hline 14 & 248 & 262 & 225 & 304 & 255 & 230 & 180 & 234 & 179 & 172 \\
\hline 15 & 355 & 354 & 303 & 427 & 359 & 312 & 245 & 330 & 255 & 223 \\
\hline 16 & 469 & 434 & 371 & 548 & 461 & 384 & 302 & 421 & 327 & 265 \\
\hline 17 & 582 & 503 & 427 & 661 & 554 & 446 & 350 & 503 & 391 & 297 \\
\hline 18 & 690 & 559 & 472 & 763 & 637 & 496 & 389 & 574 & 447 & 321 \\
\hline 19 & 927 & 1025 & 902 & 1109 & 952 & 889 & 720 & 892 & 708 & 730 \\
\hline 20 & 871 & 923 & 810 & 1038 & 885 & 807 & 646 & 823 & 647 & 629 \\
\hline 21 & 836 & 769 & 678 & 962 & 820 & 704 & 561 & 761 & 594 & 501 \\
\hline 22 & 820 & 702 & 620 & 923 & 788 & 633 & 503 & 715 & 557 & 428 \\
\hline 23 & 704 & 444 & 391 & 702 & 602 & 444 & 350 & 562 & 436 & 276 \\
\hline
\end{tabular}


Table C.18 Third-point plus Support Restraints, Multiple Span, Interior Support

\begin{tabular}{|c|c|c|c|c|c|c|c|c|c|c|}
\hline \multicolumn{1}{c|}{} & \multicolumn{9}{c|}{ Purlin Designation } \\
\hline Combination & $\mathbf{P 1}$ & $\mathbf{P 2}$ & $\mathbf{P 3}$ & $\mathbf{P 4}$ & $\mathbf{P 5}$ & $\mathbf{P 6}$ & $\mathbf{P 7}$ & P8 & P9 & P10 \\
\hline $\mathbf{1}$ & 1274 & 894 & 682 & 1336 & 1051 & 757 & 548 & 925 & 680 & 492 \\
\hline $\mathbf{2}$ & 944 & 718 & 539 & 1068 & 830 & 620 & 442 & 747 & 538 & 417 \\
\hline $\mathbf{3}$ & 623 & 546 & 401 & 806 & 614 & 487 & 338 & 574 & 400 & 344 \\
\hline $\mathbf{4}$ & 19 & 174 & 102 & 283 & 182 & 198 & 114 & 199 & 101 & 198 \\
\hline $\mathbf{5}$ & -634 & -157 & -166 & -263 & -266 & -58 & -85 & -134 & -165 & 45 \\
\hline $\mathbf{6}$ & -1265 & -498 & -440 & -739 & -659 & -323 & -290 & -477 & -438 & -88 \\
\hline $\mathbf{7}$ & -1807 & -790 & -676 & -1225 & -1057 & -549 & -466 & -770 & -672 & -225 \\
\hline $\mathbf{8}$ & -2351 & -1085 & -912 & -1673 & -1425 & -778 & -643 & -1066 & -907 & -350 \\
\hline $\mathbf{9}$ & -2852 & -1357 & -1130 & -2044 & -1731 & -989 & -806 & -1339 & -1124 & -407 \\
\hline $\mathbf{1 0}$ & -3254 & -1602 & -1327 & -2416 & -2036 & -1179 & -953 & -1584 & -1318 & -572 \\
\hline $\mathbf{1 1}$ & -3667 & -1800 & -1486 & -2758 & -2315 & -1353 & -1087 & -1809 & -1496 & -668 \\
\hline $\mathbf{1 2}$ & 46 & 24 & 24 & 44 & 39 & 32 & 27 & 39 & 35 & 25 \\
\hline $\mathbf{1 3}$ & 302 & 311 & 237 & 371 & 295 & 263 & 189 & 264 & 188 & 218 \\
\hline $\mathbf{1 4}$ & 464 & 464 & 356 & 567 & 449 & 389 & 281 & 403 & 288 & 304 \\
\hline $\mathbf{1 5}$ & 639 & 588 & 453 & 753 & 598 & 496 & 360 & 536 & 388 & 368 \\
\hline $\mathbf{1 6}$ & 813 & 692 & 533 & 926 & 735 & 584 & 426 & 656 & 479 & 416 \\
\hline $\mathbf{1 7}$ & 979 & 776 & 596 & 1081 & 857 & 656 & 478 & 761 & 558 & 450 \\
\hline $\mathbf{1 8}$ & 1130 & 842 & 644 & 1216 & 960 & 712 & 517 & 849 & 624 & 474 \\
\hline $\mathbf{1 9}$ & 1611 & 1834 & 1521 & 1947 & 1609 & 1495 & 1134 & 1469 & 1096 & 1304 \\
\hline $\mathbf{2 1}$ & 1539 & 1612 & 1334 & 1831 & 1510 & 1362 & 1028 & 1382 & 1026 & 1124 \\
\hline $\mathbf{2 2}$ & 1425 & 1241 & 1025 & 1614 & 1330 & 1116 & 837 & 1224 & 906 & 829 \\
\hline $\mathbf{2 3}$ & 1366 & 1094 & 901 & 1507 & 1241 & 956 & 713 & 1107 & 818 & 672 \\
\hline & 1039 & 591 & 480 & 1004 & 824 & 584 & 428 & 769 & 563 & 375 \\
\hline
\end{tabular}

Table C.19 Third-point plus Support Restraints, Multiple Span, Third-point

\begin{tabular}{|c|c|c|c|c|c|c|c|c|c|c|}
\hline \multicolumn{1}{c|}{} & \multicolumn{9}{|c|}{ Purlin Designation } \\
\hline Combination & P1 & P2 & P3 & P4 & P5 & P6 & P7 & P8 & P9 & P10 \\
\hline $\mathbf{1}$ & 1709 & 1611 & 1362 & 1849 & 1552 & 1290 & 1010 & 1392 & 1086 & 1026 \\
\hline $\mathbf{2}$ & 1342 & 1312 & 1114 & 1514 & 1271 & 1080 & 846 & 1162 & 906 & 876 \\
\hline $\mathbf{3}$ & 985 & 1025 & 875 & 1186 & 997 & 876 & 688 & 941 & 731 & 730 \\
\hline $\mathbf{4}$ & 271 & 413 & 337 & 535 & 451 & 420 & 332 & 446 & 341 & 457 \\
\hline $\mathbf{5}$ & -454 & -176 & -123 & -170 & -146 & 53 & 27 & 21 & -23 & 172 \\
\hline $\mathbf{6}$ & -1170 & -766 & -614 & -759 & -629 & -387 & -297 & -431 & -363 & -133 \\
\hline $\mathbf{7}$ & -1766 & -1246 & -1014 & -1380 & -1149 & -726 & -563 & -801 & -645 & -411 \\
\hline $\mathbf{8}$ & -2383 & -1753 & -1435 & -1954 & -1628 & -1086 & -843 & -1191 & -948 & -665 \\
\hline $\mathbf{9}$ & -2954 & -2221 & -1825 & -2407 & -2008 & -1417 & -1100 & -1550 & -1230 & -900 \\
\hline $\mathbf{1 0}$ & -3392 & -2643 & -2177 & -2884 & -2406 & -1715 & -1333 & -1874 & -1485 & -1111 \\
\hline $\mathbf{1 1}$ & -3864 & -2961 & -2442 & -3322 & -2773 & -1988 & -1546 & -2171 & -1719 & -1305 \\
\hline $\mathbf{1 2}$ & 270 & 317 & 272 & 319 & 270 & 252 & 198 & 249 & 191 & 223 \\
\hline $\mathbf{1 3}$ & 541 & 584 & 504 & 604 & 517 & 465 & 373 & 472 & 376 & 408 \\
\hline $\mathbf{1 4}$ & 776 & 828 & 715 & 862 & 738 & 661 & 530 & 671 & 534 & 581 \\
\hline $\mathbf{1 5}$ & 986 & 1041 & 897 & 1095 & 934 & 832 & 664 & 849 & 672 & 720 \\
\hline $\mathbf{1 6}$ & 1180 & 1225 & 1052 & 1308 & 1114 & 981 & 779 & 1010 & 797 & 829 \\
\hline $\mathbf{1 8}$ & 1365 & 1379 & 1178 & 1506 & 1276 & 1105 & 874 & 1154 & 907 & 915 \\
\hline $\mathbf{1 9}$ & 1541 & 1507 & 1282 & 1686 & 1423 & 1208 & 950 & 1281 & 1003 & 980 \\
\hline $\mathbf{2 0}$ & 1713 & 1731 & 1519 & 1933 & 1648 & 1460 & 1167 & 1497 & 1174 & 1182 \\
\hline $\mathbf{2 1}$ & 1756 & 1741 & 1523 & 1963 & 1677 & 1466 & 1173 & 1523 & 1198 & 1165 \\
\hline $\mathbf{2 2}$ & 1749 & 1685 & 1459 & 1927 & 1643 & 1407 & 1120 & 1493 & 1173 & 1102 \\
\hline $\mathbf{2 3}$ & 1735 & 1654 & 1425 & 1899 & 1617 & 1357 & 1075 & 1457 & 1142 & 1066 \\
\hline & 1629 & 1549 & 1306 & 1740 & 1466 & 1232 & 961 & 1332 & 1034 & 1007 \\
\hline
\end{tabular}




\section{APPENDIX D: REGRESSION ANALYSIS SAMPLE REPORTS}


This appendix contains two sample regression reports, one for the constant panel stiffness regression and one for variable panel stiffness regression. The reports were generated by the computer software program SigmaPlot 5.0 (1999). The following descriptions of each result in the regression reports are quoted from the SigmaPlot 5.0 User's Manual (1999).

\section{Equation Code}

This is a printout of the code used to generate the regression results.

\section{$R$ and $\boldsymbol{R}^{2}$}

$R$, the multiple correlation coefficient, and $R^{2}$, the coefficient of determination, are both measures of how well the regression model describes the data. $R$ values near 1 indicate that the equation is a good description of the relation between the independent and dependent variables.

$R$ equals zero when the values of the independent variable does not allow any prediction of the dependent variables, and equals 1 when you can perfectly predict the dependent variables from the independent variables.

\section{Adjusted $\boldsymbol{R}^{2}$}

The adjusted $R^{2}, R_{\text {adj, }}^{2}$ is also a measure of how well the regression model describes the data, but takes into account the number of independent variables, which reflects the degrees of freedom. Larger $R_{\text {adj }}^{2}$ values (nearer to 1 ) indicate that the equation is a good description of the relation between the independent and dependent variables.

\section{Standard Error of the Estimate}

The standard error of the estimate is a measure of the actual variability about the regression plane of the underlying population. The underlying population generally falls within about two standard errors of the observed sample.

\section{Statistical Summary Table}


The standard error, $t$ and $P$ values are approximations based on the final iteration of the regression.

Estimate The value for the constant and coefficients of the independent variables for the regression model are listed.

Standard Error The standard errors are estimates of the uncertainties in the estimates of the regression coefficients (analogous to the standard error of the mean). The true regression coefficients of the underlying population generally fall within about two standard errors of the observed sample coefficients. Large standard errors may indicate multicollinearity.

t statistic The $t$ statistic tests the null hypothesis that the coefficient of the independent variable is zero, that is, the independent variable does not contribute to predicting the dependent variable. $t$ is the ratio of the regression coefficient to its standard error.

You can conclude from "large" $t$ values that the independent variable can be used to predict the dependent variable (i.e., that the coefficient is not zero).

$\boldsymbol{P}$ value $P$ is the $P$ value calculated for $t$. The $P$ value is the probability of being wrong in concluding that the coefficient is not zero (i.e., the probability of falsely rejecting the null hypothesis, or committing a Type I error, based on t). The smaller the P value, the greater the probability that the coefficient is not zero.

Traditionally, you can conclude that the independent variable can be used to predict the dependent variable when $P<0.05$.

\section{Analysis of Variance (ANOVA) Table}

The ANOVA (analysis of variance) table lists the ANOVA statistics for the regression and the corresponding $F$ value for each step.

SS (Sum of Squares) The sum of squares are measures of variability of the dependent variable.

The sum of squares due to regression measures the difference of the regression plane from the mean of the dependent variable. 
The residual sum of squares is a measure of the size of the residuals, which are the differences between the observed values of the dependent variable and the values predicted by regression model.

DF (Degrees of Freedom) Degrees of freedom represent the number observations and variables in the regression equation.

The regression degrees of freedom is a measure of the number of independent variables.

The residual degrees of freedom is a measure of the number of observations less the number of terms in the equation.

MS (Mean Square) The mean square provides two estimates of the population variances. Comparing these variance estimates is the basis of analysis of variance.

The mean square regression is a measure of the variation of the regression from the mean of the dependent variable.

The residual mean square is a measure of the variation of the residuals about the regression plane.

\section{F statistic}

The F test statistic gauges the contribution of the independent variables in predicting the dependent variable.

If $F$ is a large number, you can conclude that the independent variables contribute to the prediction of the dependent variable (i.e., at least one of the coefficients is different from zero, and the "unexplained variability" is smaller than what is expected from random sampling variability of the dependent variable about its mean). If the $F$ ratio is around 1 , you can conclude that there is no association between the variables (i.e., the data is consistent with the null hypothesis that all the samples are just randomly distributed).

$\boldsymbol{P}$ value The $P$ value is the probability of being wrong in concluding that there is an association between the dependent and independent variables (i.e., the probability of falsely rejecting the null hypothesis, or committing a Type I error, 
based on F). The smaller the $P$ value, the greater the probability that there is an association.

Traditionally, you can conclude that the independent variable can be used to predict the dependent variable when $P<0.05$.

\section{Regression Diagnostics}

The regression diagnostic results display the values for the predicted values, residuals, and other diagnostic results. All results that qualify as outlying values are flagged with a symbol.

Row This is the row number of the observation.

Predicted Values This is the value for the dependent variable predicted by the regression model for each observation.

Residuals These are the unweighted raw residuals, the difference between the predicted and observed values for the dependent variables.

Standardized Residuals The standardized residual is the raw residual divided by the standard error of the estimate .

If the residuals are normally distributed about the regression, about 66\% of the standardized residuals have values between -1 and +1 , and about 95\% of the standardized residuals have values between -2 and +2 . A larger standardized residual indicates that the point is far from the regression; the suggested value flagged as an outlier is 2.5 . 


\section{Constant Panel Stiffness Regression: Support Restraints, Single Span}

Nonlinear Regression

[Variables]

$\mathrm{y}=\operatorname{col}(1)$

$\mathrm{n}=\operatorname{col}(2)$

$\theta=\operatorname{col}(3)$

$\mathrm{b}=\operatorname{col}(4)$

$\mathrm{d}=\operatorname{col}(5)$

$\mathrm{t}=\operatorname{col}(6)$

$\mathrm{L}=\operatorname{col}(7)$

$\mathrm{Ixy}=\operatorname{col}(8)$

$\mathrm{Ix}=\operatorname{col}(9)$

$\mathrm{w}=1 / \mathrm{abs}(\operatorname{col}(1))$

[Parameters]

$\mathrm{C} 1=0.5^{\prime}\{$ \{ previous: 0.482717$\left.\}\right\}$

$\mathrm{C} 2=6.0$ ' $\{$ \{previous: 5.82341$\}\}$

[Equation]

$\mathrm{nmax}=0.5+\mathrm{d} /(2 * \mathrm{C} 2 * \mathrm{t})$

$\mathrm{P}=((0.5 * \mathrm{Ixy} / \mathrm{Ix}+0.3333 * \mathrm{~b} / \mathrm{d}) * \cos (\theta)-\sin (\theta)) * 100 * \mathrm{~L}$

$\mathrm{f}=\mathrm{if}(\mathrm{n}>\mathrm{nmax}, \mathrm{P} * \mathrm{C} 1 * \mathrm{nmax} *(1-\mathrm{C} 2 *(\mathrm{t} / \mathrm{d}) *(\mathrm{nmax}-1)), \mathrm{P} * \mathrm{C} 1 * \mathrm{n} *(1-\mathrm{C} 2 *(\mathrm{t} / \mathrm{d}) *(\mathrm{n}-1)))$

fit $\mathrm{f}$ to $\mathrm{y}$ with weight $\mathrm{w}$

[Constraints]

[Options]

tolerance $=0.000100$

stepsize $=100$

iterations $=100$

$\mathrm{R}=0.99889532$

Rsqr $=0.99779186$

Adj Rsqr $=0.99777780$

Standard Error of Estimate $=1.6724$

$\begin{array}{lllll} & \text { Coefficient } & \text { Std. Error } & \mathbf{t} & \mathbf{P} \\ \mathrm{C} 1 & 0.4827 & 0.0038 & 125.9753 & <0.0001 \\ \mathrm{C} 2 & 5.8234 & 0.0853 & 68.2860 & <0.0001\end{array}$

Analysis of Variance:

DF

Regression 1

Residual 157

Total $\quad 158$

Regression Diagnostics:

Row Predicted

$1 \quad 786.2594$

665.6563

544.9182

302.9242

$-163.1989$

$-380.2566$

$-583.0401$

\section{SS}

198414.3094

439.0960

198853.4054

\section{Wtd Resid}

$-1.8526$

$-2.2112$

$-2.2909$

$-2.7969$

$-2.9821$

$-2.3988$

$-2.0239$
MS

198414.3094

2.7968

1258.5659

Wtd Std Resid

$-1.1078$

$-1.3222$

$-1.3699$

$-1.6724$

$-1.7832$

$-1.4344$

$-1.2102$ 


$\begin{array}{llll}8 & -769.9923 & -1.8477 & -1.1049 \\ 9 & -940.9248 & -1.6216 & -0.9697 \\ 10 & -1096.4003 & -1.4941 & -0.8934 \\ 11 & 474.1318 & 0.5384 & 0.3219 \\ 12 & 630.4955 & -0.6657 & -0.3981 \\ 13 & 733.0577 & -2.1945 & -1.3122 \\ 14 & 781.8184 & -2.8138 & -1.6826 \\ 15 & 786.2594 & -2.3526 & -1.4068 \\ 16 & 786.2594 & -2.0055 & -1.1992 \\ 17 & 1314.4738 & -1.2765 & -0.7633 \\ 18 & 1089.7206 & -1.2888 & -0.7706 \\ 19 & 864.9749 & -1.0726 & -0.6414 \\ 20 & 415.2748 & -3.0271 & -1.8101 \\ 21 & -448.1763 & -1.7157 & -1.0259 \\ 22 & -849.0302 & 0.0698 & 0.0417 \\ 23 & -1222.8048 & 0.0516 & 0.0309 \\ 24 & -1566.7628 & -0.0060 & -0.0036 \\ 25 & -1880.6892 & 0.0390 & 0.0233 \\ 26 & -2165.7394 & -0.0056 & -0.0033 \\ 27 & 452.6558 & 0.7093 & 0.4241 \\ 28 & 647.9744 & 1.1155 & 0.6670 \\ 29 & 822.6201 & 0.8716 & 0.5211 \\ 30 & 976.5928 & 0.3629 & 0.2170 \\ 31 & 1109.8927 & -0.2680 & -0.1603 \\ 32 & 1222.5197 & -0.8254 & -0.4935 \\ 33 & 1643.0923 & -1.1534 & -0.6897 \\ 34 & 1362.1507 & -0.6327 & -0.3783 \\ 35 & 1081.2186 & -0.4661 & -0.2787 \\ 36 & 519.0935 & -1.6423 & -0.9820 \\ 37 & -560.2204 & 0.4358 & 0.2606 \\ 38 & -1061.2878 & 2.3646 & 1.4139 \\ 39 & -1528.5059 & 2.1697 & 1.2974 \\ 40 & -1958.4535 & 2.0928 & 1.2514 \\ 41 & -2350.8615 & 2.1695 & 1.2973 \\ 42 & -2707.1743 & 2.1619 & 1.2927 \\ 43 & 565.8198 & 1.3954 & 0.8344 \\ 44 & 809.9680 & 1.8711 & 1.1189 \\ 45 & 1028.2751 & 1.5739 & 0.9411 \\ 46 & 1220.7411 & 0.9113 & 0.5449 \\ 47 & 1387.3659 & 0.1242 & 0.0743 \\ 48 & 1528.1497 & -0.6227 & -0.3724 \\ 49 & 1022.2022 & -0.8302 & -0.4965 \\ 50 & 846.9375 & -0.7991 & -0.4778 \\ 51 & 671.6836 & -0.5334 & -0.3190 \\ 52 & 321.0273 & -1.6987 & -1.0157 \\ 53 & -352.2019 & -0.7725 & -0.4619 \\ 54 & -664.7228 & -1.2226 & -0.7311 \\ 55 & -956.1180 & 0.7237 & 0.4328 \\ 56 & -1224.2561 & 0.6128 & 0.3665 \\ 57 & -1468.9718 & 0.7103 & 0.4247 \\ 58 & -1691.1684 & 0.6413 & 0.3835 \\ 59 & 441.0891 & 1.0636 & 0.6360 \\ 60 & 615.2490 & 1.2099 & 0.7235\end{array}$




$\begin{array}{llll}61 & 758.4858 & 0.4864 & 0.2908 \\ 62 & 870.7995 & -0.4026 & -0.2407 \\ 63 & 952.1902 & -1.0278 & -0.6146 \\ 64 & 1002.6577 & -1.2451 & -0.7445 \\ 65 & 1277.7527 & -0.8995 & -0.5379 \\ 66 & 1058.6719 & -0.8934 & -0.5342 \\ 67 & 839.6045 & -0.6493 & -0.3883 \\ 68 & 401.2841 & -2.2317 & -1.3344 \\ 69 & -440.2524 & -1.1927 & -0.7132 \\ 70 & -830.9035 & 0.7345 & 0.4392 \\ 71 & -1195.1475 & 0.5290 & 0.3163 \\ 72 & -1530.3201 & 0.3936 & 0.2354 \\ 73 & -1836.2148 & 0.5689 & 0.3402 \\ 74 & -2113.9606 & 0.4801 & 0.2871 \\ 75 & 551.3613 & 1.5509 & 0.9274 \\ 76 & 769.0612 & 1.6092 & 0.9622 \\ 77 & 948.1072 & 0.7664 & 0.4583 \\ 78 & 1088.4994 & -0.2892 & -0.1729 \\ 79 & 1190.2377 & -1.0667 & -0.6379 \\ 80 & 1253.3221 & -1.3040 & -0.7797 \\ 81 & 1827.9748 & -0.6119 & -0.3659 \\ 82 & 1490.9699 & -0.7313 & -0.4373 \\ 83 & 1154.2221 & -0.5706 & -0.3412 \\ 84 & 481.1309 & -0.0516 & -0.0309 \\ 85 & -808.6283 & -0.1883 & -0.1126 \\ 86 & -1406.2246 & -0.6811 & -0.4073 \\ 87 & -1962.7629 & -0.9654 & -0.5772 \\ 88 & -2474.2958 & 0.2680 & 0.1603 \\ 89 & -2940.6294 & 0.0301 & 0.0180 \\ 90 & -3363.5978 & -0.2306 & -0.1379 \\ 91 & 629.4864 & 0.9202 & 0.5502 \\ 92 & 901.1064 & 1.6179 & 0.9674 \\ 93 & 1143.9777 & 1.5043 & 0.8995 \\ 94 & 1358.1001 & 1.0408 & 0.6223 \\ 95 & 1543.4738 & 0.4184 & 0.2502 \\ 96 & 1700.0987 & -0.1725 & -0.1032 \\ 97 & 2132.6373 & 0.7808 & 0.4669 \\ 98 & 1739.4649 & 0.5842 & 0.3493 \\ 99 & 1346.5925 & 0.6324 & 0.3782 \\ 100 & 561.3194 & 0.8979 & 0.5369 \\ 101 & -943.3997 & -0.7272 & -0.4348 \\ 102 & -1640.5953 & -1.7257 & -1.0319 \\ 103 & -2289.8901 & -2.1078 & -1.2604 \\ 104 & -2886.6784 & -1.0382 & -0.6208 \\ 105 & -3430.7343 & -1.4380 & -0.8598 \\ 106 & -3924.1974 & -1.7443 & -1.0430 \\ 107 & 734.4008 & 1.3181 & 0.7882 \\ 108 & 1051.2909 & 2.1976 & 1.3141 \\ 109 & 1334.6406 & 2.2909 & 1.3699 \\ 110 & 1584.4502 & 1.9980 & 1.1947 \\ 111 & 1800.7195 & 1.5340 & 0.9172 \\ 112 & 1983.4485 & 1.0771 & 0.6440 \\ 113 & 1210.7847 & -1.4911 & -0.8916\end{array}$




$\begin{array}{llll}114 & 986.3095 & -1.4770 & -0.8832 \\ 115 & 762.0172 & -1.7197 & -1.0283 \\ 116 & -545.1230 & -3.5298 & -2.1106 \\ 117 & -943.0105 & -1.7714 & -1.0592 \\ 118 & -1313.5280 & -1.8156 & -1.0857 \\ 119 & -1654.0538 & -1.8964 & -1.1340 \\ 120 & -1964.4648 & -1.8892 & -1.1296 \\ 121 & -2245.9876 & -0.9818 & -0.5871 \\ 122 & 603.0798 & 0.5604 & 0.3351 \\ 123 & 827.4341 & 0.1928 & 0.1153 \\ 124 & 1000.3314 & -1.0719 & -0.6409 \\ 125 & 1121.7715 & -2.2149 & -1.3244 \\ 126 & 1191.7546 & -2.7037 & -1.6167 \\ 127 & 1210.7847 & -2.2188 & -1.3268 \\ 128 & 1412.5822 & -1.1504 & -0.6879 \\ 129 & 1150.6945 & -1.6831 & -1.0064 \\ 130 & 889.0201 & -2.1206 & -1.2680 \\ 131 & -635.9768 & -6.2397 & -3.7311 \\ 132 & -1100.1789 & -4.5552 & -2.7238 \\ 133 & -1532.4494 & -4.4310 & -2.6495 \\ 134 & -1929.7294 & -4.7095 & -2.8161 \\ 135 & -2291.8757 & -4.6773 & -2.7968 \\ 136 & -2620.3189 & -3.8691 & -2.3135 \\ 137 & 703.5931 & 0.4266 & 0.2551 \\ 138 & 965.3398 & 0.0855 & 0.0511 \\ 139 & 1167.0532 & -1.1023 & -0.6591 \\ 140 & 1308.7334 & -2.1861 & -1.3072 \\ 141 & 1390.3804 & -1.3207 & -0.7897 \\ 142 & 1412.5822 & -1.1504 & -0.6879 \\ 143 & 2208.7573 & -2.1945 & -1.3122 \\ 144 & 1745.2570 & 0.1849 & 0.1106 \\ 145 & 1282.6349 & -2.1771 & -1.3018 \\ 146 & 359.4788 & -2.2069 & -1.3197 \\ 147 & -542.4841 & 0.5863 & 0.3506 \\ 148 & -1403.8521 & -0.6128 & -0.3664 \\ 149 & -2218.3659 & 1.0166 & 0.6079 \\ 150 & -2975.4414 & 0.5609 & 0.3354 \\ 151 & -3669.9835 & 0.1485 & 0.0888 \\ 152 & -4302.0011 & 1.4335 & 0.8572 \\ 153 & -4874.2329 & 1.0569 & 0.6320 \\ 154 & 673.3536 & -0.1683 & -0.1006 \\ 155 & 979.7394 & 0.4208 & 0.2516 \\ 156 & 1265.9311 & 0.3932 & 0.2351 \\ 157 & 1531.9287 & 0.0018 & 0.0011 \\ 158 & 1777.7323 & -0.6388 & -0.3820 \\ 159 & 2003.3418 & -1.4150 & -0.8461\end{array}$




\section{Variable Panel Stiffness Regression: Support Restraints, Single Span}

Nonlinear Regression

[Variables]
$\mathrm{y}=\operatorname{col}(1)$
$\mathrm{G}=\operatorname{col}(2)$
$\mathrm{n}=\operatorname{col}(3)$
$\mathrm{m}=\operatorname{col}(4)$
$\mathrm{P}=\operatorname{col}(5)$
$\alpha=\operatorname{col}(6)$
$\mathrm{w}=1 / \mathrm{abs}(\operatorname{col}(1))$

[Parameters]

$\mathrm{C} 3=0.5^{\prime}\{$ \{previous: 0.27669$\left.\}\right\}$

[Equation]

$\mathrm{C} 1=0.50$

$\mathrm{X}=\mathrm{m}^{*} \alpha+\mathrm{n} * \mathrm{C} 3 * \log (\mathrm{G} / 2500)$

$\mathrm{f}=\mathrm{if}(\mathrm{X}<\mathrm{n}, \mathrm{P} * \mathrm{C} 1 * \mathrm{X}, \mathrm{P} * \mathrm{C} 1 * \mathrm{n})$

fit $\mathrm{f}$ to $\mathrm{y}$ with weight $\mathrm{w}$

[Constraints]

[Options]

tolerance $=0.000100$

stepsize $=100$

iterations $=100$

$\mathrm{R}=0.98584812 \quad$ Rsqr $=0.97189651 \quad$ Adj Rsqr $=0.97189651$

Standard Error of Estimate $=2.4679$

$\begin{array}{lllll} & \text { Coefficient } & \text { Std. Error } & \mathbf{t} & \mathbf{P} \\ \text { C3 } & 0.2767 & 0.0094 & 29.3891 & <0.0001\end{array}$

Analysis of Variance:

$\begin{array}{llll} & \text { DF } & \text { SS } & \text { MS } \\ \text { Regression } & 0 & 12426.6169 & 12426.6169 \\ \text { Residual } & 59 & 359.3297 & 6.0903 \\ \text { Total } & 59 & 12785.9466 & 216.7110 \\ & & & \\ \text { Regression } & \text { Diagnostics: } & & \\ \text { Row } & \text { Predicted } & \text { Wtd Resid } & \text { Wtd Std Resid } \\ 1 & 1707.0923 & -3.6977 & -1.4983 \\ 2 & 1392.5755 & -0.1497 & -0.0607 \\ 3 & 1103.7275 & -0.5379 & -0.2180 \\ 4 & 970.6502 & -1.5684 & -0.6355 \\ 5 & 806.1905 & -2.6646 & -1.0797 \\ 6 & 682.1957 & -2.7948 & -1.1325 \\ 7 & 1960.0000 & -2.6293 & -1.0654 \\ 8 & 1877.6809 & -2.3884 & -0.9678 \\ 9 & 1618.9322 & -0.2476 & -0.1003 \\ 10 & 1499.7222 & -0.5650 & -0.2290 \\ 11 & 1352.4000 & -2.3412 & -0.9487 \\ 12 & 1241.3261 & -4.5835 & -1.8573\end{array}$




$\begin{array}{llll}13 & 2452.0000 & -2.1041 & -0.8526 \\ 14 & 2336.9263 & -3.4276 & -1.3889 \\ 15 & 2013.2133 & -1.6854 & -0.6829 \\ 16 & 1861.6434 & -2.3983 & -0.9718 \\ 17 & 1691.2901 & -1.8729 & -0.7589 \\ 18 & 1538.6052 & -4.5552 & -1.8458 \\ 19 & 1851.8366 & -1.7753 & -0.7194 \\ 20 & 1570.6689 & 2.0490 & 0.8303 \\ 21 & 1312.4483 & 2.2881 & 0.9272 \\ 22 & 1193.4816 & 0.9569 & 0.3877 \\ 23 & 1046.4600 & -1.5989 & -0.6479 \\ 24 & 935.6128 & -3.8139 & -1.5454 \\ 25 & 2300.5966 & -2.0141 & -0.8161 \\ 26 & 1950.4818 & 2.1117 & 0.8557 \\ 27 & 1627.8249 & 2.2225 & 0.9006 \\ 28 & 1476.7495 & 0.7792 & 0.3158 \\ 29 & 1306.9520 & -1.7267 & -0.6997 \\ 30 & 1154.7653 & -4.1863 & -1.6963 \\ 31 & 2728.0000 & -2.7116 & -1.0988 \\ 32 & 2563.9814 & -1.7272 & -0.6999 \\ 33 & 2202.3835 & 0.3104 & 0.1258 \\ 34 & 2085.3278 & -0.0072 & -0.0029 \\ 35 & 1882.3200 & -1.9162 & -0.7765 \\ 36 & 1674.4480 & -5.3324 & -2.1607 \\ 37 & 3180.0000 & -2.4650 & -0.9988 \\ 38 & 2930.2157 & -0.5051 & -0.2047 \\ 39 & 2510.4092 & 1.4089 & 0.5709 \\ 40 & 2374.2772 & 0.9496 & 0.3848 \\ 41 & 2194.2000 & -0.5411 & -0.2193 \\ 42 & 1895.8044 & -4.9031 & -1.9868 \\ 43 & 2304.0049 & -1.6965 & -0.6874 \\ 44 & 1918.8102 & 2.0122 & 0.8154 \\ 45 & 1559.3331 & 1.3118 & 0.5315 \\ 46 & 1442.9640 & 0.2371 & 0.0961 \\ 47 & 1241.1468 & -2.0800 & -0.8428 \\ 48 & 1034.4940 & -4.0562 & -1.6436 \\ 49 & 2633.1314 & -2.3760 & -0.9628 \\ 50 & 2180.3171 & 1.5727 & 0.6373 \\ 51 & 1762.6228 & 0.7174 & 0.2907 \\ 52 & 1627.1758 & -0.4030 & -0.1633 \\ 53 & 1448.0046 & -2.1075 & -0.8540 \\ 54 & 1151.1103 & -4.1719 & -1.6905 \\ 55 & 2872.0000 & -2.9736 & -1.2049 \\ 56 & 2872.0000 & -4.2720 & -1.7311 \\ 57 & 2554.8516 & -1.3403 & -0.5431 \\ 58 & 2431.9718 & -0.7349 & -0.2978 \\ 59 & 2280.3680 & -0.6827 & -0.2766 \\ 60 & 1999.8486 & -2.8594 & -1.1587\end{array}$




\section{VITA}

Michael Christopher Neubert was born on March 19, 1976 in Manchester, Connecticut. He attended RHAM High School in Hebron, Connecticut, and graduated in June 1994. Michael graduated Summa Cum Laude from the Virginia Polytechnic Institute and State University with a Bachelor of Science degree in civil engineering in May 1998. In August 1999, he received a Master of Science degree in Civil and Environmental Engineering, also from the Virginia Polytechnic Institute and State University. He has worked summers at the Rhode Island Department of Transportation in Providence, Rhode Island and at Pratt \& Whitney in East Hartford, Connecticut. After graduation, Michael will work for Skidmore, Owings \& Merrill in Chicago.

Michael Neubert 